\title{
The role of dairy products and constituents in metabolic risk management
}

Citation for published version (APA):

van Meijl, L. E. C. (2010). The role of dairy products and constituents in metabolic risk management. [Doctoral Thesis, Maastricht University]. https://doi.org/10.26481/dis.20101217lm

Document status and date:

Published: 01/01/2010

DOI:

10.26481/dis.20101217/m

Document Version:

Publisher's PDF, also known as Version of record

\section{Please check the document version of this publication:}

- A submitted manuscript is the version of the article upon submission and before peer-review. There can be important differences between the submitted version and the official published version of record.

People interested in the research are advised to contact the author for the final version of the publication, or visit the DOI to the publisher's website.

- The final author version and the galley proof are versions of the publication after peer review.

- The final published version features the final layout of the paper including the volume, issue and page numbers.

Link to publication

\footnotetext{
General rights rights.

- You may freely distribute the URL identifying the publication in the public portal. please follow below link for the End User Agreement:

www.umlib.nl/taverne-license

Take down policy

If you believe that this document breaches copyright please contact us at:

repository@maastrichtuniversity.nl

providing details and we will investigate your claim.
}

Copyright and moral rights for the publications made accessible in the public portal are retained by the authors and/or other copyright owners and it is a condition of accessing publications that users recognise and abide by the legal requirements associated with these

- Users may download and print one copy of any publication from the public portal for the purpose of private study or research.

- You may not further distribute the material or use it for any profit-making activity or commercial gain

If the publication is distributed under the terms of Article $25 \mathrm{fa}$ of the Dutch Copyright Act, indicated by the "Taverne" license above, 
The role of dairy products

and constituents in metabolic risk management 


\section{noutín}

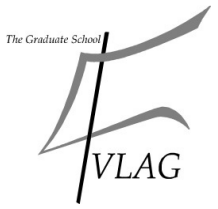

The studies presented in this thesis were performed within NUTRIM School for Nutrition, Toxicology \& Metabolism, which participates in the Graduate School VLAG (Food Technology, Agrobiotechnology, Nutrition and Health Sciences), accredited by the Royal Netherlands Academy of Arts and Sciences.

Cover design: Linda Rampen

Layout: Leonie van Meijl

Printed by: Datawyse / Universitaire Pers Maastricht

(C) Leonie van Meijl, Maastricht 2010

ISBN 9789052789897 


\title{
The role of dairy products and constituents in metabolic risk management
}

\author{
PROEFSCHRIFT \\ ter verkrijging van de graad van doctor \\ aan de Universiteit Maastricht \\ op gezag van de Rector Magnificus Prof. mr. G.P.M.F. Mols, \\ volgens het besluit van het College van Decanen, \\ in het openbaar te verdedigen \\ op vrijdag 17 december 2010 om 14.00 uur \\ door \\ Leonie Elisabeth Catharina van Meijl \\ geboren te Eindhoven op 30 december 1982
}

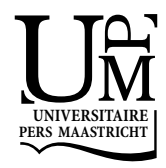




\section{Promotor}

Prof. dr. ir. R.P. Mensink

\section{Beoordelingscommissie}

Prof. dr. K.R. Westerterp (voorzitter)

Dr. J.M. Geleijnse (Wageningen University \& Research centre)

Prof. dr. E. Mariman

Prof. dr. A.M.W.J. Schols

Dr. P.L. Zock (Unilever Food \& Health Research Institute)

The research described in this thesis was funded by the Dutch Dairy Association.

Financial support by the Dutch Dairy Association for the publication of this thesis is gratefully acknowledged. 


\section{CONTENTS}

Chapter 1

General introduction

Chapter 2

Dairy product consumption and the metabolic syndrome

Chapter 3

Effects of low-fat dairy consumption on metabolic risk parameters in overweight subjects

Chapter 4

Effects of low-fat dairy consumption on markers of low-grade systemic inflammation and endothelial function in overweight subjects

Chapter 5

Effects of milk and milk constituents on postprandial lipid and glucose metabolism in overweight subjects

Chapter 6

Effects of amino acids on Akt phosphorylation, IL-8 production and NF- $\kappa B$ activity in HepG2 liver cells

Chapter 7

General discussion 81

References

Summary

105

Samenvatting

109

Appendix

Dankwoord

Curriculum vitae

119

List of publications 



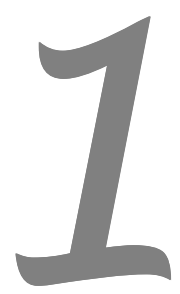

General introduction 


\section{Introduction}

The concept of the metabolic syndrome has first been described as early as in the 1920s [1]. Earlier described as the insulin resistance syndrome [2], syndrome X [3], or the deadly quartet [4], the metabolic syndrome is a constellation of metabolic disturbances that strongly enhances the risk of cardiovascular disease (CVD) and type 2 diabetes mellitus [5]. Together with the global epidemic of obesity and diabetes, the incidence of the metabolic syndrome has increased strikingly during the past few decades [6]. In countries with westernized lifestyles, the prevalence has been estimated to exceed $20 \%$ and is expected to further increase during the next years [7]. In the Netherlands, the average proportion of the adult population having the metabolic syndrome has been estimated around 15\%, and this number increases with age $[8,9]$. However, although it has for long been regarded as a disease of adults, its prevalence in children and teenagers is also rising at an alarming rate [10]. It may therefore be clear that there is an urgent need for timely recognition and treatment of the metabolic syndrome.

\section{Definition of the metabolic syndrome}

The metabolic syndrome is characterized by abnormalities in a wide variety of metabolic risk markers, including abdominal obesity, hypertension, atherogenic dyslipidemia, insulin resistance, and a prothrombotic and proinflammatory state. During the past decades, several clinical criteria for the diagnosis of the metabolic syndrome were developed. In 1998, the World Health Organisation (WHO) was the first to propose a set of criteria for diagnosing the metabolic syndrome, in an attempt to achieve some agreement on definition [11]. Subsequent definitions were formulated by the European Group for the Study of Insulin Resistance (EGIR) [12], the National Cholesterol Education Program's (NCEP) Adult Treatment Panel III (ATP III) [13] raised by the National Heart, Lung, and Blood Institute (NHLBI), and the International Diabetes Federation (IDF) [14]. To date, the ATP III definition is the most widely used [15]. To diagnose the metabolic syndrome according to the ATP III criteria, at least 3 of the following risk factors should be present: abdominal obesity, increased triglycerides (TG), decreased high density lipoprotein (HDL) cholesterol, elevated blood pressure, or increased fasting glucose (Table 1.1). 
Table 1.1. NECP-ATP III clinical criteria for diagnosis of the metabolic syndrome.

\begin{tabular}{ll}
\hline Risk factor & Defining level \\
\hline Abdominal obesity, given as waist circumference & $>102 \mathrm{~cm}$ (men) \\
& $>88 \mathrm{~cm}$ (women) \\
Triglycerides & $\geq 1.7 \mathrm{mmol} / \mathrm{L}$ \\
HDL cholesterol & $<1.03 \mathrm{mmol} / \mathrm{L}$ (men) \\
& $<1.30 \mathrm{mmol} / \mathrm{L}$ (women) \\
Blood pressure & $\geq 130 / \geq 85 \mathrm{~mm} \mathrm{Hg}$ \\
Fasting glucose & $\geq 6.1 \mathrm{mmol} / \mathrm{L}$ \\
\hline
\end{tabular}

\section{Pathophysiology of the metabolic syndrome}

The aetiology of the metabolic syndrome has not yet been established. However, it is clear that obesity, insulin resistance, inflammation and environmental factors, such as diet, are major players in its development. An overview of the pathophysiology of the metabolic syndrome is presented in Figure 1.1.

\section{Obesity}

One major hypothesis to describe the pathophysiology of the metabolic syndrome, supported by the NHLBI, presumes obesity to be the primary underlying cause [13]. Obesity contributes to hypertension, dyslipidemia, inflammation and hyperglycaemia and is associated with CVD risk. Although obesity is not a requirement for having the metabolic syndrome, the worldwide increase in obesity during the past two decades was accompanied by a rise in the incidence of the metabolic syndrome [6]. In this respect, abdominal fat is more important than total body fat, which is why waist circumference is one of the ATP III diagnostic criteria. Adipose tissue, in particular visceral adipose tissue, is now regarded as an endocrine organ, secreting numerous hormones and adipokines involved in lipid and glucose metabolism, regulation of blood pressure, inflammatory processes and thrombotic function, including cytokines and plasminogen activator inhibitor-1 (PAI-1) [16]. Moreover, adipose tissue releases free fatty acids (FFA), which are thought to be a main contributor to the pathogenesis of the metabolic syndrome $[17,18]$.

\section{Insulin resistance}

Insulin is produced by the pancreas in response to elevated plasma glucose concentrations and stimulates glucose uptake in various tissues. In skeletal muscle and adipose tissue, insulin stimulates glucose uptake by translocation of the GLUT4 glucose transporter to the cell surface. In skeletal muscle and liver, insulin stimulates the synthesis of glycogen from glucose and inhibits its degradation (glycogenolysis). In the liver, insulin suppresses the production of glucose (gluconeogenesis), preventing 
rises in blood glucose levels. In adipose tissue, insulin inhibits fat breakdown (lipolysis) and stimulates glucose uptake. The net effect of all these actions is an increase in glucose uptake, a decrease in circulating glucose, and an increase in the conversion of glucose into storage molecules (glycogen or fat). In insulin resistance, adipose, muscle and liver cells do not respond appropriately to insulin. The resulting rises in blood glucose levels, and the related increases in insulin concentrations, may subsequently lead to pathologies.

Identifying a unique role for insulin resistance in the pathophysiology of the metabolic syndrome is complicated by the fact that it is linked to obesity. Insulin resistance generally rises with increasing body fat content, although insulin sensitivity varies widely at any given level of body fat and insulin resistance also occurs at BMI $<25 \mathrm{~kg} / \mathrm{m}^{2}$ [19]. So, since obesity and insulin resistance are tightly intertwined, dissociation of these two factors in patients with the metabolic syndrome is difficult. An increased flux of FFA to the liver, muscles and pancreas, overloading these tissues with lipid, may enhance insulin resistance $[18,20]$. Circulating fatty acids are mainly derived from adipose tissue TG stores, released through the action of the enzyme hormone sensitive lipase. An increased flux of FFA to the liver increases the hepatic fat content, which may result in the development of fatty liver and hepatic insulin resistance [21]. Insulin resistance in the liver leads to hepatic overproduction of glucose and a reduced inhibition of glucose production by insulin. Also, insulin suppression of glycogenolysis is reduced, all contributing to elevated plasma glucose concentrations. Further, the secretion of very low density lipoproteins (VLDL) from the liver is enhanced. In muscle, excess FFA reduces insulin sensitivity by inhibiting insulin-mediated glucose uptake through glucose transporters [22].

\section{Atherogenic dyslipidemia}

Lipids are transported in the body by lipoproteins. In the intestine, TG and cholesterol are incorporated into chylomicrons, which are transported via the lymph system into the circulation. The enzyme lipoprotein lipase ( $L P L)$ hydrolyzes the TG into FFA, which are used in muscle or stored in adipose tissue, thereby reducing the chylomicron size. The chylomicron remnant is transported to the liver, where it is taken up and degraded. In the liver, TG are synthesized from FFA and, when exogenous cholesterol supply is insufficient, endogenous cholesterol is synthesized from acetylcoenzyme A. These TG and cholesterol molecules are incorporated into VLDL particles for transport from the liver to the peripheral tissues. Like chylomicrons, VLDL particles release their TG content in the form of FFA to the tissues through the action of LPL. As its density increases, the particle becomes an intermediate density lipoprotein (IDL). IDL further loses its TG, as well as its apolipoproteins (apo), except for apoB100. The remaining particle is thus composed of mainly cholesterol esters and apoB100 proteins and is now called LDL. LDL delivers cholesterol to the periph- 
eral tissues and the liver and is subsequently taken up and degraded by the liver. $\mathrm{HDL}$ is the smallest lipoprotein and has the highest density, because of the relatively high content of protein in the particle, predominantly apoA-I and apoA-II. HDL is the lipoprotein responsible for the transport of cholesterol from the tissues back to the liver and HDL cholesterol is therefore regarded as the 'good' cholesterol. HDL is synthesized in the liver and picks up cholesterol on its way through the circulation.

The key features of atherogenic dyslipidemia in the metabolic syndrome are elevated plasma TG, reduced HDL cholesterol, and increased small dense LDL particles [13]. Both insulin resistance and abdominal obesity are associated with atherogenic dyslipidemia and an increased flux of FFA to the liver is probably the major contributor [23]. Under normal conditions, insulin inhibits the production of apoB, the major lipoprotein on VLDL particles, and the secretion of VLDL into the circulation. In the insulin resistant state, an increased flux of FFA to the liver increases hepatic TG synthesis, apoB production, and TG secretion in the form of VLDL [24]. In this way, VLDL output by the liver is enhanced and plasma concentrations of TG rise [25]. Further, the activity of LPL, the rate-limiting and major mediator of VLDL clearance, is regulated by insulin. In case of insulin resistance, VLDL clearance is therefore reduced, also contributing to elevated levels of TG in the circulation [26].

The rise in VLDL is usually associated with a decrease in HDL-C and an increase in LDL density. The TG in VLDL are transferred to HDL by the cholesterol ester transport protein (CETP) in exchange for cholesterol esters, resulting in TG-enriched HDL and cholesterol ester-enriched VLDL particles. The TG-enriched HDL is a better substrate for hepatic lipase, and is therefore rapidly cleared from the circulation, leaving fewer HDL particles available for cholesterol transport from the tissues to the liver. Similarly, small dense LDL particles are formed. CETP facilitates the transfer of TG from large VLDL to LDL in exchange for cholesterol esters, after which hepatic lipase increases lipolysis of TG-rich LDL, resulting in the formation of small dense LDL particles [24]. Small dense LDL might be more atherogenic than large buoyant LDL, because it is more toxic to the endothelium, it passes the endothelial basement membrane more easily, it is more susceptible to oxidation, and/or it is more selectively bound to scavenger receptors on macrophages $[27,28]$.

\section{Low-grade chronic inflammation}

Although inflammatory markers are currently not included in the ATP III or WHO diagnostic criteria for the metabolic syndrome, chronic inflammation is receiving large attention as a metabolic syndrome component and cardiovascular risk factor. Inflammatory markers such as C-reactive protein (CRP), interleukin-6 (IL-6), tumour necrosis factor- $\alpha$ (TNF- $\alpha$ ), and fibrinogen, among others, have been linked to the metabolic syndrome [29]. An enlarged adipose tissue mass is responsible for the increased production of cytokines such as TNF- $\alpha$ and IL-6, which may in turn stimulate 
the production of CRP by the liver. Although many inflammatory markers have been associated with CVD risk, CRP concentrations are particularly predictive of CVD risk [30]. These inflammatory proteins are now also thought to play a major role in the development of insulin resistance in muscle and liver [31]. Cytokines also stimulate the production of fibrinogen and PAI-1 by the liver, resulting in a prothrombotic state [29].

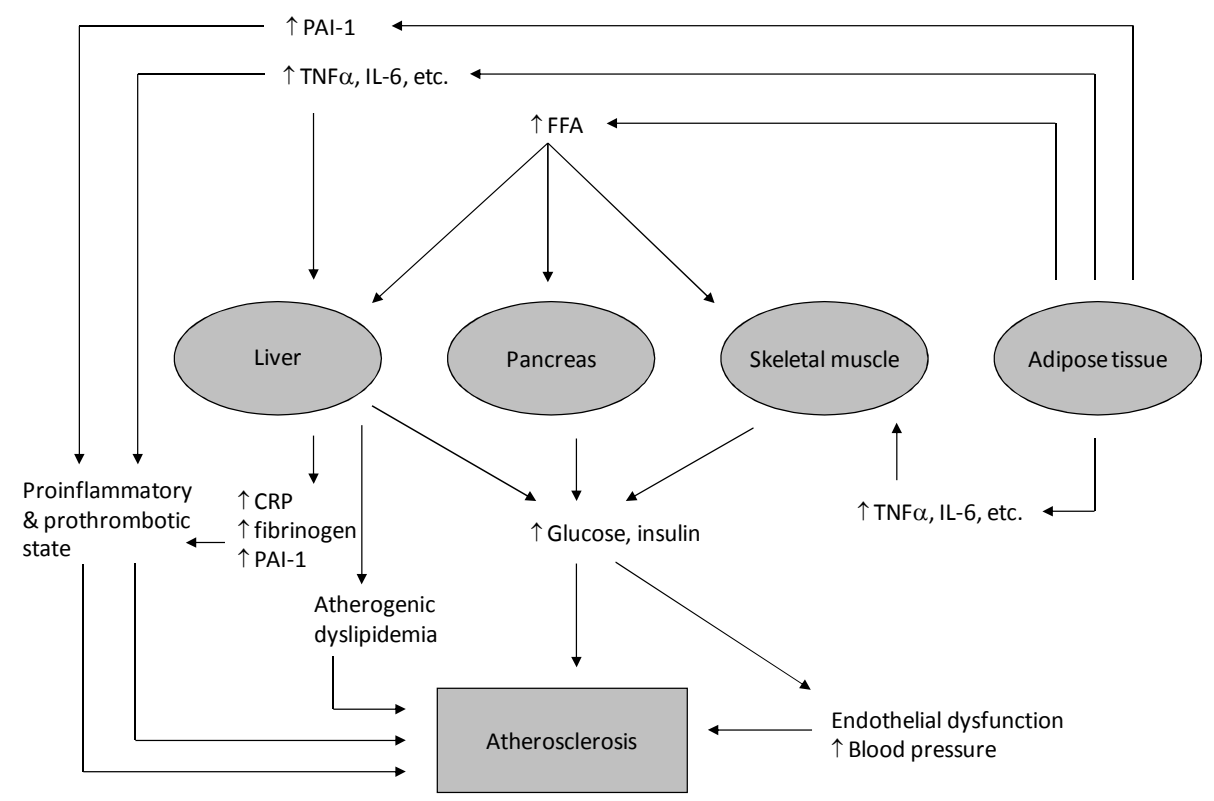

Figure 1.1. Pathophysiology of the metabolic syndrome.

\section{Complications of the metabolic syndrome}

It seems self-evident that a condition characterized by multiple risk factors will carry a greater risk for adverse clinical outcomes than will a single risk factor. Although ATP III identified CVD as the primary clinical outcome of the metabolic syndrome, people with this syndrome may also have insulin resistance, which strongly predisposes to the development type 2 diabetes mellitus. When diabetes becomes clinically apparent, CVD risk is even more enhanced. Beyond CVD and type 2 diabetes, patients with the metabolic syndrome are also susceptible to other conditions, including polycystic ovary syndrome, fatty liver, cholesterol gallstones, asthma, sleep disturbances, and some forms of cancer [13].

The term CVD refers to the class of diseases that involve the heart and blood vessels, such as myocardial infarction, diseases of the heart valves or muscle, heart failure, and stroke. However, the term CVD is usually used to describe atherosclerosis: a slow, complex, chronic disease, which is the primary cause of CVD [32]. The 
process of atherosclerosis is a continuum, already starting at an early age, in which a plaque is formed in the vessel wall. Endothelial dysfunction seems to be the process initiating the development of atherosclerosis. High concentrations of glucose, FFA, LDL cholesterol, and inflammatory cytokines, among others, are factors that can damage the endothelial layer of the blood vessel, making it more permeable for atherogenic LDL particles. Once migrated into the underlying intima layer, the accumulating LDL particles can undergo oxidation. Oxidized LDL stimulates the expression of adhesion molecules, such as intracellular adhesion molecule-1 (ICAM-1) and vascular cell adhesion molecule-1 (VCAM-1), on the endothelial cells, attracting monocytes to the site of damage. The monocytes migrate into the intima layer, where they transform into macrophages. These macrophages are able to take up large amounts of oxidized LDL through their scavenger receptors and become lipidfilled foam cells. Surrounding smooth muscle cells and endothelial cells then start to secrete cytokines and growth factors, promoting smooth muscle cells to proliferate and migrate through the endothelium. The migrated smooth muscle cells then begin to synthesize extracellular matrix components, particularly collagen. Eventually, the lipid-filled foam cells are covered by a fibrous cap, consisting of collagen-rich fibrous tissue, smooth muscle cells, macrophages and thrombocytes. This is called the mature atherosclerotic plaque. The plaque protrudes into the arterial lumen and can finally obstruct the artery. Moreover, rupture of the plaque causes the formation of a thrombus, which can block a coronary or cerebral artery and lead to a myocardial or cerebrovascular infarction.

\section{Treatment of the metabolic syndrome}

Due to its multifaceted character, no straightforward approach exists to treat the metabolic syndrome. The primary goal of clinical management of the metabolic syndrome is to reduce the risk for CVD and type 2 diabetes. Lifestyle modification, focusing on weight reduction and exercise, is an important part of the treatment regimen $[33,34]$. Modest weight reduction through diet and exercise will result in an improved serum lipoprotein profile, reduced blood pressure, improved glucose homeostasis, and a reduced inflammatory state. A regular exercise program, including a minimum of 30 minutes of moderate physical exercise on most days of the week, is advised. In addition, a diet rich in vegetables, fruits, whole grains, fish, and low-fat dairy products is recommended to improve cardiovascular health. Patients should reduce the intake of saturated fats, trans fats, cholesterol, and simple sugars. Moreover, nutrient-dense, low-energy foods should replace low-nutrient, highcalorie foods. Besides these dietary principles, there might be additional food products or food compounds that have a beneficial impact on the metabolic syndrome or its components. In this respect, dairy products are one group of food products 
that are thought to have positive effects and that deserve special attention. The effects of dairy product consumption on the metabolic syndrome are discussed in chapter 2. Finally, drug therapy might be appropriate to reduce the risk of developing CVD or type 2 diabetes mellitus. However, it should be noticed that no single drug could treat all risk factors belonging to the metabolic syndrome.

\section{Outline of the thesis}

This thesis describes the results of human intervention studies and in vitro experiments addressing the effects of dairy products or its constituents on several metabolic disturbances associated with the metabolic syndrome. In chapter $\mathbf{2}$, an overview of the literature available on the effects of low-fat dairy consumption on the metabolic syndrome is given. The human intervention study described in chapter $\mathbf{3}$ was designed to investigate the effects of low-fat dairy consumption on metabolic syndrome components in overweight and obese subjects. In chapter $\mathbf{4}$, the effects of low-fat dairy consumption on a range of markers of low-grade chronic inflammation in the same population are described. Further, we studied the effects of dairy and dairy constituents on postprandial responses in overweight and obese men. The results of this trial are presented in chapter $\mathbf{5}$. In the in vitro experiments described in chapter 6, we studied the effects of the amino acids glutamine, leucine and proline on inflammatory cytokine production and insulin signalling in a liver cell model. Finally, chapter $\mathbf{7}$ discusses the main findings and conclusions based on the studies described in this thesis. 


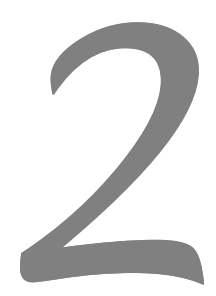

\section{Dairy product consumption and the metabolic syndrome}

Leonie E.C. van Meijl, Ruth Vrolix, Ronald P. Mensink

Nutrition Research Reviews 2008; 21(2): 148-57 


\section{ABSTRACT}

The metabolic syndrome is an important risk factor for type 2 diabetes mellitus and cardiovascular disease. Epidemiological studies have now suggested protective effects of dairy consumption on the development of this syndrome. Here we review the physiological effects and possible mechanisms involved of three main dairy constituents (calcium, protein, fat) on important components of the metabolic syndrome. Calcium supplements improve the serum lipoprotein profile, particularly by decreasing serum total and LDL-cholesterol concentrations. They also lower systolic and diastolic blood pressure. Insufficient evidence exists for a significant role of calcium supplements or dairy in body weight management. Effects of calcium may be related to intestinal binding to fatty acids or bile acids, or to changes in intracellular calcium metabolism by suppressing calciotropic hormones. Dietary proteins may increase satiety on both the short and longer term, which may result in a reduced energy intake. They have also been reported to improve the serum lipoprotein profile as compared to carbohydrates. Dairy proteins are precursors of ACE-inhibitory peptides, which may lower blood pressure. Such effects, however, have inconsistently been reported in human studies. Finally, conjugated linoleic acid (CLA), which effectively lowers body weight in animals, has no such effect in humans in the quantities provided by dairy products. To reduce the intake of saturated fatty acids, the consumption of low-fat instead of high-fat dairy is recommended. In conclusion, more research is warranted to better understand the physiological effects and the mechanisms involved of dairy products in the prevention and treatment of the metabolic syndrome. 


\section{Introduction}

The metabolic syndrome dramatically enhances the risk to develop cardiovascular disease and type 2 diabetes mellitus. It consists of a combination of different metabolic abnormalities, such as abdominal obesity, atherogenic dyslipidemia, elevated blood pressure, insulin resistance, glucose intolerance, impaired endothelial and haemostatic function, and a low-grade inflammatory state [13]. The prevalence of the metabolic syndrome among the adult population exceeds $20 \%$ in many Western societies and is expected to increase in the very near future [35]. Without doubt, this will have important economic and health consequences, and unfortunately no straightforward approach exists to prevent or treat the metabolic syndrome.

However, it is well established that both energy restriction and dietary composition play an important role in this respect. More specifically, several studies have suggested that dairy food products have a positive impact on the prevention of the metabolic syndrome. The aim of the present review is now to briefly summarize findings from epidemiological studies on the relationship between dairy consumption and the metabolic syndrome and to discuss the results from intervention studies on the effects of dairy and dairy constituents on features of this syndrome. In addition, attention is paid to underlying mechanisms. We hereby focussed on studies carried out during the last decade.

\section{Dairy consumption and the metabolic syndrome}

A number of epidemiological studies have investigated the relationship between dairy consumption and the prevalence or incidence of the metabolic syndrome. In 2000, Mennen et al. [36] showed in a cross-sectional study that consumption of dairy products was inversely related with the prevalence of the metabolic syndrome in men (aged 30-64 y), but not in women. Men who consumed more than 1 portion of dairy products per day had a $40 \%$ lower prevalence of the metabolic syndrome compared with men who did not consume dairy products at all. In another crosssectional study, Azadbakht et al. [37] demonstrated an inverse association between dairy consumption and the metabolic syndrome in healthy Tehranian subjects aged 18-74 y. In the group with the highest dairy intake ( $\geq 3.1$ servings/d of milk, yogurt, cheese and milk-based desserts) the prevalence of the metabolic syndrome was $7 \%$ lower compared with the group with the lowest dairy intake $(<1.7$ servings/d). In addition, Elwood and colleagues [38] have recently found a negative relationship between milk and dairy intake and the prevalence of the metabolic syndrome in a study among 45-49 y old men. Similar results were observed by Ruidavets et al. [39], who showed in a cross-sectional sample of 45-64 y old men that intake of dairy products (milk and cheese) was negatively related to the prevalence of the 
metabolic syndrome. However, a cross-sectional study by Beydoun et al. [40] among 4519 US adults showed that the various dairy products may have different associations with the metabolic syndrome. While cheese consumption showed a positive relationship with the prevalence of the metabolic syndrome, the intake of yogurt resulted in a negative relationship. In contrast, in an elderly Dutch population Snijder et al. [41] did not find associations between dairy consumption and the metabolic syndrome. Also after differentiation between low-fat and high-fat dairy products, no significant associations were found. In the same population, baseline dairy consumption was also not related to the risk to develop the metabolic syndrome in the next 6.4 years [42]. However, in the prospective Coronary Artery Risk Development in Young Adults (CARDIA) study [43] among more than 3000 young (aged 18-30 y) men and women, it was found that in overweight subjects dairy consumption was inversely associated with the development of all components of the metabolic syndrome over the next 10 years. In another prospective study by Lutsey et al. [44], dairy consumption was inversely associated with the incidence of the metabolic syndrome in more than 9500 US subjects (45-64 y) after 9 years of follow-up.

Though not consistent, the majority of epidemiological studies do suggest that dairy products may play a role in the prevention and development of the metabolic syndrome. However, which of the components from dairy products may be responsible for these possible positive effects is not clear, as are the mechanisms behind these effects. However, several intervention studies have been performed on the effects of single nutrients from dairy products on the different features of the metabolic syndrome. In this respect, much attention has been paid to calcium, protein, and fat.

\section{Calcium}

Dairy products are an important source of calcium $[45,46]$. High intakes of dietary calcium may be associated with a lower prevalence of the various risk markers belonging to the metabolic syndrome, as indicated by epidemiological studies $[47,48]$. A number of intervention studies also showed beneficial effects of calcium on features of the metabolic syndrome.

\section{Effects of calcium on the serum lipid profile}

Calcium may affect the serum lipoprotein profile. Calcium provided as a food supplement has been found to increase serum HDL-cholesterol concentrations [49], and to decrease serum total cholesterol[50] and LDL-cholesterol concentrations [51]. As a consequence, calcium intake also improved the HDL:LDL cholesterol ratio, 
which may be even a better marker to predict cardiovascular risk than LDL or HDL per se. Reid et al. [49] found beneficial effects on circulating lipid levels after 12 months of calcium supplementation. Two hundred and twenty-three postmenopausal women were given $1 \mathrm{~g}$ of calcium daily as calcium citrate or placebo. HDL cholesterol and the HDL:LDL cholesterol ratio significantly increased by $0.13 \mathrm{mmol} / \mathrm{L}$ and 0.06 , respectively. No statistically significant decreases in total cholesterol $(-0.18 \mathrm{mmol} / \mathrm{L})$ and $\mathrm{LDL}$ cholesterol $(-0.29 \mathrm{mmol} / \mathrm{L})$ were observed. In the cross-over study of Ditscheid et al. [50], thirty-one healthy adults received $1 \mathrm{~g}$ of calcium daily, supplied as pentacalcium hydroxy-triphosphate in bread, or nonsupplemented bread for 4 weeks. A significant decrease in total cholesterol (-0.24 $\mathrm{mmol} / \mathrm{L})$, and non-significant decreases in LDL cholesterol $(-0.14 \mathrm{mmol} / \mathrm{L})$ and the LDL:HDL cholesterol ratio $(-0.85)$ were found. Shahkhalili et al. [51] observed significantly decreased serum LDL cholesterol concentrations $(-0.32 \mathrm{mmol} / \mathrm{L})$ and a non-significant decrease in total cholesterol $(-0.34 \mathrm{mmol} / \mathrm{L})$. In this study, ten healthy men received calcium supplemented chocolate ( $900 \mathrm{mg}$ calcium daily) or non-supplemented chocolate for 2 weeks in a crossover design. On the contrary, Bostick et al. [52] did not find significant effects of calcium supplementation on the serum lipoprotein profile in 193 men and women aged 30-74 y. Subjects received 1 or $2 \mathrm{~g}$ of calcium daily, given as calcium carbonate, for 4 months. No statistically significant differences in serum total cholesterol and HDL cholesterol concentrations were found between the calcium and placebo groups. A summary of human intervention studies on the effects of calcium supplements on the serum lipid profile is given in Table 2.1.

\section{Possible mechanisms underlying the effects of calcium on the serum lipid profile}

Two potential mechanisms have been proposed by which calcium might affect lipoprotein metabolism. One mechanism is the inhibition of fat absorption in the intestine (Figure 2.1). Calcium interacts in particular with saturated fatty acids to form calcium-fatty acid soaps. The formation of these insoluble complexes increases fecal fat excretion. Evidence for this interaction comes from a number of human studies [51, 53-55]. More recently, however, Boon and colleagues only observed a tendency towards an increased fecal fat excretion on high calcium (1200 or 2500 versus 400 $\mathrm{mg}$ ) diets [56]. In support of a decreased fat absorption, Lorenzen et al. [57] have shown that calcium from dairy (milk and low-fat yogurt), in contrast to supplementary calcium, diminished the triacylglycerol content of chylomicrons postprandially. This suggests either an increase in chylomicron clearance, or a decrease in fat absorption. As there is no evidence in the literature suggesting that calcium interferes with chylomicron clearance, effects on fat absorption are very likely. However, the reason for the difference between the effects of dairy and supplemental calcium is not clear. The authors suggested that other properties of dairy may be responsible 
for the different effects, such as the chemical form of calcium (calcium phosphate in dairy vs. calcium carbonate in supplements) or the synergistic action of other dairy components.

Table 2.1 Overview of intervention studies on the effects of dairy and calcium supplementation on serum lipid profile, blood pressure and glucose metabolism.

\begin{tabular}{|c|c|c|c|c|c|c|c|}
\hline $\begin{array}{l}\text { MetS com- } \\
\text { ponent }\end{array}$ & Subjects & Design & $\begin{array}{l}\text { Additional calcium } \\
\text { intake ( } \mathrm{mg} / \text { day })+ \\
\text { source }\end{array}$ & Control & Effects & & Authors \\
\hline Lipid profile & $\begin{array}{l}223 \text { elderly } \\
\text { women }\end{array}$ & $\begin{array}{l}\text { Randomized, } \\
1 \text { year }\end{array}$ & $\begin{array}{l}1000 \\
\text { (calcium citrate) }\end{array}$ & Placebo & $\begin{array}{l}\text { TC } \\
\text { LDL-C } \\
\text { HDL-C } \\
\text { HDL/LDL } \\
\text { TG }\end{array}$ & $\begin{array}{l}-0.18 \mathrm{mmol} / \mathrm{L} \\
-0.29 \mathrm{mmol} / \mathrm{L} \\
+0.13 \mathrm{mmol} / \mathrm{L}^{*} \\
+0.06^{*} \\
-0.02 \mathrm{mmol} / \mathrm{L}\end{array}$ & $\begin{array}{l}\text { Reid } \\
2002 \text { [49] }\end{array}$ \\
\hline Lipid profile & $\begin{array}{l}31 \text { healthy } \\
\text { adults }\end{array}$ & $\begin{array}{l}\text { Cross-over, } \\
\text { double-blind, } \\
2 \times 4 \text { wk }\end{array}$ & $\begin{array}{l}1000 \text { (calcium } \\
\text { phosphate in } \\
\text { bread) }\end{array}$ & $\begin{array}{l}\text { Non-supplemented } \\
\text { bread }\end{array}$ & $\begin{array}{l}\text { TC } \\
\text { LDL-C } \\
\text { LDL/HDL }\end{array}$ & $\begin{array}{l}-0.24 \mathrm{mmol} / \mathrm{L}^{*} \\
-0.14 \mathrm{mmol} / \mathrm{L} \\
-0.85\end{array}$ & $\begin{array}{l}\text { Ditscheid } \\
2005[50]\end{array}$ \\
\hline Lipid profile & $\begin{array}{l}10 \text { healthy } \\
\text { men }\end{array}$ & $\begin{array}{l}\text { Randomized, } \\
\text { double-blind, } \\
\text { cross-over, } \\
2 \times 2 \mathrm{wk}\end{array}$ & $\begin{array}{l}900 \\
\text { (supplemented } \\
\text { chocolate) }\end{array}$ & $\begin{array}{l}\text { Non-supplemented } \\
\text { chocolate }\end{array}$ & $\begin{array}{l}\text { TC } \\
\text { LDL-C }\end{array}$ & $\begin{array}{l}-0.34 \mathrm{mmol} / \mathrm{L} \\
-0.32 \mathrm{mmol} / \mathrm{L}^{*}\end{array}$ & $\begin{array}{l}\text { Shahkhalili } \\
2001[51]\end{array}$ \\
\hline Lipid profile & $\begin{array}{l}193 \text { healthy } \\
\text { adults }\end{array}$ & $\begin{array}{l}\text { Randomized, } \\
\text { double blind, } \\
4 \text { months }\end{array}$ & $\begin{array}{l}1000 \text { or } 2000 \text { (cal- } \\
\text { cium carbonate) }\end{array}$ & Placebo & $\begin{array}{l}\text { TC } \\
\text { HDL-C }\end{array}$ & $\begin{array}{l}-0.07 \mathrm{mmol} / \mathrm{L} \\
+0.01 \mathrm{mmol} / \mathrm{L}\end{array}$ & $\begin{array}{l}\text { Bostick } \\
2000[52]\end{array}$ \\
\hline $\begin{array}{l}\text { Blood pres- } \\
\text { sure }\end{array}$ & $\begin{array}{l}34 \text { obese } \\
\text { adults }\end{array}$ & $\begin{array}{l}\text { Randomized, } \\
24 \mathrm{wk}\end{array}$ & $\begin{array}{l}700 \\
\text { (dairy) }\end{array}$ & $\begin{array}{l}\text { Low-calcium, } \\
\text { low-dairy diet }\end{array}$ & $\begin{array}{l}\text { SBP } \\
\text { DBP }\end{array}$ & $\begin{array}{l}-6.99 \mathrm{~mm} \mathrm{Hg}^{*} \\
-4.37 \mathrm{~mm} \mathrm{Hg}^{*}\end{array}$ & $\begin{array}{l}\text { Zemel } \\
2005 \text { [58] }\end{array}$ \\
\hline $\begin{array}{l}\text { Blood pres- } \\
\text { sure }\end{array}$ & $\begin{array}{l}459 \text { healthy } \\
\text { adults }\end{array}$ & $\begin{array}{l}\text { Randomized, } \\
8 \mathrm{wk}\end{array}$ & $\begin{array}{l}820 \text { (dairy in diet } \\
\text { rich in fruits and } \\
\text { vegetables) }\end{array}$ & $\begin{array}{l}\text { Diet rich in fruits } \\
\text { and vegetables }\end{array}$ & $\begin{array}{l}\text { SBP } \\
\text { DBP }\end{array}$ & $\begin{array}{l}-2.7 \mathrm{~mm} \mathrm{Hg}^{*} \\
-1.9 \mathrm{~mm} \mathrm{Hg}^{*}\end{array}$ & $\begin{array}{l}\text { Appel } \\
1997[59]\end{array}$ \\
\hline $\begin{array}{l}\text { Blood pres- } \\
\text { sure }\end{array}$ & $\begin{array}{l}34 \text { obese } \\
\text { adults }\end{array}$ & $\begin{array}{l}\text { Randomized, } \\
12 \mathrm{wk}\end{array}$ & $\begin{array}{l}600 \\
\text { (dairy in energy } \\
\text { deficit diet) }\end{array}$ & $\begin{array}{l}\text { Low-calcium, en- } \\
\text { ergy deficit diet }\end{array}$ & $\begin{array}{l}\text { SBP } \\
\text { DBP }\end{array}$ & $\begin{array}{l}-2.59 \mathrm{~mm} \mathrm{Hg} \\
-4.37 \mathrm{~mm} \mathrm{Hg}^{*}\end{array}$ & $\begin{array}{l}\text { Zemel } \\
2005[60]\end{array}$ \\
\hline $\begin{array}{l}\text { Blood pres- } \\
\text { sure }\end{array}$ & $\begin{array}{l}193 \text { healthy } \\
\text { adults }\end{array}$ & $\begin{array}{l}\text { Randomized, } \\
\text { double blind, } \\
6 \text { months }\end{array}$ & $\begin{array}{l}1000 \text { or } 2000 \text { (cal- } \\
\text { cium carbonate) }\end{array}$ & Placebo & $\begin{array}{l}\text { SBP } \\
\text { DBP }\end{array}$ & $\begin{array}{l}-0.8 \mathrm{~mm} \mathrm{Hg} \\
-0.4 \mathrm{~mm} \mathrm{Hg}\end{array}$ & $\begin{array}{l}\text { Bostick } \\
2000[52]\end{array}$ \\
\hline $\begin{array}{l}\text { Glucose } \\
\text { metabolism }\end{array}$ & $\begin{array}{l}34 \text { obese } \\
\text { adults }\end{array}$ & $\begin{array}{l}\text { Randomized, } \\
24 \mathrm{wk}\end{array}$ & $\begin{array}{l}700 \\
\text { (dairy) }\end{array}$ & $\begin{array}{l}\text { Low-calcium, } \\
\text { low-dairy diet }\end{array}$ & $\begin{array}{l}\text { Fasting } \\
\text { insulin }\end{array}$ & -19.7 pM* & $\begin{array}{l}\text { Zemel } \\
2005 \text { [58] }\end{array}$ \\
\hline $\begin{array}{l}\text { Glucose } \\
\text { metabolism }\end{array}$ & $\begin{array}{l}32 \text { obese } \\
\text { adults }\end{array}$ & $\begin{array}{l}\text { Randomized, } \\
24 \mathrm{wk}\end{array}$ & $\begin{array}{l}1200-1300 \\
\text { (dairy in energy } \\
\text { deficit diet) }\end{array}$ & $\begin{array}{l}\text { Low-calcium, } \\
\text { low dairy energy } \\
\text { deficit diet }\end{array}$ & \multicolumn{2}{|c|}{$\begin{array}{l}\text { Glucose AUC } \downarrow * \\
\text { Fasting insulin } \downarrow^{*}\end{array}$} & $\begin{array}{l}\text { Zemel } \\
2004[61]\end{array}$ \\
\hline
\end{tabular}

TC, Total Cholesterol; LDL-C, Low Density Lipoprotein Cholesterol; HDL-C, High Density Lipoprotein Cholesterol; TG, Triglycerides; SBP, Systolic Blood Pressure; DBP, Diastolic Blood Pressure; AUC, Area Under the Curve. ${ }^{*} \mathrm{P}<0.05$ 
Saturated fatty acids are known to increase total and LDL cholesterol, most likely by suppressing LDL-receptor activity [62]. The reduced absorption of saturated fatty acids may, at least in part, contribute to the LDL cholesterol-lowering effects of calcium. Some studies have suggested that this mechanism may be less effective under high-protein conditions, because protein would increase the intestinal absorption of calcium $[55,63]$. Whether or not this decreases the amount of calcium that is available for binding to fatty acids has, however, not been investigated. In fact, calcium is only partially absorbed and it may be speculated that the calcium content of high dairy diets is high enough to leave sufficient amounts of calcium in the gastrointestinal tract for binding to fatty acids. Another possible mechanism is that calcium binds to bile acids (Figure 2.1). Indeed, in some human studies, calcium increased the fecal excretion of bile acids $[50,51,64]$. In this way, reabsorption of bile acids into the enterohepatic circulation is inhibited, leading to an increased conversion of cholesterol to bile acids in the liver and ultimately to decreased LDL cholesterol levels.

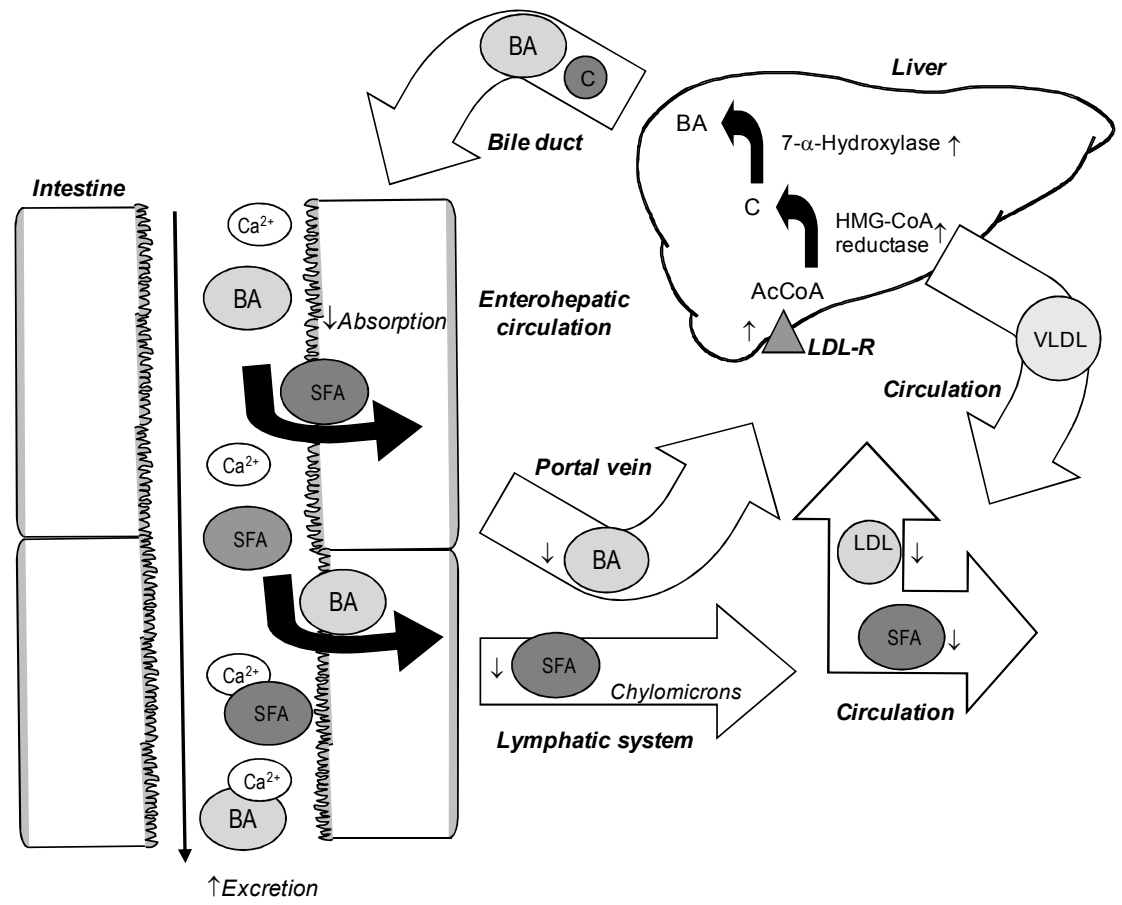

Figure 2.1. One of the proposed mechanisms of action of dietary calcium. Calcium binds to saturated fatty acids (SFA) or bile acids (BA) in the intestine, inhibiting their absorption. SFA raise LDL cholesterol, probably by decreasing LDL receptor activity. Reduced absorption of SFA can therefore lower serum LDL cholesterol. In the liver, cholesterol is converted into BA. Lowering the absorption of BA in the intestine will therefore lead to an increased conversion of cholesterol and reduced serum LDL cholesterol levels. 


\section{Effects of calcium and dairy on body weight and fat mass}

Calcium may exert its effects on the metabolic syndrome by mediating body weight and fat mass. Observational as well as intervention studies suggest that high calcium intakes are associated with lower body weight and fat mass. Zemel and colleagues were among the first to report beneficial effects of calcium on body weight and fat mass. Furthermore, they have proposed that calcium from dairy sources exerts larger effects calcium from non-dairy sources. In a six-month trial [61], thirty-two obese subjects were maintained on energy deficit ( $-500 \mathrm{~kJ} /$ day) diets and randomized to control (zero to one servings of dairy products/day supplemented with placebo, providing 400-500 mg calcium/day), high calcium (control diet supplemented with $800 \mathrm{mg}$ calcium/day as calcium carbonate), or high dairy (three servings/day supplemented with placebo, providing $1200-1300 \mathrm{mg}$ of calcium/day) diets. Both weight loss and fat loss were higher on the high calcium diet than on the control diet, but even higher on the high dairy diet. Additionally, the largest percentage of fat from the trunk was lost on the high dairy diet, shifting the distribution of body fat loss to a more favourable pattern. Thus, dairy products exerted a substantially larger effect on both fat loss and fat distribution compared with an equivalent amount of supplemental calcium. This has been attributed to additional bioactive compounds in dairy, that may act synergistically with calcium to modulate body weight and fat mass [65]. Although the macronutrient composition of the diets was similar and the diets only differed in calcium content, the observed effects might partly be due to differences in protein source, for example. The augmentation of weight loss by dairy products was also observed in another study, in which an energy deficit yogurt diet (1100 $\mathrm{mg} \mathrm{Ca}$ ) was compared to an energy deficit control (400-500 mg Ca) diet [60]. While macronutrients were held constant and only calcium contents differed, it cannot be concluded whether the effects are due to calcium alone or also to other bioactive components in dairy.

Despite these positive results $[60,61]$, many other studies did not provide evidence for weight or body fat reducing effects of calcium. Recently, Lanou and Barnard [66] thoroughly reviewed forty-nine randomized controlled trials on the effects of dairy and calcium intake, with or without energy restriction, on body weight and adiposity. Of seventeen studies on dairy intake, fifteen showed no effect on body weight, while two reported weight gain. Nineteen trials used calcium supplements and found no effect on weight, while one study showed weight loss and one study found a lower rate of weight gain on calcium treatment. They identified six trials using dairy products in combination with reduced energy intake, of which three reported no effects and three showed body weight loss. Of the five studies on calcium supplementation combined with energy restriction, four found no effect and one study observed weight loss. The authors therefore concluded that the majority of the current evidence from clinical trials does not support the hypothesis that calcium or dairy consumption promotes weight or fat loss. 
There is no clear explanation for the discrepancy between the positive results from the studies by Zemel $[60,61]$ and the large number of studies reporting no weight reducing effects of calcium and dairy consumption. It has been proposed that effects of calcium on body weight are only present in populations with low habitual intakes, and that at calcium consumption above $800 \mathrm{mg}$ per day, no additive beneficial effects of increasing dietary calcium will occur [67]. However, Lanou and Barnard [66] also included trials among populations with suboptimal calcium intakes, which does not support this threshold hypothesis. It might also be speculated that dairy products and calcium supplements reduce body weight and fat mass only when part of an energy-restricted diet. This reasoning is, however, also not supported by the majority of studies [66].

\section{Possible mechanisms underlying the effects of calcium on body weight and fat mass}

For the effects of calcium on body weight and body composition, the ability of calcium to bind fatty acids and thereby inhibiting fat absorption, as discussed above, is proposed as one possible mechanism of action. Another way by which calcium might affect body composition, is by regulating intracellular calcium levels, as hypothesized by Zemel et al. (Figure 2.2) [65]. Intracellular calcium levels are regulated by calciotropic hormones, such as parathyroid hormone (PTH) and 1,25hydroxyvitamin $\mathrm{D}_{3}$ (calcitriol). High dietary calcium now depresses the levels of calcitriol, thereby decreasing intracellular calcium. This results in a stimulation of lipolysis. Additionally, low intracellular calcium inhibits the expression of fatty acid synthase (FAS), which is a key enzyme in de novo lipogenesis $[65,68]$. Therefore, calcium intake may directly affect storage and breakdown of fat in adipose tissue. This mechanism has been demonstrated in human adipocytes in vitro, in which calcitriol increased intracellular calcium concentrations and inhibited lipolysis. Additionally, in transgenic mice, a high calcium diet reduced lipogenesis and stimulated lipolysis, resulting in reductions in body weight and adipose tissue mass [69]. However, this concept has not yet been shown in humans. In fact, in a series of trials performed by Boon and colleagues, the various steps of the Zemel hypothesis could not be confirmed. Although high calcium/high dairy intake did affect calcitriol metabolism [70], and although changes in intracellular calcium did change lipolysis [71], changes in serum calcitriol did not alter fat metabolism in vivo [70].

\section{Effects of calcium on blood pressure}

Epidemiological as well as intervention studies have shown an inverse relationship between calcium intake and blood pressure $[72,73]$. Several potential mechanisms may explain the positive effect of calcium on blood pressure, including reduced 
membrane permeability to monovalent and divalent cations, reduced intracellular calcium levels, decreased concentrations of calcium-regulating hormones, reduced sympathetic nervous system activity, and altered metabolism of other electrolytes e.g. increased sodium excretion [74]. Again, the effect of calcium might be mediated by suppression of the hormone calcitriol. Suppression of this hormone could lower intracellular calcium levels in vascular smooth muscle cells, thereby reducing peripheral resistance and blood pressure [75]. Although it has been shown that calcitriol increases intracellular calcium in arteries of rats [76], and that an association exists between calcitriol and blood pressure in normotensive men [77], this hypothesized mechanism has not yet been demonstrated in humans. A summary of human intervention studies on the effects of dairy and calcium supplements on blood pressure is given in Table 2.1.

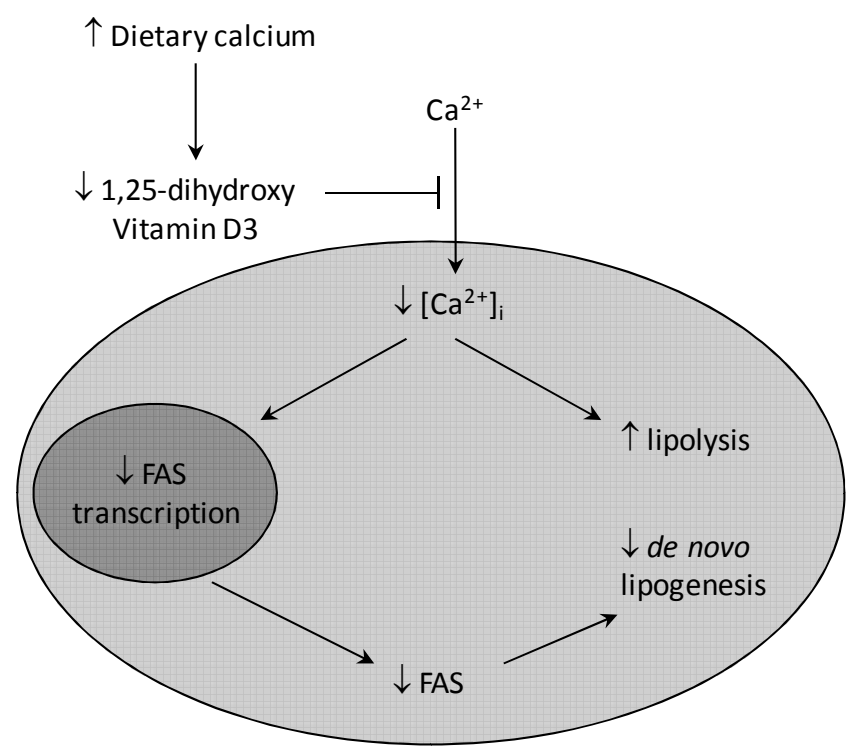

Figure 2.2. Hypothesized mechanism of stimulation of lipolysis and inhibition of lipogenesis by dietary calcium. Increased dietary calcium intake lowers the level of the hormone 1,25-dihydroxy vitamin $D_{3}$, thereby lowering the uptake of $\mathrm{Ca}^{2+}$ into the cell. Decreased levels of intracellular calcium stimulate lipolysis and decrease the transcription of fatty acid synthase (FAS), resulting in inhibition of lipogenesis.

\section{Effects of calcium on glucose metabolism}

Finally, one study showed a significant decrease in insulin levels in subjects consuming a high dairy diet compared with subjects on a low dairy diet [58]. Thirty-four obese African-American adults were maintained on a low calcium (500 mg/day)/low dairy ( $<1$ serving/day) or a high dairy ( $1200 \mathrm{mg}$ calcium/day including 3 servings of dairy) diet for 24 weeks. Circulating insulin decreased by $19.7 \mathrm{pM}$ in subjects on the 
high dairy diet compared with the low dairy diet $(\mathrm{P}<0.05)$. Although no differences in body weight were observed, subjects on the high dairy diet showed a decrease in body fat and an increase in lean mass, which might be related to the improved insulin sensitivity. Another report from this laboratory showed similar results in thirtytwo obese adults [61]. Fasting glucose levels were unaffected by diet, but a $27 \%$ decrease in the area under the glucose curve and a $44 \%$ decrease in fasting plasma insulin levels was observed on a high dairy diet, while these were unaffected on the low dairy diet. However, in this study it was not possible to discern whether these are direct effects of the high dairy diet, or secondary effects of the greater weight and fat loss found on this diet. Although in both studies the diets only differed in calcium content, it cannot be excluded that differences in the source of protein, for example, could have influenced the observed effects of dairy product consumption. Table 2.1 shows an overview of these studies of dairy on glucose metabolism.

\section{Conclusion}

Calcium supplements improve the serum lipid profile, most likely by decreasing total and LDL-cholesterol, thereby improving the HDL:LDL cholesterol ratio. Calcium and dairy also reduce blood pressure. While some studies have reported positive effects of dairy and calcium on body weight and body composition, the majority of trials do not support these findings. Calcium may exert its effects by intestinal binding to fatty acids and bile acids, or by depressing calciotropic hormones and changing intracellular calcium metabolism, although the evidence for the latter mechanism is limited.

\section{Dairy protein}

Dairy products are an important source of protein. Nowadays, more and more attention is paid to the role of protein in metabolic diseases.

\section{Effects of protein on the serum lipid profile and body weight regulation}

Recent evidence suggests that protein added to the diet at the expense of carbohydrates has favourable effects on serum lipoprotein profiles. Krauss et al. found a slight increase in both LDL and HDL cholesterol, but a decrease in the total:HDL cholesterol ratio by proteins replacing carbohydrates [78]. In general, other studies also reported a decrease in the ratio of total:HDL cholesterol on high protein diets [79]. However, in the OmniHeart trial, a high protein diet decreased serum total cholesterol, LDL cholesterol, HDL cholesterol, and triacylglycerol concentrations [80]. 
Another interesting property of protein is its role in body weight regulation, which consists of different aspects. First, protein increases satiety, which may result in a decreased energy intake. On the short term, i.e. after an acute meal, consumption of high protein meals ( 60 to $81 \%$ of energy from protein) resulted in higher satiety compared with low or moderate protein meals [81-84] and a reduced energy intake $[82,83,85]$. Also in the longer term, high protein diets in studies lasting up to 4 days caused a continuously higher satiety throughout the day [86, 87]. In this respect, the effects of high protein diets do not seem to depend on the type of macronutrient that is substituted. However, effects may be different for diverse types of protein. For example, it was shown that satiety was acutely increased and energy intake was decreased after a whey diet compared with a casein diet [88].

Furthermore, high protein diets may preserve or increase fat free mass and reduce fat mass during weight loss and weight regain, contributing to an improved body composition and metabolic profile. Layman et al. [89] found an improved body composition during weight loss in adult women, when proteins replaced carbohydrates. In a trial by Westerterp-Plantenga et al. [90], overweight and obese subjects who consumed $18 \%$ of energy as protein regained less weight $(1 \mathrm{~kg})$ during 3 months after a weight loss period than subjects who consumed $15 \%$ of energy from protein $(2 \mathrm{~kg})$. In addition, body composition of the regained body mass was more favourable in the high protein group, in which no fat mass, but only fat free mass was regained, resulting in a lower percentage of body fat.

\section{Effects of bioactive peptides on blood pressure and coagulation}

Milk contains two major protein groups: caseins and whey proteins. Caseins are a mixture of related phosphoproteins, characterized as one of the most nutritive milk proteins, containing all of the common amino acids and being rich in the essential ones. They are a heterogeneous family of proteins, mainly $\alpha_{\mathrm{S1}^{-}}, \alpha_{\mathrm{S2}}, \beta,{ }^{-}$, and $\kappa^{-}$ caseins. Caseins account for almost $80 \%$ of total protein in bovine milk and exist primarily as calcium phosphate stabilized micellular complexes [91]. Whey protein is the name for a collection of globular proteins that can be isolated from whey, a byproduct of cheese manufactured from cow's milk. Whey proteins account for $20 \%$ of total milk protein, and are also a heterogeneous group of proteins. They mainly consist of $\alpha$-lactalbumin, $\beta$-lactoglobulin, and serum albumin [91].

Both caseins and whey proteins are precursors of many different biologically active peptides. These peptides are inactive within the protein sequence, requiring enzymatic proteolysis for release of the bioactive fragment from the protein precursor. These fragments can be released either during gastrointestinal digestion or during food processing, for example during fermentation with bacteria such as Lactobacillus helveticus $[92,93]$. One class of bioactive peptides derived from dairy protein is the group of the angiotensin-l-converting enzyme (ACE) inhibitory proteins. 
ACE is a multifunctional enzyme, which plays a key physiological role in the regulation of peripheral blood pressure. Associated with the renin-angiotensin system, ACE converts angiotensin I to the highly potent vasoconstrictor angiotensin II. Inhibition of this enzyme prevents the formation of angiotensin II and will therefore result in reduced blood pressure. ACE-inhibitory peptides are present in the amino acid sequences of caseins, as well as in whey proteins $[93,94]$. In this way, blood pressure is one feature of the metabolic syndrome that could be affected by dairy protein (Figure $\mathbf{2 . 3}$ ).

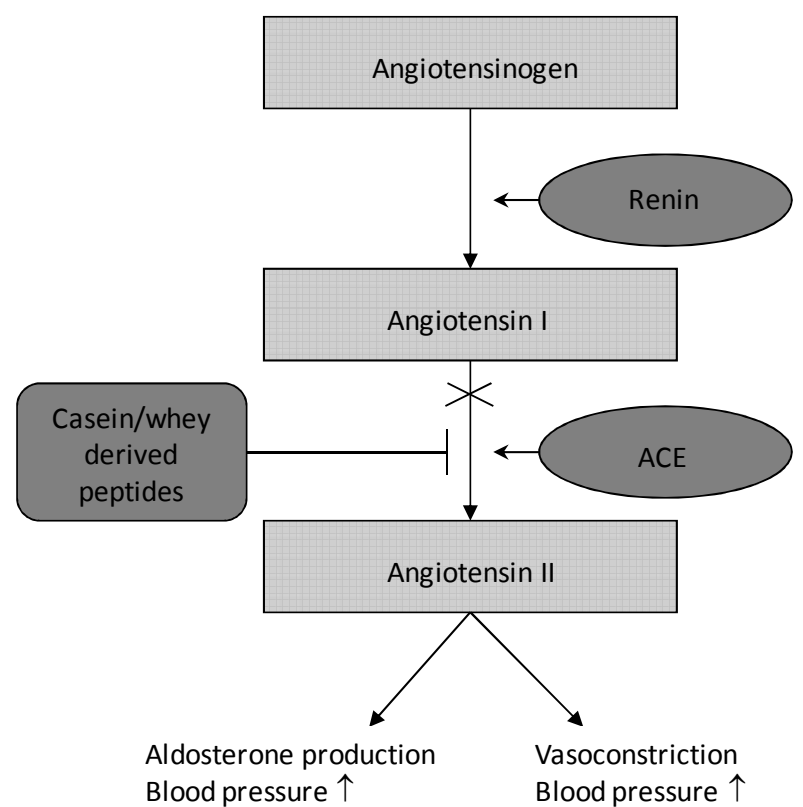

Figure 2.3. Inhibition of conversion from angiotensin I to angiotensin II by bioactive peptides derived from milk proteins. These peptides block the action of angiotensin converting enzyme (ACE) and may, in this way, lower blood pressure.

However, most studies on the ACE-inhibitory effects of milk peptides have been performed in vitro, and the number of human studies is limited. Aihara et al. [95] performed a 4-week trial with 40 subjects with high-normal blood pressure and forty mild hypertensive subjects, receiving either powdered fermented milk tablets (12 g) or placebo tablets. They found decreases in systolic and diastolic blood pressures by $3.2 \mathrm{mmHg}$ (non-significant) and $5.0 \mathrm{mmHg}(P<0.05)$, respectively, in the high-normal subjects. In the mild hypertensive subjects, systolic blood pressure was decreased by $11.2 \mathrm{mmHg}(\mathrm{P}<0.05)$ and diastolic pressure by $6.5 \mathrm{mmHg}(\mathrm{P}=0.055)$. In the study of Mizuno et al. [96], forty-eight subjects with high-normal blood pressure and eighty-three mild hypertensive subjects received casein hydrolysate (3.6 $\mathrm{mg} /$ day) or placebo tablets for 6 weeks. In the high-normal group, non- significant 
changes in both systolic $(-3.1 \mathrm{mmHg})$ and diastolic $(-0.3 \mathrm{mmHg})$ blood pressure were observed. Systolic blood pressure decreased significantly by $11.8 \mathrm{mmHg}$ in the mildly hypertensive subjects, while diastolic blood pressure was decreased by 2.9 $\mathrm{mmHg}$. In a trial with thirty-nine hypertensive patients performed by Seppo et al. [97], skim milk fermented with Lactobacillus helveticus ( $150 \mathrm{~mL} /$ day) seemed to cause a reduction in blood pressure after 21 weeks, compared with skim milk fermented with Lactococcus sp. However, after intention-to-treat analysis, no significant differences between test product group and control group were observed. In addition, in a recent placebo-controlled trial in 135 mildly hypertensive subjects by Engberink et al., no effects of milk-derived peptides on blood pressure, ACE-activity or plasma angiotensin II concentrations were found after 8 weeks of treatment [98]. Also, bioavailability of these peptides is questionable [92], although one study has demonstrated the uptake of intact lactotripeptides [99]. Finally, the amount of ACEinhibitory peptides in non-enriched dairy products may simply be too low to play a significant role in blood pressure regulation. Taken together, human studies do currently not provide unequivocal evidence that bioactive peptides from dairy protein lower systolic or diastolic blood pressure.

Additionally, bioactive peptides in dairy protein can exert beneficial effects on the prothrombotic state characterizing the metabolic syndrome. A large number of similarities between blood clotting and milk clotting exist, including sequence identities between fibrinogen and some milk proteins, and some functional similarities. Casoplatelins are peptides derived from $\kappa$-casein that display antithrombotic activity. They show some sequence similarity to the interacting region of the fibrinogen $\gamma$-chain in platelet aggregation. Their inhibitory effect is probably due to the competition between antithrombotic peptides and the fibrinogen $\gamma$-chain for platelet receptors $[93,100]$. Again, much of this antithrombotic activity has been measured in vitro, which does not necessarily imply antithrombotic activity in vivo. Human studies are lacking, but in vivo antithrombotic activity of milk peptides has been shown in some animal studies [101]. An overview of the effects of dairy protein on metabolic syndrome components found in human studies is presented in Table 2.2. 
Table 2.2. Overview of recent intervention studies on the effects of fermented dairy products or dairy protein on components of the metabolic syndrome.

\begin{tabular}{|c|c|c|c|c|c|c|}
\hline $\begin{array}{l}\text { MetS } \\
\text { compo- } \\
\text { nent }\end{array}$ & Subjects & Design & Intervention & Control & Effects & Authors \\
\hline $\begin{array}{l}\text { Blood } \\
\text { pressure }\end{array}$ & $\begin{array}{l}40 \mathrm{HN}+ \\
40 \mathrm{MH} \\
\text { subjects }\end{array}$ & $\begin{array}{l}\text { Randomized, } \\
\text { double blind, } \\
4 \mathrm{wk}\end{array}$ & $\begin{array}{l}6 \text { Powdered } \\
\text { fermented milk } \\
\text { tablets }(12 \mathrm{~g})\end{array}$ & $\begin{array}{l}\text { Placebo } \\
\text { tablets }\end{array}$ & $\begin{array}{c}\text { HN SBP }-3.2 \mathrm{~mm} \mathrm{Hg} \\
\text { DBP }-5.0 \mathrm{~mm} \mathrm{Hg} * \\
\text { MH SBP }-11.2 \mathrm{~mm} \mathrm{Hg} * \\
\text { DBP }-6.5 \mathrm{~mm} \mathrm{Hg}\end{array}$ & $\begin{array}{l}\text { Aihara } \\
2005 \text { [95] }\end{array}$ \\
\hline $\begin{array}{l}\text { Blood } \\
\text { pressure }\end{array}$ & $\begin{array}{l}48 \mathrm{HN}+ \\
83 \mathrm{MH} \\
\text { subjects }\end{array}$ & $\begin{array}{l}\text { Randomized, } \\
\text { single blind, } \\
6 \mathrm{wk}\end{array}$ & $\begin{array}{l}\text { Casein } \\
\text { hydrolysate, } \\
3.6 \mathrm{mg} / \mathrm{d}\end{array}$ & $\begin{array}{l}\text { Placebo } \\
\text { tablets }\end{array}$ & $\begin{array}{c}\mathrm{HN} \text { SBP }-3.1 \mathrm{~mm} \mathrm{Hg} \\
\text { DBP }-0.3 \mathrm{~mm} \mathrm{Hg} \\
\text { MH SBP }-11.8 \mathrm{~mm} \mathrm{Hg} * \\
\text { DBP }-2.9 \mathrm{~mm} \mathrm{Hg}\end{array}$ & $\begin{array}{l}\text { Mizuno } \\
2005[96]\end{array}$ \\
\hline $\begin{array}{l}\text { Blood } \\
\text { pressure }\end{array}$ & $\begin{array}{l}39 \\
\text { hypertensive } \\
\text { patients }\end{array}$ & $\begin{array}{l}\text { Randomized, } \\
21 \mathrm{wk}\end{array}$ & $\begin{array}{l}\text { Skim milk } \\
\text { fermented with } \\
\text { Lactobacillus } \\
\text { helveticus } 150 \\
\mathrm{~mL} / \mathrm{d}\end{array}$ & $\begin{array}{l}\text { Skim milk } \\
\text { fermented } \\
\text { with Lacto- } \\
\text { coccus sp. } \\
150 \mathrm{~mL} / \mathrm{d}\end{array}$ & $\begin{array}{l}\text { SBP }-5.0 \mathrm{~mm} \mathrm{Hg} \\
\text { DBP }-2.5 \mathrm{~mm} \mathrm{Hg}\end{array}$ & $\begin{array}{l}\text { Seppo } \\
2003 \text { [97] }\end{array}$ \\
\hline
\end{tabular}

TC, Total Cholesterol; HDL-C, High Density Lipoprotein Cholesterol; HN, High-Normal blood pressure; $\mathrm{MH}$, Mild Hypertensive; SBP, Systolic Blood Pressure; DBP, Diastolic Blood Pressure. ${ }^{*} \mathrm{P}<0.05$

\section{Conclusion}

In conclusion, protein can play a role in body weight regulation by increasing satiety, resulting in reduced energy intake. In body weight loss and regain, protein may improve body composition by preserving or increasing fat free mass and reducing fat mass. It also affects the serum lipid profile when compared to carbohydrates by decreasing both LDL and HDL cholesterol, but it improves the total:HDL ratio. Furthermore, dairy proteins are precursors of bioactive peptides, which can inhibit ACE-activity and thereby reduce blood pressure, but evidence for such effects is currently not provided by human studies.

\section{Dairy fat}

The western diet provides approximately 90 grams of fat per day. Of this daily fat consumption, a substantial portion is supplied by dairy products [46]. High-fat dairy products are relatively rich in saturated fatty acids, especially in myristic (14:0), palmitic (16:0), and stearic (18:0) acids [102]. While stearic acid has little effect on the serum lipoprotein profile, myristic and palmitic acid are known to increase serum LDL and HDL cholesterol concentrations. Intervention studies have also shown that replacing saturated fatty acids by cis-unsaturated fatty acids lowers the risk of 
cardiovascular disease [103].To improve an atherogenic lipoprotein profile, it is currently recommended to reduce the intake of saturated fatty acids.

It is hypothesized that fat in milk, butter and cheese affects blood lipids differently due to matrix effects. Tholstrup et al. could not confirm different effects of fat in milk and butter, but found a moderately lower LDL cholesterol concentrations after a cheese diet compared to a butter diet [104]. Biong et al. [105] observed significantly lower total cholesterol concentrations after a cheese diet than after a butter diet, while the difference in LDL cholesterol almost reached statistical significance. These observations could be related to the fact that the diets differed in calcium content, with the highest calcium intake from the cheese diet. Similar results were found by Nestel et al. [106] in mildly hypercholesterolemic subjects. The macronutrient composition of the diets was similar, but no data on calcium contents were given.

\section{Effects of CLA}

Recently, much attention has been paid to conjugated linoleic acid (CLA). CLA is a positional and geometric conjugated isomer of linoleic acid. Two common isomers of CLA exist, trans10,cis12-CLA $(t 10, c 12-C L A)$ and cis9,trans11-CLA $(c 9, t 11-C L A)$, which may have distinct metabolic effects. The $c 9, t 11$ isomer accounts for over $90 \%$ of the total CLA intake from food. Milk fat is relatively rich in $c 9, t 11-C L A$, although levels are still low (less than $0.5 \%$ of total milk fat). Many animal studies have shown positive effects of CLA on body weight and fat deposition [107, 108]. In addition, some animal trials reported cholesterol-lowering effects of CLA [109]. However, results of human studies are less consistent. In a recent meta-analysis, it was found that, given at a dose of $3.2 \mathrm{~g} /$ day, CLA produces a modest loss in body fat in humans [110]. In contrast, a number of reviews concluded that CLA is not effective in reducing body weight and plasma cholesterol concentrations in humans, and that especially $t 10, c 12-C L A$ may actually adversely affect human health, for example by inducing insulin resistance [107-109]. In addition, effects, if any, are only observed at high intakes (>3 g/day). Therefore, the amount of CLA in dairy fat is too low to play a significant role in the prevention of the metabolic syndrome.

\section{Conclusion}

To reduce cardiovascular risk, it is important to limit the intake of saturated fatty acids. Therefore, the consumption of low-fat instead of high-fat dairy products is strongly recommended. While different responses to fat from different dairy products have not been confirmed, other dairy constituents, such as calcium, seem to influence the effects. It is not likely that CLA, in the amounts present in dairy products, have any risk reducing effects. 


\section{Final conclusion}

Several epidemiological studies have suggested that consumption of dairy products contribute to a decreased risk to develop the metabolic syndrome. If so, an important question is which components of dairy products are actually responsible for the favourable effects. Calcium and protein have been reported to positively affect several components of the metabolic syndrome. The fat fraction of dairy products does not seem to contain any bioactive compounds in this respect. The different components may act synergistically leading to augmented beneficial effects, but this certainly warrants further investigation. Without doubt, the intake of saturated fatty acids should be limited. Therefore, it is important to focus on low-fat instead of high-fat dairy products.

Taken together, evidence exists that dairy products may play a role in the prevention and treatment of the metabolic syndrome. However, most of the studies focussed on single features of the metabolic syndrome. In addition, not all features of the syndrome (e.g. the inflammatory and prothrombotic state) have been studied in depth. Furthermore, most research focussed on single dairy constituents, while studies on the effects of dairy products mainly had an observational design. Therefore, as yet, there is insufficient evidence to decisively conclude that dairy products play a role in the development of the metabolic syndrome. Hence, more experimental research is needed to fully elucidate the physiological effects of an increased consumption of dairy products as related to the metabolic syndrome, as well as the mechanisms involved. 



\section{Effects of low-fat dairy consumption on metabolic risk parameters in overweight subjects}




\section{ABSTRACT}

Epidemiological studies have indicated a negative relation between low-fat dairy consumption and the metabolic syndrome. However, evidence from intervention studies is scarce. Our aim was to investigate the effects of daily consumption of low-fat dairy products on metabolic risk parameters in overweight and obese men and women. Thirty-five healthy subjects (BMI >27 $\mathrm{kg} / \mathrm{m}^{2}$ ) consumed daily for 8 weeks in random order low-fat dairy products (500 mL low-fat milk and $150 \mathrm{~g}$ low-fat yogurt) or carbohydrate-rich control products ( $600 \mathrm{~mL}$ fruit juice and 3 fruit biscuits). Compared with the control period, the decrease in plasma 1,25-dihydroxy vitamin $D_{3}$ concentrations of $9 \pm$ $27 \mathrm{pmol} / \mathrm{L}$ after the low-fat dairy period confirmed dietary compliance. Systolic blood pressure was decreased by $2.9 \mathrm{mmHg}$ (95\% confidence interval $(\mathrm{Cl}),-5.5$ to $-0.3 \mathrm{mmHg}$; $\mathrm{P}=0.027$ ) after dairy consumption compared with control, while the difference in diastolic blood pressure did not reach statistical significance (95\% Cl, -3.4 to $0.3 \mathrm{mmHg} ; \mathrm{P}=0.090)$. Low-fat dairy consumption decreased $\mathrm{HDL}$-cholesterol concentrations by $0.04 \mathrm{mmol} / \mathrm{L}(95 \% \mathrm{Cl},-0.07$ to -0.01 $\mathrm{mmol} / \mathrm{L} ; \mathrm{P}=0.021)$ and apoA-1 concentrations by $0.04 \mathrm{~g} / \mathrm{L}(95 \% \mathrm{Cl},-0.07$ to $-0.01 \mathrm{~g} / \mathrm{L} ; \mathrm{P}=0.016)$ compared with control. Serum total cholesterol, LDLcholesterol, apoB, triacylglycerols, non-esterified fatty acids, glucose, insulin, $\mathrm{C}$-reactive protein and plasminogen activator inhibitor-1 were unchanged. We conclude that in overweight and obese subjects, daily intake of low-fat dairy products for 8 weeks decreased systolic blood pressure, but did not improve other metabolic risk factors related to the metabolic syndrome. 


\section{Introduction}

Cross-sectional and prospective cohort studies have suggested that an increased consumption of low-fat dairy products lowers the risk to develop the metabolic syndrome [36-40, 43, 44], a constellation of metabolic risk factors that increases the risk to develop cardiovascular disease and type 2 diabetes mellitus [34]. However, other studies did not find such an association [41, 42]. Further, due to the nature of these studies, it cannot be concluded that increased consumption of dairy products is causally related to (some of the components of) the metabolic syndrome. Intervention studies addressing the effects of dairy products on the metabolic syndrome are missing. As yet, intervention trials only studied single, major dairy components (e.g. calcium or protein) or assessed the effects of dairy on one single or a few of the syndrome components $[58,59,111]$, or as part of energy deficit diets [60]. In the present study, we therefore examined the effects of low-fat dairy products as part of the normal diet on the multiple risk parameters of the metabolic syndrome in overweight and obese subjects. These subjects are at increased risk of metabolic disorders, and often display one or more characteristics of the metabolic syndrome.

\section{Methods}

\section{Study population}

The Medical Ethics Committee of Maastricht University approved the study. Subjects, recruited in Maastricht and surroundings, gave their written informed consent before they entered the screening procedure. During the screening visits, height, weight, waist circumference and blood pressure were measured. Blood pressure was measured three times on the non-dominant arm using a digital automatic blood pressure monitor (Omron, Kyoto, Japan), while seated. The mean of the last two measurements was used for further analysis. Also, two fasting blood samples, separated by a period of at least 3 days, were drawn to determine serum lipid and lipoprotein concentrations. Subjects were enrolled in the study when they met the following criteria: $18-70 \mathrm{y} ; \mathrm{BMI}>27 \mathrm{~kg} / \mathrm{m}^{2}$ and/or waist circumference $>88 \mathrm{~cm}$ in women or $>102 \mathrm{~cm}$ in men; no active cardiovascular disease, familial hypercholesterolemia, or severe medical conditions that might interfere with the study; no abuse of alcohol or drugs; no pregnancy or breastfeeding; stable body weight during the last 3 months; and dairy (milk, yogurt and cheese products) consumption <500 g per day, as asked during the screening visits. Forty overweight and obese volunteers (10 male and 30 female) were selected. One subject withdrew because the protocol was too demanding and 3 subjects withdrew because of personal circumstances. One subject was excluded from the analyses due to non-adherence to the protocol. 
Subjects were asked not to change their dietary habits, use of alcohol, level of physical exercise, smoking habits or use of oral contraceptives during the study.

\section{Study design and intervention}

The study had a crossover design and consisted of two intervention periods of 8 weeks, separated by a washout period of at least 2 weeks. At the start of both periods and after 4,7 , and 8 weeks of intervention, subjects visited the university. Subjects were randomly allocated to one of two treatment groups. During the first period, the first group $(n=17)$ received dairy products, while they received control products during the second period, and vice versa for the second group $(n=18)$. In the dairy period, subjects consumed $500 \mathrm{~mL}$ low-fat (1.5\%) milk and $150 \mathrm{~g}$ low-fat (1.5\%) yogurt (Campina, Woerden, The Netherlands) per day. In the control period, subjects consumed $600 \mathrm{~mL}$ fruit juice (Refresco, Dordrecht, The Netherlands) and 43 $\mathrm{g}$ fruit biscuits ( 3 pieces) (Verkade, Zaandam, The Netherlands) per day. Subjects received at each visit the products needed till the next visit, free of charge. The products were packed in daily portions and subjects were instructed to consume the products throughout the day. The total energy contents of the dairy and control products were comparable (Table 3.1). At the end of each experimental period, energy and nutrient intakes during the previous 4 weeks were estimated using a validated food frequency questionnaire [112]. Subjects were asked to record daily any signs of illness, use of medication, or deviations from the study protocol in a diary.

Table 3.1. Composition of dairy and control products.

\begin{tabular}{lcccc}
\hline & \multicolumn{2}{c}{ Dairy } & \multicolumn{2}{c}{ Control } \\
\hline & $\begin{array}{c}\text { Product } \\
\text { content }\end{array}$ & $\begin{array}{c}\text { \% of subjects' } \\
\text { daily intake }\end{array}$ & $\begin{array}{c}\text { Product } \\
\text { content }\end{array}$ & $\begin{array}{c}\text { \% of subjects' } \\
\text { daily intake }\end{array}$ \\
\hline Energy (MJ) & 1.5 & $16.3 \pm 3.7$ & 1.7 & $18.9 \pm 3.4$ \\
Protein (g) & 24.4 & $24.0 \pm 5.0$ & 2.8 & $3.3 \pm 0.7$ \\
Fat total (g) & 9.8 & $12.8 \pm 3.6$ & 3.8 & $5.5 \pm 1.4$ \\
SFA (g) & 6.3 & $21.2 \pm 5.9$ & 1.6 & $6.6 \pm 2.1$ \\
MUFA (g) & 2.4 & $10.4 \pm 3.7$ & 0 & - \\
PUFA (g) & 0.3 & $2.0 \pm 0.5$ & 0.6 & $3.9 \pm 1.0$ \\
TFA (g) & 0.4 & $23.6 \pm 14.5$ & 0 & - \\
Carbohydrates (g) & 39.7 & $15.7 \pm 4.3$ & 85.0 & $30.6 \pm 6.0$ \\
Mono- and disaccharides (g) & 39.2 & $30.4 \pm 9.9$ & 70.2 & $45.1 \pm 11.0$ \\
Fiber (g) & 0 & - & 2.7 & $12.1 \pm 3.5$ \\
Cholesterol (mg) & 27.5 & $13.7 \pm 3.7$ & 0 & - \\
Calcium (mg) & 800 & $53.2 \pm 9.2$ & 75 & $9.0 \pm 3.1$ \\
\hline
\end{tabular}

All values are means \pm SD. SFA, saturated fatty acids; MUFA, monounsaturated fatty acids; PUFA, polyunsaturated fatty acids; TFA, trans fatty acids. 


\section{Blood pressure and body weight}

Blood pressure was measured at each visit following the same procedures as during the screening visits. Thus, subjects were already familiarized with the measurements. Subjects on antihypertensive medication did not alter their use of medication during the study. Body weight was measured at each visit without shoes and heavy clothing.

\section{Blood sampling and analyses}

At weeks $0,4,7$, and 8 , blood samples were taken after an overnight fast. Venous blood was sampled using a vacutainer system (Becton Dickinson Vacutainer Systems, Franklin Lakes, USA). Blood was drawn into serum separator tubes for analysis of lipids, apolipoproteins (apo) A-1 and B, and C-Reactive Protein (CRP). After clotting at room temperature for at least $30 \mathrm{~min}$, serum was obtained by centrifugation at $2500 \mathrm{~g}$ for $30 \mathrm{~min}$ at room temperature and stored at $-80^{\circ} \mathrm{C}$. In addition, EDTA tubes were drawn for measurement of lipoprotein particles, insulin and 1,25dihydroxy-vitamin $D_{3}$, sodium citrate tubes for plasminogen activator inhibitor-1 (PAI-1) and sodium fluoride (NaF) tubes for glucose and non-esterified fatty acid (NEFA) concentrations. These tubes were kept on ice and centrifuged within 1 hour after venipuncture at $2500 \mathrm{~g}$ for $30 \mathrm{~min}$ at $4^{\circ} \mathrm{C}$, and samples were snap-frozen in liquid nitrogen and stored at $-80^{\circ} \mathrm{C}$.

Concentrations of total cholesterol (CHOD-PAP method; Roche, Basel, Switzerland), HDL-cholesterol (precipitation method; Roche, Basel, Switzerland), apolipoproteins A-1 and B (UNI-KIT apoA-1 and apoB; Roche, Basel, Switzerland) and triacylglycerol (TAG) with correction for free glycerol (GPO Trinder; Sigma Diagnostics, St. Louis, USA) were determined in all samples. LDL cholesterol was calculated using the Friedewald equation [113]. Lipoprotein particles were measured in pooled samples from weeks 7 and 8 by NMR spectroscopy (Liposcience, Raleigh, USA) and NEFA by an enzymatic assay (WAKO, Neuss, Germany). Glucose was measured in all samples (Horiba ABX, Montpellier, France) and insulin concentrations were determined in samples from weeks 7 and 8 (Mercodia, Uppsala, Sweden). Insulin sensitivity was calculated using a homeostasis model assessment for insulin resistance (HOMAir) [114]. Hs-CRP was measured in all samples (Kamiya Biomedical Company, Seattle, USA). PAI-1 activity was measured in citrated plasma from weeks 7 and 8 (Chromolize PAI-1; Biopool, Umea, Sweden). Results of two subjects could not be used due to extreme low concentrations $(<0.2 \mathrm{U} / \mathrm{mL})$. To check for subjects' compliance, serum concentrations of 1,25-dihydroxy vitamin $D_{3}$ were measured in pooled samples from weeks 7 and 8 (Immunodiagnostic Systems, Boldon, United Kingdom). For lipids, lipoproteins, hs-CRP, and glucose, the within-run and between-run coefficients of variation (CV) were below $2.5 \%$ and for insulin below $5 \%$. For NMR analys- 
es, CVs have been reported elsewhere [115]. For PAI-1 and 1,25-dihydroxy vitamin $D_{3}$, the number of runs $(n=2)$ was too limited to provide informative CVs.

\section{Statistics}

Statistical analyses were performed using SPSS 16 for Macintosh OS X package (SPSS, Chicago, USA). For each subject, results of measurements taken at weeks 7 and 8 of each intervention period were averaged before statistical analysis. Differences in endpoints of the dairy and control period, which were normally distributed as indicated by the Shapiro-Wilk test, were evaluated by paired t-test analysis. The presence of time and sequence effects, which were not present, was tested as described [116]. Also, values for the parameters measured at the start of the two dietary periods were comparable, as tested by paired t-tests. Finally, responses did not differ between men and women, as tested by unpaired t-tests. Values are presented as means \pm standard deviation. A P-value $<0.05$ was considered as statistically significant.

\section{Results}

\section{Subjects, diets and dietary adherence}

Baseline characteristics of the subjects are shown in Table 3.2. Mean body weights at the end of each period did not differ between the diets $(P=0.561)$ and were 91.1 $\pm 13.1 \mathrm{~kg}$ on the dairy diet and $91.3 \pm 13.5 \mathrm{~kg}$ on the control diet. Changes in body weight did not correlate with changes in any of the other parameters. Total energy intake was not different in the dairy and control condition (Table 3.3). Changes in the intakes of protein, fat, fatty acids, carbohydrates, fibre, cholesterol and calcium reflected the exchange of the low-fat dairy products for the carbohydrate-rich products. Besides the experimental products, there were no differences in dairy consumption between the two periods, except for a slightly higher intake of milk drinks in the control period $(150 \pm 141 \mathrm{~mL} / \mathrm{d})$ than in the dairy period (102 \pm 126 $\mathrm{mL} / \mathrm{d}, \mathrm{P}=0.022$ ). From the number of products returned by the subjects, it was calculated that the mean daily intake was $500 \mathrm{~mL}$ milk and $150 \mathrm{~g}$ yogurt, or $601 \mathrm{~mL}$ fruit juice and $43 \mathrm{~g}$ fruit biscuits, indicating a compliance of virtually $100 \%$. Plasma concentrations of $1,25-(\mathrm{OH})_{2} \mathrm{D}_{3}$ were significantly lower $(\mathrm{P}=0.034)$ after the dairy intervention $(119 \pm 30 \mathrm{pmol} / \mathrm{L})$ than after control $(128 \pm 37 \mathrm{pmol} / \mathrm{L})$. 
Table 3.2. Baseline characteristics of subjects.

\begin{tabular}{lccc}
\hline & Men & Women & All \\
\hline & $\mathrm{n}=10$ & $\mathrm{n}=25$ & $\mathrm{n}=35$ \\
Age (y) & $52.3 \pm 10.7$ & $47.2 \pm 14.2$ & $49.5 \pm 13.2$ \\
BMI (kg/m ${ }^{2}$ ) & $31.1 \pm 1.2$ & $32.4 \pm 4.4$ & $32.0 \pm 3.8$ \\
Waist circumference (cm) & $111 \pm 6.0$ & $105 \pm 10.5$ & $106 \pm 9.7$ \\
Systolic blood pressure (mmHg) & $138 \pm 14.4$ & $134 \pm 21.9$ & $135 \pm 19.9$ \\
Diastolic blood pressure (mmHg) & $94 \pm 10.9$ & $86 \pm 13.6$ & $88 \pm 13.2$ \\
Use of antihypertensive medication & $\mathrm{n}=4$ & $\mathrm{n}=6$ & $\mathrm{n}=10$ \\
Total cholesterol (mmol/L) & $6.31 \pm 0.9$ & $5.96 \pm 1.1$ & $6.06 \pm 1.0$ \\
HDL cholesterol (mmol/L) & $1.28 \pm 0.2$ & $1.45 \pm 0.4$ & $1.40 \pm 0.4$ \\
LDL cholesterol (mmol/L) & $4.32 \pm 0.7$ & $3.92 \pm 1.0$ & $4.04 \pm 1.0$ \\
Triacylglycerols (mmol/L) & $1.54 \pm 0.5$ & $1.29 \pm 0.5$ & $1.36 \pm 0.5$ \\
Glucose (mmol/L) & $6.11 \pm 0.6$ & $5.51 \pm 0.5$ & $5.68 \pm 0.6$ \\
\hline Allvalues arem & &
\end{tabular}

All values are means \pm SD.

Table 3.3. Mean daily dietary intakes during the intervention periods estimated from food frequency questionnaires.

\begin{tabular}{lcc}
\hline & Dairy & Control \\
\hline Energy (MJ) & $9.4 \pm 2.1$ & $9.2 \pm 1.6$ \\
Protein (En\%) & $19.2 \pm 3.2^{*}$ & $16.0 \pm 2.4$ \\
Fat total (En\%) & $33.1 \pm 4.7^{*}$ & $29.9 \pm 4.9$ \\
SFA (En\%) & $12.8 \pm 2.1^{*}$ & $10.7 \pm 2.1$ \\
MUFA (En\%) & $10.3 \pm 1.9^{*}$ & $9.2 \pm 1.9$ \\
PUFA (En\%) & $6.6 \pm 1.1$ & $6.6 \pm 1.2$ \\
TFA (En\%) & $0.9 \pm 0.3$ & $0.8 \pm 0.3$ \\
Carbohydrates (En\%) & $45.9 \pm 6.1^{*}$ & $52.5 \pm 5.8$ \\
Mono- and disaccharides (En\%) & $25.6 \pm 6.1^{*}$ & $30.0 \pm 5.5$ \\
Alcohol (En\%) & $1.9 \pm 2.3$ & $1.7 \pm 2.3$ \\
Fiber (g/MJ) & $2.3 \pm 0.6^{*}$ & $2.6 \pm 0.7$ \\
Cholesterol (mg/MJ) & $23.3 \pm 5.6^{*}$ & $19.7 \pm 4.5$ \\
Calcium (mg) & $1550 \pm 281^{*}$ & $931 \pm 291$
\end{tabular}

All values are means \pm SD. *Significantly different from control, $P<0.05$. SFA, saturated fatty acids; MUFA, monounsaturated fatty acids; PUFA, polyunsaturated fatty acids; TFA, trans fatty acids.

\section{Serum lipids and (apo)lipoproteins}

No statistically significant changes in serum concentrations of total cholesterol, LDLcholesterol and TAG were observed (Table 3.4). Also, the concentration of small dense LDL particles, the mean LDL particle size, and the numbers of LDL and VLDL particles did not differ between the diets. The mean VLDL particle size was decreased by $2.46 \pm 6.11 \mathrm{~nm}(\mathrm{P}=0.024)$. HDL-cholesterol was reduced by $0.04 \pm 0.09$ $\mathrm{mmol} / \mathrm{L}(\mathrm{P}=0.021)$ and the number of $\mathrm{HDL}$ particles was decreased by $1.07 \pm 2.14$ $\mu \mathrm{mol} / \mathrm{L}(\mathrm{P}=0.006)$. The mean HDL particle size however was not different between 
the diets. Dairy consumption increased the total to HDL-cholesterol ratio by $0.13 \pm$ $0.37(P=0.048)$. There was no difference in concentrations of apolipoprotein $B$, while apoA-1 concentrations were decreased by $0.04 \pm 0.10 \mathrm{~g} / \mathrm{L}(\mathrm{P}=0.016)$. Concentrations of NEFA were not different between the dairy and control period. Changes in total, HDL-, and LDL-cholesterol, apolipoproteins, NEFA and TAG were not correlated with baseline values.

Table 3.4. Effects of dairy consumption on serum lipids and lipoprotein concentrations.

\begin{tabular}{|c|c|c|c|c|c|c|c|}
\hline & Dairy & Control & $\begin{array}{l}\text { Absolute } \\
\text { change }\end{array}$ & $\begin{array}{c}\text { Relative } \\
\text { change } \\
(\%)\end{array}$ & \multicolumn{2}{|c|}{$\begin{array}{c}95 \% \mathrm{Cl} \text { for } \\
\text { absolute } \\
\text { change }\end{array}$} & $\begin{array}{c}\text { P for } \\
\text { absolute } \\
\text { change }\end{array}$ \\
\hline $\begin{array}{l}\text { Total cholesterol } \\
\text { (mmol/L) }\end{array}$ & $6.21 \pm 1.04$ & $6.23 \pm 1.01$ & $-0.02 \pm 0.43$ & -0.2 & -0.17 to & 0.13 & 0.774 \\
\hline $\begin{array}{l}\text { HDL cholesterol } \\
\text { (mmol/L) }\end{array}$ & $1.40 \pm 0.34$ & $1.44 \pm 0.34$ & $-0.04 \pm 0.09$ & -2.7 & -0.07 to & -0.01 & 0.021 \\
\hline $\begin{array}{l}\text { LDL cholesterol } \\
\qquad(\mathrm{mmol} / \mathrm{L})\end{array}$ & $4.12 \pm 0.98$ & $4.09 \pm 0.93$ & $0.03 \pm 0.43$ & 1.3 & -0.12 to & 0.18 & 0.667 \\
\hline $\begin{array}{l}\text { Total:HDL } \\
\text { ratio }\end{array}$ & $4.60 \pm 1.07$ & $4.47 \pm 1.00$ & $0.13 \pm 0.37$ & 3.0 & 0.00 to & 0.26 & 0.049 \\
\hline $\begin{array}{l}\text { VLDL particles } \\
\text { (nmol/L) }\end{array}$ & $70.1 \pm 30.6$ & $69.0 \pm 28.9$ & $1.18 \pm 20.3$ & 5.9 & -5.80 to & 8.15 & 0.734 \\
\hline $\begin{array}{l}\text { LDL particles } \\
\text { (nmol/L) }\end{array}$ & $1427 \pm 352$ & $1432 \pm 331$ & $-4.29 \pm 151$ & -0.0 & -56.1 to & 47.5 & 0.867 \\
\hline $\begin{array}{l}\text { Small LDL parti- } \\
\text { cles (nmol/L) }\end{array}$ & $919 \pm 397$ & $897 \pm 395$ & $22.1 \pm 215$ & 7.9 & -51.7 to & 95.8 & 0.547 \\
\hline $\begin{array}{l}\text { HDL particles } \\
\qquad(\mu \mathrm{mol} / \mathrm{L})\end{array}$ & $30.8 \pm 4.7$ & $31.9 \pm 4.9$ & $-1.07 \pm 2.15$ & -3.4 & -1.81 to & -0.33 & 0.006 \\
\hline $\begin{array}{l}\text { VLDL particle size } \\
\qquad(\mathrm{nm})\end{array}$ & $50.4 \pm 7.5$ & $52.8 \pm 7.2$ & $-2.46 \pm 6.11$ & -4.1 & -4.56 to & -0.36 & 0.024 \\
\hline $\begin{array}{l}\text { LDL particle size } \\
\qquad(\mathrm{nm})\end{array}$ & $20.9 \pm 0.62$ & $20.9 \pm 0.66$ & $-0.02 \pm 0.38$ & -0.1 & -0.15 to & 0.12 & 0.794 \\
\hline $\begin{array}{l}\text { HDL particle size } \\
\qquad(\mathrm{nm})\end{array}$ & $8.88 \pm 0.4$ & $8.91 \pm 0.4$ & $-0.03 \pm 0.14$ & -0.4 & -0.08 to & 0.02 & 0.166 \\
\hline $\begin{array}{l}\text { Triacylglycerols } \\
\text { (mmol/L) }\end{array}$ & $1.46 \pm 0.61$ & $1.50 \pm 0.56$ & $-0.04 \pm 0.37$ & -1.3 & -0.16 to & 0.09 & 0.552 \\
\hline $\begin{array}{l}\text { Apolipoprotein } \\
\text { A-1 (g/L) }\end{array}$ & $1.49 \pm 0.23$ & $1.53 \pm 0.24$ & $-0.04 \pm 0.10$ & -2.5 & -0.07 to & -0.01 & 0.016 \\
\hline $\begin{array}{l}\text { Apolipoprotein B } \\
\text { (g/L) }\end{array}$ & $1.06 \pm 0.19$ & $1.07 \pm 0.18$ & $-0.01 \pm 0.07$ & -1.1 & -0.04 to & 0.01 & 0.309 \\
\hline $\begin{array}{l}\text { NEFA } \\
\qquad(\mu \mathrm{mol} / \mathrm{L})\end{array}$ & $358 \pm 147$ & $346 \pm 124$ & $12.3 \pm 94.1$ & 5.8 & -20.0 to & 44.5 & 0.446 \\
\hline
\end{tabular}




\section{Blood pressure}

Systolic blood pressure was significantly decreased by $2.9 \pm 7.4 \mathrm{mmHg}(\mathrm{P}=0.027$, Table 3.5) after dairy consumption. Diastolic blood pressure was non-significantly decreased by $1.6 \pm 5.2 \mathrm{mmHg}(P=0.090)$. Exclusion of subjects using blood pressure lowering medication $(n=10)$ did not alter these outcomes. In fact, in non-users, systolic blood pressure was $4.2 \pm 7.6 \mathrm{mmHg}(95 \% \mathrm{Cl},-7.4$ to $-1.1 \mathrm{mmHg}$; $\mathrm{P}=0.010)$ lower after dairy than after control, while diastolic blood pressure was reduced by $1.8 \pm 4.5 \mathrm{mmHg}(95 \% \mathrm{Cl},-3.7$ to $0.0 \mathrm{mmHg} ; \mathrm{P}=0.055)$. Changes in blood pressure were not correlated with baseline values.

Table 3.5. Effects of dairy consumption on glucose, insulin, CRP, and PAI-1 concentrations, blood pressure and HOMAir.

\begin{tabular}{|c|c|c|c|c|c|c|}
\hline & Dairy & Control & $\begin{array}{l}\text { Absolute } \\
\text { change }\end{array}$ & $\begin{array}{c}\text { Relative } \\
\text { change } \\
(\%)\end{array}$ & $\begin{array}{c}95 \% \mathrm{Cl} \text { for } \\
\text { absolute } \\
\text { change }\end{array}$ & $\begin{array}{c}\text { P for } \\
\text { absolute } \\
\text { change }\end{array}$ \\
\hline $\begin{array}{r}\text { Systolic BP } \\
(\mathrm{mmHg})\end{array}$ & $128.4 \pm 19.2$ & $131.3 \pm 18.3$ & $-2.91 \pm 7.4$ & -2.2 & -5.45 to -0.34 & 0.027 \\
\hline $\begin{array}{c}\text { Diastolic BP } \\
(\mathrm{mmHg})\end{array}$ & $85.4 \pm 10.2$ & $87.0 \pm 11.5$ & $-1.55 \pm 5.2$ & -1.5 & -3.35 to 0.25 & 0.090 \\
\hline $\begin{array}{l}\text { Glucose } \\
\text { (mmol/L) }\end{array}$ & $5.75 \pm 0.63$ & $5.74 \pm 0.66$ & $0.01 \pm 0.034$ & 0.4 & -0.11 to 0.13 & 0.851 \\
\hline $\begin{array}{l}\text { Insulin } \\
\qquad(\mathrm{mU} / \mathrm{L})\end{array}$ & $11.2 \pm 5.5$ & $11.7 \pm 7.0$ & $-0.49 \pm 3.12$ & 1.0 & -1.58 to 0.60 & 0.371 \\
\hline HOMAir & $2.90 \pm 1.55$ & $3.02 \pm 1.86$ & $-0.12 \pm 0.89$ & 2.0 & -0.43 to 0.19 & 0.433 \\
\hline $\begin{array}{l}\text { CRP } \\
\qquad(\mathrm{mg} / \mathrm{L})\end{array}$ & $4.07 \pm 3.50$ & $4.54 \pm 4.09$ & $-0.47 \pm 1.74$ & 6.3 & -1.10 to 0.17 & 0.147 \\
\hline $\begin{array}{l}\text { PAl-1 } \\
\qquad(\mathrm{U} / \mathrm{mL})\end{array}$ & $22.9 \pm 18.7$ & $24.8 \pm 18.0$ & $-1.91 \pm 8.92$ & 6.3 & -5.08 to 1.25 & 0.227 \\
\hline
\end{tabular}

All values are means \pm SD. BP, blood pressure; HOMAir, homeostasis model assessment for insulin resistance; CRP, C-reactive protein; PAI-1, plasminogen activator inhibitor-1.

\section{Glucose, insulin, C-Reactive Protein, and Plasminogen Activator Inhibitor-1}

There were no significant changes in plasma glucose and insulin concentrations, and HOMAir between dairy and control conditions (Table 3.5). Serum CRP concentrations and plasma concentrations of active PAI-1 were also unaffected by dairy consumption. Changes in glucose and CRP were not correlated with baseline values. 


\section{Discussion}

In the present study, we found that daily consumption of $500 \mathrm{~mL}$ low-fat milk and $150 \mathrm{~g}$ low-fat yogurt did not improve metabolic risk parameters in overweight and obese subjects, except for a reduction in systolic blood pressure. In fact, HDLcholesterol concentrations were decreased after dairy consumption. Subjects' compliance was confirmed by the expected decrease in plasma concentrations of 1,25$(\mathrm{OH})_{2} \mathrm{D}_{3}$. In addition, the food frequency questionnaires showed that daily calcium intake was increased by more than $600 \mathrm{mg}$. Since subjects who do not use low-fat dairy products in daily life may consume carbohydrate-rich drinks and foods instead, fruit juice and fruit biscuits were used as control products. Low-fat dairy products were used instead of high-fat products, as it is well established that the intake of saturated fatty acids should be as low as possible, as these fatty acids may unfavourably affect the serum lipoprotein profile and insulin sensitivity $[117,118]$. Thus, in our controlled 8-week intervention study we did not observe results indicating that consumption of low-fat dairy products instead of carbohydrate-rich products may protect against the development of the metabolic syndrome, unlike what can be suggested based on epidemiological studies.

Several components of the low-fat dairy products have been reported to affect metabolic risk markers. First of all, a few intervention studies have been performed on the effects of calcium supplementation on the serum lipid and lipoprotein profile $[49-51,53]$. These studies mostly showed reduced concentrations of total and LDLcholesterol. One study also reported an increased concentration of HDL-cholesterol [49]. Denke and colleagues [53] observed beneficial effects of calcium at intakes of $2200 \mathrm{mg}$ per day, compared with $410 \mathrm{mg}$ in the control condition. Others have compared calcium intakes of $1850-2200 \mathrm{mg}$ in the calcium-rich period with 900 $1200 \mathrm{mg}$ in the control period and did observe positive effects [49-51]. We, however, found no effects of increasing the intake of low-fat dairy products on serum concentrations of total and LDL-cholesterol. It might be speculated that the calcium intake of our subjects during the control period was already too high to find effects of additional calcium consumption. However, this suggestion is not supported by the results of the before mentioned supplementation studies [49-51] that used even higher calcium intakes during the control period.

Effects of protein, another important constituent of dairy products, on the serum lipid profile are conflicting. Krauss et al. [78] found slightly increased concentrations of HDL- and LDL-cholesterol after a high protein diet compared with a high carbohydrate diet, whereas these values were decreased by protein versus carbohydrates in the OmniHeart trial [80]. In both studies, however, the total to HDLcholesterol ratio was decreased on the high-protein diet. We did not find any effects of dairy consumption on LDL-cholesterol, but did observe a decrease in HDLcholesterol, apolipoprotein A1, and HDL particle number. As a consequence, the to- 
tal to HDL-cholesterol ratio was increased. This reduction in HDL-cholesterol is in line with the OmniHeart results, and might therefore be a result of the exchange of carbohydrate for protein intake, when subjects switch from the control diet to the low-fat dairy diet. However, dietary protein content in the OmniHeart trial amounted $15 \mathrm{En \%}$ in the carbohydrate diet and $25 \mathrm{En} \%$ in the protein diet. This difference was accomplished by adjusting meat and plant protein, while dairy protein was similar in both diets. In our study, difference in protein intake between the two diets was only $3.2 \mathrm{En \%}$. In addition, Krauss et al. observed a significant increase in LDL particle diameter after a high protein diet [78]. We, however, did not find changes in LDL or HDL particle sizes, but we did observe a decrease in VLDL particle diameter after the dairy intervention. Larger VLDL particles are thought to be precursors of small dense LDL particles [119] and have been inversely associated with cardiovascular disease risk [120]. This decrease in VLDL particle size would therefore imply a beneficial metabolic effect of dairy consumption, although this may be a chance finding as the change was not accompanied by the frequently related changes in other lipoproteins, such as in LDL particle diameter [120].

It should be noted however that besides protein, carbohydrate and calcium, also the intake of fat and fatty acids was different between the two diets. Although we used low-fat dairy products, total fat consumption was increased by $3.2 \mathrm{En} \%$, saturated fatty acid intake by $2.1 \mathrm{En} \%$, and monounsaturated fatty acid intake by 1.1 En\%. It can be estimated that this would have caused an increase of $0.07 \mathrm{mmol} / \mathrm{L}$ in total cholesterol, of $0.06 \mathrm{mmol} / \mathrm{L}$ in LDL-cholesterol, and of $0.03 \mathrm{mmol} / \mathrm{L}$ in $\mathrm{HDL}$ cholesterol [117]. Though small, these changes in fat and fatty acids intakes should also be taken into account when discussing the effects of low-fat dairy product on the serum lipoprotein profile and the other metabolic risk markers.

We observed a $2.9 \mathrm{mmHg}$ decrease in systolic blood pressure by dairy consumption. This decrease is comparable to the results found in the well-known DASH-trial, which compared a diet high in fruits, vegetables and dairy products with a diet rich in fruits and vegetables alone [59]. This could be a specific effect of dairy constituents, but it could also be a result of the fact that carbohydrate intake was reduced and replaced by some protein and fat. In fact, Appel et al. [80] have reported that protein and fat decreased systolic and diastolic blood pressure to the same extent when compared with carbohydrates. Additionally, a meta-analysis showed that calcium supplementation at a mean dose of $1200 \mathrm{mg} / \mathrm{d}$ reduced systolic blood pressure by $1.9 \mathrm{mmHg}$ and diastolic BP by $1.0 \mathrm{mmHg}$ [73]. In people with habitual calcium intakes $<800 \mathrm{mg} / \mathrm{d}$, somewhat larger reductions were found (-2.6 and $-1.3 \mathrm{mmHg}$ for systolic and diastolic blood pressure, respectively), which is comparable to the effects we observed in this study. Further, Van Beresteijn et al. [121] observed a larger decrease in systolic blood pressure after 6 weeks consumption of normal milk than after milk depleted in calcium, phosphorus, potassium and 
magnesium. Thus, results suggest that both the proteins and the minerals from milk contribute to the antihypertensive action of milk.

Studies on dairy or calcium effects on PAI-1 or other fibrinolytic players are very limited. Mennen et al. [122] found a negative relation between dairy products and tissue-type plasminogen activator antigen (t-PA-Ag), which might imply a beneficial effect on fibrinolysis. However, we did not observe effects of dairy consumption on PAI-1 in our study.

Although observational studies suggest an inverse association between calcium intake and the risk of type $2 \mathrm{DM}$, evidence from human intervention trials is very limited [123]. In a study by Zemel and colleagues, a high-dairy diet reduced circulating insulin concentrations [58]. Although subjects maintained their body weight, effects were possibly due to an improvement in body composition. Though controversial [124], a number of studies have indicated that saturated fatty acids may have deleterious effects on insulin sensitivity $[118,125]$. Nonetheless, we did not detect any effects of dairy consumption on glucose or insulin concentrations, possibly due to the fact that glucose and insulin concentrations of our subjects were within the normal range.

In summary, the results of the present study indicate that in overweight and obese subjects, daily consumption of low-fat dairy products compared with carbohydrate-rich products for 8 weeks decreased systolic blood pressure, but did not have beneficial effects on other metabolic risk markers. 


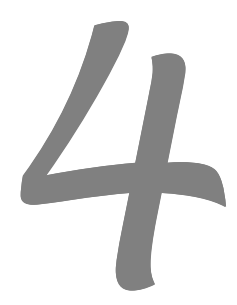

\section{Effects of low-fat dairy consumption on markers of low-grade systemic inflammation and endothelial function in overweight subjects}




\section{ABSTRACT}

Although increased concentrations of plasma inflammatory markers are not one of the criteria to diagnose the metabolic syndrome, low-grade systemic inflammation is receiving large attention as a metabolic syndrome component and cardiovascular risk factor. As several epidemiological studies have suggested a negative relationship between the low-fat dairy consumption and the metabolic syndrome, we decided to investigate in an intervention study the effects of low-fat dairy consumption on inflammatory markers and adhesion molecules in overweight and obese subjects. Thirty-five healthy subjects (BMI $>27$ $\mathrm{kg} / \mathrm{m}^{2}$ ) consumed, in random order, low-fat dairy products $(500 \mathrm{~mL}$ low-fat milk and $150 \mathrm{~g}$ low-fat yogurt) or carbohydrate-rich control products (600 mL fruit juice and 3 fruit biscuits) daily for 8 weeks. Plasma concentrations of TNF- $\alpha$ were decreased by $0.16 \pm 0.50 \mathrm{pg} / \mathrm{mL}(\mathrm{P}=0.070)$ and soluble TNF- $\alpha$ receptor-1 (s-TNFR-1) was increased by $110.0 \pm 338.4 \mathrm{pg} / \mathrm{mL}(\mathrm{P}=0.062)$ after the low-fat dairy period compared with control. s-TNFR-2 was increased by $227.0 \pm$ $449.0 \mathrm{pg} / \mathrm{mL}(\mathrm{P}=0.020)$ by the dairy intervention. As a result, the TNF- $\alpha$ index, defined as the TNF- $\alpha$ / s-TNFR2 ratio, was decreased by $0.000053 \pm 0.00012$ $(P=0.015)$ after the dairy diet. Low-fat dairy consumption had no effect on IL-6, monocyte chemoattractant protein-1 (MCP-1), intracellular adhesion molecule-1 (ICAM-1), and vascular cell adhesion molecule-1 (VCAM-1) concentrations. Our results indicate that in overweight and obese subjects, low-fat dairy consumption compared with carbohydrate-rich product consumption for 8 weeks may increase concentrations of soluble TNF- $\alpha$ receptors, but has no effects on other markers of chronic inflammation and endothelial function. 


\section{Introduction}

The metabolic syndrome is a metabolic disorder that strongly enhances the risk to develop cardiovascular diseases (CVD) and type 2 diabetes mellitus. Abdominal obesity, atherogenic dyslipidemia, hypertension, insulin resistance, a pro-thrombotic state, and a low-grade pro-inflammatory state have now been identified as components of the metabolic syndrome that relate to CVD risk. Although inflammatory markers are currently not included in the ATP III or WHO diagnostic criteria for the metabolic syndrome [13], low-grade systemic inflammation is receiving large attention as a metabolic syndrome component and cardiovascular risk factor. Inflammatory markers such as C-Reactive Protein (CRP) [126], IL-6 [127], TNF- $\alpha$ [128], and fibrinogen [129], among others, have been linked to the metabolic syndrome.

The consumption of dairy products has been inversely associated with the prevalence or incidence of the metabolic syndrome in a number of epidemiologic studies [36-40, 43, 44]. In the CARDIA study [43], for example, the intake of dairy products was negatively correlated with the development of obesity, dyslipidemia, glucose intolerance, and hypertension over the next 10 years in overweight subjects. However, the relation between dairy consumption on the chronic inflammatory state linked to the metabolic syndrome has not yet been studied in depth. Recently, Zemel et al. reported positive effects of dairy and calcium intake on inflammatory markers, including TNF- $\alpha$, IL-6 and adiponectin, in mice [111]. Moreover, they observed reduced plasma concentrations of CRP and increased concentrations of plasma adiponectin in obese human subjects after a eucaloric or hypocaloric highdairy diet [111]. Therefore, we investigated in this intervention study with overweight and obese human subjects the effects of low-fat milk and yogurt consumption on a broad range of inflammatory markers and adhesion molecules.

\section{Methods}

\section{Study population}

The study was conducted according to the guidelines laid down in the Declaration of Helsinki and all procedures involving human subjects were approved by the Medical Ethics Committee of Maastricht University. Written informed consent was obtained from all subjects. The study protocol has been previously reported into detail [130]. Briefly, 40 male and female subjects were recruited in Maastricht and surroundings by advertisements in local newspapers and in the University Hospital newsletter, and by posters in university and hospital buildings. During the screening visits, weight, height, waist circumference, and blood pressure were measured. Two fasting blood samples, separated by a 3-day period, were taken for determination of se- 
rum lipid and lipoprotein concentrations. Subjects were enrolled in the study when they met the following criteria: $18-70$ y of age; body mass index (BMI) $>27 \mathrm{~kg} / \mathrm{m}^{2}$ or waist circumference $>88 \mathrm{~cm}$ (women) or $>102 \mathrm{~cm}$ (men); no active cardiovascular disease, familial hypercholesterolemia, or other conditions that might interfere with the study outcomes; no pregnancy or breastfeeding; no abuse of alcohol or drugs; stable body weight during the past 3 months; and dairy (milk, yogurt and cheese (products)) $<500$ g per day, as asked during the screening visits. Ten male and 30 female subjects were selected. Four subjects withdrew for personal reasons and one subject was excluded from the analyses due to non-adherence to the protocol. Thirty-five subjects (10 male and 25 female, of which 12 pre- and 13 postmenopausal) were used for analyses. Subjects were asked not to change their dietary habits, level of physical exercise, use of alcohol, smoking habits, or use of oral contraceptives during the study period.

\section{Study design and intervention}

This study consisted of two intervention periods of 8 weeks, in a crossover design, separated by a washout period of at least 2 weeks. Subjects were randomly allocated to one of two treatment groups. The first group $(n=17)$ consumed low-fat dairy products as a dietary supplement during the first intervention period, and carbohydrate-rich control products during the second intervention period, and vice versa for the second group of subjects $(n=18)$. The subjects maintained their habitual diet during the entire study. The dairy products consisted of $500 \mathrm{~mL}$ low-fat $(1.5 \% \mathrm{w} / \mathrm{w})$ milk and $150 \mathrm{~g}$ low-fat $(1.5 \% \mathrm{w} / \mathrm{w})$ yogurt (Campina, Woerden, The Netherlands) per day. The control products consisted of $600 \mathrm{~mL}$ fruit juice (Refresco, Dordrecht, The Netherlands) and $43 \mathrm{~g}$ (3 pieces) fruit biscuits (Verkade, Zaandam, The Netherlands) per day. The subjects received the products in daily packages, which they had to consume throughout the day. Total energy contents of the dairy and control products were similar (Table 4.1). At the end of each treatment period, energy and nutrient intakes during the previous 4 weeks were estimated using a validated food frequency questionnaire [112]. Subjects had to record all signs of illness, use of medication, or deviations from the study protocol in a diary. 
Table 4.1. Composition of dairy and control products.

\begin{tabular}{lcccc}
\hline & \multicolumn{2}{c}{ Dairy } & \multicolumn{2}{c}{ Control } \\
\hline & $\begin{array}{c}\text { Product } \\
\text { content }\end{array}$ & $\begin{array}{c}\text { \% of subjects' } \\
\text { daily intake }\end{array}$ & $\begin{array}{c}\text { Product } \\
\text { content }\end{array}$ & $\begin{array}{c}\text { \% of subjects' } \\
\text { daily intake }\end{array}$ \\
\hline Energy (MJ) & 1.5 & $16.3 \pm 3.7$ & 1.7 & $18.9 \pm 3.4$ \\
Protein (g) & 24.4 & $24.0 \pm 5.0$ & 2.8 & $3.3 \pm 0.7$ \\
Fat total (g) & 9.8 & $12.8 \pm 3.6$ & 3.8 & $5.5 \pm 1.4$ \\
SFA (g) & 6.3 & $21.2 \pm 5.9$ & 1.6 & $6.6 \pm 2.1$ \\
MUFA (g) & 2.4 & $10.4 \pm 3.7$ & 0 & - \\
PUFA (g) & 0.3 & $2.0 \pm 0.5$ & 0.6 & $3.9 \pm 1.0$ \\
TFA (g) & 0.4 & $23.6 \pm 14.5$ & 0 & - \\
Carbohydrates (g) & 39.7 & $15.7 \pm 4.3$ & 85.0 & $30.6 \pm 6.0$ \\
Mono- and disaccharides (g) & 39.2 & $30.4 \pm 9.9$ & 70.2 & $45.1 \pm 11.0$ \\
Fiber (g) & 0 & - & 2.7 & $12.1 \pm 3.5$ \\
Cholesterol (mg) & 27.5 & $13.7 \pm 3.7$ & 0 & - \\
Calcium (mg) & 800 & $53.2 \pm 9.2$ & 75 & $9.0 \pm 3.1$ \\
\hline
\end{tabular}

All values are means \pm SD. SFA, saturated fatty acids; MUFA, monounsaturated fatty acids; PUFA, polyunsaturated fatty acids; TFA, trans fatty acids.

\section{Blood sampling and analyses}

At the start of each period and after 4, 7, and 8 weeks, blood samples were taken after an overnight fast. Subjects were not allowed to use alcohol during the previous day or to smoke on the morning before blood sampling. Venous blood was drawn into EDTA tubes using a Vacutainer system (Becton Dickinson, Franklin Lakes, USA). After sampling, the tubes were kept on ice and centrifuged within one hour after venipuncture at $2500 \mathrm{~g}$ for $30 \mathrm{~min}$ at $4^{\circ} \mathrm{C}$, and plasma samples were snapfrozen in liquid nitrogen and stored at $-80^{\circ} \mathrm{C}$.

Samples of weeks 7 and 8 were pooled before analysis. Plasma concentrations of TNF- $\alpha$ and IL- 6 were determined using ELISA kits (R\&D Systems, Abingdon, UK). ELISA kits were also used for the measurement of plasma concentrations of Monocyte Chemoattractant Protein-1 (MCP-1) (Human MCP-1 Ultra-Sensitive Kit), soluble TNF- $\alpha$ Receptor (s-TNFR) 1 and 2 (Human TNFR1 and TNFR2 Ultra-Sensitive Kit), Intracellular Adhesion Molecule-1 (ICAM-1), and Vascular Cell Adhesion Molecule-1 (VCAM-1) (Human Vascular Injury II Kit, Meso Scale Discovery, Gaithersburg, MD, USA). TNF- $\alpha$ index was calculated as [TNF- $\alpha$ ] / [s-TNFR2] [131]. To test subjects' compliance, plasma concentrations of 1,25-dihydroxy vitamin $D_{3}\left(1,25-(\mathrm{OH})_{2}-\mathrm{D}_{3}\right)$ were determined by ELISA (Immunodiagnostic Systems, Boldon, UK). 1,25-(OH) $)_{2}-\mathrm{D}_{3}$ concentrations are expected to decrease when dietary calcium intake is increased [65]. Samples from one subject were analyzed within the same run. All intra- and inter-assay variations were $<15 \%$. 


\section{Statistics}

The statistical power to detect a true difference of $10 \%$ was more than $80 \%$ for all parameters, except for IL-6. All statistical analyses were performed using SPSS 16.0 for Macintosh OS X (SPSS, Chicago, USA). Differences in endpoints between dairy and control periods, which were normally distributed as indicated by the ShapiroWilk test, were examined by paired t-test analysis. Values are presented as means \pm standard deviations and as absolute changes (95\% confidence interval ( $\mathrm{Cl}$ ) for absolute change). A P-value $<0.05$ (two-sided) was considered as statistically significant. The presence of time and sequence effects was tested as described [116]. Also, differences between men and women were tested by an unpaired t-test.

\section{Results}

\section{Subjects, dietary intakes and compliance}

Subjects were $49.5 \pm 13.2$ y old and their BMI was $32.0 \pm 3.8 \mathrm{~kg} / \mathrm{m}^{2}$. Mean body weight at the end of the intervention periods was not different between the dairy $\operatorname{diet}(91.1 \pm 13.1 \mathrm{~kg})$ and the control diet $(91.3 \pm 13.5 \mathrm{~kg} ; \mathrm{P}=0.561)$. The mean dietary intakes in the dairy and control periods were estimated from food frequency questionnaires. The exchange of low-fat dairy products for the carbohydrate-rich control products was reflected in the changes in the intakes of protein (19.9 \pm 3.2 vs. $16.0 \pm$ 2.4 En\%), total fat ( $33.1 \pm 4.7$ vs. $29.9 \pm 4.9$ En\%), saturated fatty acids ( $12.8 \pm 2.1$ vs. $10.7 \pm 2.1$ En\%), monounsaturated fatty acids (10.3 \pm 1.9 vs. $9.2 \pm 1.9 \mathrm{En} \%)$, carbohydrates ( $45.9 \pm 6.1$ vs. $52.5 \pm 5.8 \mathrm{En} \%)$, fibre ( $2.3 \pm 0.6$ vs. $2.6 \pm 0.7 \mathrm{~g} / \mathrm{MJ})$, cholesterol $(23.3 \pm 5.6$ vs. $19.7 \pm 4.5 \mathrm{mg} / \mathrm{MJ})$, and calcium $(1550 \pm 281 \mathrm{vs.} 931 \pm 291 \mathrm{mg})$ (all $\mathrm{P}<0.05$ ). Total energy intake was not different between the dairy and control interventions. Plasma concentrations of $1,25-(\mathrm{OH})_{2}-\mathrm{D}_{3}$ were significantly decreased at the end of the dairy period $(119 \pm 30 \mathrm{pmol} / \mathrm{L})$ compared with the control period (128 $\pm 37 \mathrm{pmol} / \mathrm{L} ; \mathrm{P}=0.034)$.

\section{Inflammatory markers and adhesion molecules}

Plasma IL-6 concentrations were not different between the dairy and control period (Table 4.2), while concentrations of TNF- $\alpha$ tended to be lower after dairy consumption $(P=0.070)$. Concentrations of S-TNFR-1 tended to be higher after dairy consumption ( $P=0.062)$, and s-TNFR-2 concentrations were significantly higher after the dairy diet than after the control diet $(P=0.020)$. Although the change in s-TNFR-1 was not statistically significant, it was correlated with the change in s-TNFR-2 (Pearson $r=0.692, P<0.001)$. Calculated TNF- $\alpha$ index was lower after dairy than after con- 
trol $(P=0.015)$. Dairy consumption had no effect on plasma concentrations of MCP1, ICAM-1 and VCAM-1. No time or sequence effects were present and responses did not differ between men and women.

Table 4.2. Effects of dairy consumption on inflammatory markers and adhesion molecules.

\begin{tabular}{|c|c|c|c|c|c|}
\hline & Dairy & Control & Change & $95 \% \mathrm{Cl}$ & $\begin{array}{c}\text { P- } \\
\text { value }\end{array}$ \\
\hline $\begin{array}{l}\text { s-TNFR-1 } \\
(\mathrm{pg} / \mathrm{mL})\end{array}$ & $3729 \pm 853$ & $3619 \pm 769$ & $110.4 \pm 338.4$ & -5.77 to 226.7 & 0.062 \\
\hline $\begin{array}{l}\text { s-TNFR-2 } \\
(\mathrm{pg} / \mathrm{mL})\end{array}$ & $4367 \pm 1359$ & $4140 \pm 1122$ & $227.0 \pm 549.0$ & 38.4 to 415.6 & 0.020 \\
\hline $\begin{array}{l}\text { TNF- } \alpha \\
\qquad(\mathrm{pg} / \mathrm{mL})\end{array}$ & $2.32 \pm 0.64$ & $2.48 \pm 0.76$ & $-0.16 \pm 0.50$ & -0.33 to 0.01 & 0.070 \\
\hline TNF- $\alpha$ & 0.00057 & 0.00062 & -0.000053 & -0.000096 & 0.015 \\
\hline index & \pm 0.00021 & \pm 0.00020 & \pm 0.00012 & to -0.000011 & \\
\hline $\begin{array}{l}\text { IL-6 } \\
\qquad(\mathrm{pg} / \mathrm{mL})\end{array}$ & $3.01 \pm 3.47$ & $3.05 \pm 3.24$ & $-0.04 \pm 1.46$ & -0.54 to 0.46 & 0.875 \\
\hline $\begin{array}{l}\text { MCP-1 } \\
\quad(\mathrm{pg} / \mathrm{mL})\end{array}$ & $291.1 \pm 68.5$ & $289.7 \pm 66.5$ & $1.45 \pm 29.4$ & -8.64 to 11.5 & 0.772 \\
\hline $\begin{array}{l}\text { ICAM-1 } \\
\qquad(\mathrm{ng} / \mathrm{mL})\end{array}$ & $280.5 \pm 78.6$ & $286.9 \pm 86.6$ & $-6.43 \pm 27.7$ & -15.9 to 3.07 & 0.178 \\
\hline $\begin{array}{l}\text { VCAM-1 } \\
\qquad(\mathrm{ng} / \mathrm{mL})\end{array}$ & $447.7 \pm 110.0$ & $436.1 \pm 103.1$ & $11.6 \pm 76.4$ & -14.7 to 37.8 & 0.377 \\
\hline
\end{tabular}

s-TNFR, soluble TNF- $\alpha$ receptor; MCP-1, monocyte chemoattractant protein-1; ICAM-1, intracellular adhesion molecule-1; VCAM-1, vascular cell adhesion molecule-1.

\section{Discussion}

Data from this study indicate that low-fat dairy consumption for 8 weeks may affect markers reflecting low-grade systemic inflammation in overweight and obese subjects. We found a significant increase in plasma s-TNFR-2 concentrations after lowfat dairy consumption, while there was a trend towards higher s-TNFR-1 and lower TNF- $\alpha$ concentrations. Subjects' compliance was confirmed by the expected decrease in plasma concentrations of $1,25-(\mathrm{OH})_{2}-\mathrm{D}_{3}$.

Elevated concentrations of TNF- $\alpha$ have been found to relate to obesity, insulin resistance and the metabolic syndrome [34, 132]. An enlarged adipose tissue mass increases the production of TNF- $\alpha$, which may in turn cause insulin resistance by affecting signalling pathways in different organs. Although animal studies have established TNF- $\alpha$ as a link between obesity and insulin resistance [133, 134], evidence from human studies is less conclusive. Reduced insulin-induced glucose uptake after TNF- $\alpha$ infusion has been shown in healthy subjects [135]. Further, the use of antiTNF- $\alpha$ drugs in inflammatory conditions induced a concomitant improvement in in- 
sulin sensitivity in several human trials [136-138], whereas no beneficial effects of TNF- $\alpha$ neutralization on insulin sensitivity were found in other studies [139-141]. Further, the function of soluble TNF- $\alpha$ receptors (s-TNFR-1 and s-TNFR-2) is not yet fully understood. Elevated concentrations of soluble TNF- $\alpha$ receptors have been associated with obesity $[142,143]$ and weight loss has been found to decrease TNF- $\alpha$ and increase s-TNFR concentrations [144]. The membrane-bound forms of the two TNF- $\alpha$ receptors activate different intracellular pathways upon TNF- $\alpha$ binding, facilitating its physiological effects [145]. Circulating TNF- $\alpha$ receptors, on the contrary, are able to compete for TNF- $\alpha$ binding with the cell surface receptors and have been proposed to function as inhibitors of TNF- $\alpha$ action. Through the formation of high affinity complexes and subsequent reduction of the amount of active TNF- $\alpha$, they might protect against the potentially harmful effects of TNF- $\alpha[146,147]$. Illustrative, a dimeric recombinant form of s-TNFR-2, known as etanercept, is often used in inflammatory conditions such as rheumatoid arthritis and psoriasis and has been shown to improve inflammatory conditions in patients with the metabolic syndrome [139]. Our data show increased concentrations of s-TNFR-2 after low-fat dairy consumption, which might imply lower biological availability of TNF- $\alpha$ protein. In fact, when we calculated the TNF- $\alpha$ index, a measure for biologically available TNF- $\alpha$ [131], we found reduced numbers after the dairy intervention. The effect of dairy products on the TNF- $\alpha$ pathway in human subjects has, thus far, not been explored. Experiments in mice have indicated that calcium and dairy products may reduce TNF- $\alpha$ production $[111,148]$, but effects in humans have not been studied before. Our results might imply beneficial effects of low-fat dairy consumption on TNF$\alpha$ action, but the precise consequences of these observations have to be further examined. It may be interesting for future research to study the effects of dairy intake on the activity, besides the concentration, of TNF- $\alpha$ and related parameters, since signalling from the TNF- $\alpha$ receptor has been found to be modulated by calciumdependent proteins [149].

Other inflammatory markers and adhesion molecules, however, were not affected by dairy consumption. Studies addressing the effects of dairy products or its constituents on inflammation or endothelial function are scarce. Wennersberg et al. studied the effects of 6-month dairy consumption in overweight men and women and found no differences in markers of inflammation (IL-6, CRP, TNF- $\alpha$ ) and endothelial dysfunction (E-selectin, Von Willebrand Factor), except for a decrease in VCAM-1, which was only present in women [150]. Zemel et al. reported reductions in plasma TNF- $\alpha$ and IL-6, and an increase in plasma adiponectin in mice fed a highdairy diet [111]. They also evaluated samples from obese men and women who followed a high-dairy eucaloric or hypocaloric diet for four weeks. Compared with a low-dairy group, they observed decreased concentrations of CRP and increased concentrations of adiponectin after the high-dairy diets. Although the effects of an 
improved body composition cannot be fully excluded, the authors also suggest a role for the suppression of $1,25-(\mathrm{OH})_{2}-\mathrm{D}_{3}$. In previous in vitro experiments, they showed that $1,25-(\mathrm{OH})_{2}-\mathrm{D}_{3}$ stimulated TNF- $\alpha$ and IL-6 expression $[151,152]$. On the contrary, other in vitro and animal studies provide evidence that $1,25-(\mathrm{OH})_{2}-\mathrm{D}_{3}$ has anti-inflammatory properties [153-155]. In our study, concentrations of $1,25-(\mathrm{OH})_{2}-$ $\mathrm{D}_{3}$ were measured as marker of dietary compliance and were indeed reduced by dairy consumption, but its role in the modulation of the TNF- $\alpha$ pathway remains to be elucidated. Recently, Zemel et al. showed that a eucaloric dairy-rich diet reduced inflammatory markers (IL-6, TNF- $\alpha$, MCP-1) and increased adiponectin in overweight and obese subjects when compared with a soy-rich diet, in the absence of changes in adiposity [156]. Effects were already present after 7 days of intervention, and were even more pronounced after 28 days. Our results now suggest that effects on TNF- $\alpha$ related parameters are still present after an 8-week intervention period. However, whether these changes are enduring for a longer period needs further study. Further, unlike Zemel et al. [156], we observed no effects on IL-6 an MCP-1 for which we have no obvious explanation.

Taken together, our results indicate that low-fat dairy consumption for 8 weeks, compared with carbohydrate-rich product consumption, may modulate TNF- $\alpha$ signalling by increasing s-TNFR-2, but does not affect other markers of low-grade systemic inflammation and endothelial function in overweight and obese subjects. 



\section{Effects of milk and milk constituents on postprandial lipid and glucose metabolism in overweight subjects}




\section{ABSTRACT}

Increased postprandial hyperlipidemia and hyperglycemia are positively associated with cardiovascular disease. Several studies have suggested that two major milk constituents, casein and calcium, favourably affect postprandial lipid responses. However, the effects of milk on postprandial responses are unknown. In this study, we investigated the effects of addition of milk to a highfat meal on lipid and glucose responses in overweight and obese men. To identify the constituent responsible for the effects, we also studied responses to calcium and protein. Sixteen male subjects $\left(B M I>27 \mathrm{~kg} / \mathrm{m}^{2}\right.$ ) participated in 4 postprandial tests. They consumed a breakfast ( $44 \mathrm{~g}$ of fat) plus a drink: a control, calcium, or protein drink, or low-fat milk $(500 \mathrm{~mL})$. Blood samples were taken before the meals and at regular time points during $6 \mathrm{~h}$ thereafter. The incremental area under the curve (iAUC) for serum triacylglycerol (TAG) was increased by $25 \%$ after the milk meal $(\mathrm{P}=0.024)$ and by $38 \%$ after the protein meal $(P=0.001)$ compared with the control meal. Glucose iAUC was not different between the test meals, but the maximal increase in plasma glucose was reduced by $13 \%$ in the milk intervention $(P=0.030)$ and by $20 \%$ in the protein intervention $(P=0.001)$. The milk meal increased insulin iAUC by $35 \%(P=0.001)$. Free fatty acid concentrations were not different between test meals. Our results indicate that the addition of milk to a fat-containing meal increases the postprandial iAUC for insulin and TAG, but decrease the maximal increase in glucose. The protein fraction seems to be the main determinant, while calcium has no effects on these parameters. 


\section{Introduction}

Postprandial hyperlipidemia and hyperglycemia are strongly associated with cardiovascular disease (CVD) $[157,158]$. In fact, postprandial changes in plasma triacylglycerol (TAG) and glucose concentrations might be more strongly associated with CVD risk than their fasting concentrations [159-161]. As people in the Western world are in a non-fasting state for most of the day, these are important findings. Fasting glucose concentrations have found to be predictive of postmeal glucose excursions [162] and high concentrations of fasting TAG are often predictive of postprandial hyperlipidemia [163, 164], which is therefore frequently seen in patients with the metabolic syndrome [165].

The macronutrient composition of a meal is an important determinant of the postprandial response. High-fat meals have been found to increase TAG concentrations [166, 167], impair endothelial function [168-170], and increase markers of inflammation and endothelial dysfunction $[171,172]$. However, Westphal et al. have shown that adding carbohydrates (glucose) to a high-fat meal resulted in a delay and reduction of postprandial lipidemia [173]. Casein had an even stronger effect: chylomicron responses were further reduced and delayed, which could not be explained by gastric emptying time. Further, concentrations of C-peptide and insulin were elevated during the post-absorptive phase ( $4-8 \mathrm{~h}$ ) after the casein-containing meals. Whether dairy products have comparable effects on postprandial metabolism, as has milk protein alone, is not known. Furthermore, it has been reported that increased calcium intake from dairy products reduced chylomicron TAG concentrations after a meal [57]. However, the effects of calcium on other postprandial responses have not been studied before. In this study, we therefore investigated effects of addition of low-fat milk to a high-fat breakfast on postprandial lipid and carbohydrate metabolism in overweight and obese subjects. To evaluate which of the dairy components may be responsible for the effects, we also studied the postprandial responses of milk protein and calcium, two major milk constituents.

\section{Methods}

\section{Study population}

Subjects were recruited in Maastricht and surroundings by advertisements in local newspapers and posters in hospital and university buildings. People who were interested to participate were informed about the purposes and requirements of the study and all gave their written informed consent before they entered the screening procedure. The study was approved by the Medical Ethical Committee of Maastricht University Medical Centre+ and was registered at ClinicalTrials.gov as NCT00917878. 
Subjects were invited for the screening procedure when they met the following inclusion criteria: male; $18-70$ y; non-smoking; $\mathrm{BMI}>27 \mathrm{~kg} / \mathrm{m}^{2}$; no active cardiovascular disease, familial hyperlipidemia, inflammatory diseases, or other medical conditions that might interfere with the study outcomes; no abuse of alcohol or drugs; stable body weight during the past 3 months. During two screening visits, body weight, height and blood pressure were measured and a fasting blood sample was taken to determine serum lipid and lipoprotein concentrations. Sixteen subjects were enrolled in the study (Table 5.1). They were asked not to change their dietary habits, use of alcohol, and level of physical exercise during the study. They were also requested to record any signs of illness, use of medication or other important details during the study period in a diary. All subjects completed the study.

\section{Study design and intervention}

The study consisted of four test days, which were separated by a washout period of at least 3 days. On each test day, subjects received a different test meal in randomized order, and participated in a postprandial test. Subjects were asked not to perform any strenuous physical exercise and not to consume alcohol on the day before testing. They were also asked to refrain from high-fat foods on the day prior to the test days. After an overnight fast, subjects arrived at the university by public transport or car. An intravenous cannula (Venfon ${ }^{\circledR}$; Becton Dickinson, Franklin Lakes, USA) was inserted in an antecubital vein and blood samples were collected for analysis of fasting concentrations of metabolic risk markers. Subjects were then requested to consume one of the test meals within 10 minutes. Subsequent blood samples were drawn at $15,30,45,60,90,120,180,240,300$, and 360 min after meal consumption. Subjects were allowed to drink water $(250 \mathrm{~mL})$ directly after the $\mathrm{T}=120$ and $\mathrm{T}=240$ blood collections. The test meals consisted of $168 \mathrm{~g}$ butter cake and $500 \mathrm{~mL}$ of one of four drinks (Table 5.2). In the milk intervention, subjects consumed skimmed milk ( $0 \%$ fat; Campina, Woerden, The Netherlands). All drinks contained an equal amount of lactose (DMV International, Veghel, The Netherlands). The protein drink contained the same amount of protein (REFIT Total Milk Protein; DMV International) as the milk, while the calcium content (Lactoval; DMV International) of the calcium and protein drinks was equal to that of the milk. The amino acid composition of all meals is given in Table 5.3. 
Table 5.1. Characteristics of the subjects.

\begin{tabular}{lc}
\hline & \\
\hline Age $(\mathrm{y})$ & $49.8 \pm 15.5$ \\
$\mathrm{BMI}\left(\mathrm{kg} / \mathrm{m}^{2}\right)$ & $31.2 \pm 3.6$ \\
Weight $(\mathrm{kg})$ & $101.5 \pm 10.6$ \\
Height $(\mathrm{m})$ & $180.8 \pm 4.6$ \\
Systolic blood pressure (mmHg) & $129.1 \pm 12.3$ \\
Diastolic blood pressure (mmHg) & $86.0 \pm 8.1$ \\
Glucose (mmol/L) & $5.66 \pm 0.35$ \\
Insulin (mU/L) & $23.0 \pm 10.2$ \\
Total cholesterol (mmol/L) & $5.58 \pm 0.87$ \\
HDL cholesterol (mmol/L) & $1.23 \pm 0.27$ \\
LDL cholesterol (mmol/L) & $3.57 \pm 0.70$ \\
Triacylglycerol (mmol/L) & $1.71 \pm 0.62$ \\
\hline Allvalues aremeans \pm SD. &
\end{tabular}

All values are means \pm SD.

Table 5.2. Composition of the test meals.

\begin{tabular}{lllll}
\hline & Control & Calcium & Protein & Milk \\
\hline Products & $\begin{array}{l}\text { Butter cake } 168 \mathrm{~g} \\
\text { Water } 500 \mathrm{~mL}\end{array}$ & $\begin{array}{l}\text { Butter cake } 168 \mathrm{~g} \\
\text { Water } 500 \mathrm{~mL}\end{array}$ & $\begin{array}{l}\text { Butter cake } 168 \mathrm{~g} \\
\text { Water } 500 \mathrm{~mL}\end{array}$ & $\begin{array}{l}\text { Butter cake } 168 \mathrm{~g} \\
\text { Lilk } 500 \mathrm{~mL}\end{array}$ \\
& & $\begin{array}{l}\text { Lactose } 29 \mathrm{~g} \\
\text { Calcium } 2.3 \mathrm{~g}\end{array}$ & $\begin{array}{l}\text { Milk protein 23.4 g } \\
\text { Calcium } 1.3 \mathrm{~g}\end{array}$ & \\
& & & 948 & 948 \\
Energy (kcal) & 864 & 864 & 29 & 29 \\
Protein (g) & 8 & 8 & 109 & 109 \\
Carbohydrates (g) & 109 & 109 & & 74 \\
Of which: & & & 74 & 30 \\
Mono/disaccharides (g) & 74 & 74 & 30 & 44 \\
Lactose (g) & 30 & 30 & 44 & 697 \\
Fat (g) & 44 & 44 & 703 & 600 \\
Calcium (mg) & 49 & 699 & 407 & \\
Phosphorus (mg) & 100 & 353 & &
\end{tabular}

\section{Blood sampling and analyses}

Venous blood was sampled using a Vacutainer system (Becton Dickinson). Blood was drawn into serum separator tubes for the analysis of lipids and lipoproteins. After clotting at room temperature for at least $30 \mathrm{~min}$, serum was obtained by centrifugation at $1300 \mathrm{~g}$ for $15 \mathrm{~min}$ at room temperature and stored at $-80^{\circ} \mathrm{C}$. Further, blood was sampled into EDTA tubes for the analysis of insulin and free fatty acids (FFA) concentrations and sodium fluoride (NaF) tubes were used for analysis of plasma glucose and amino acid concentrations. EDTA and NaF tubes were kept on ice until centrifugation at $1300 \mathrm{~g}$ for $15 \mathrm{~min}$ at $4^{\circ} \mathrm{C}$. Plasma samples were snapfrozen in liquid nitrogen and stored at $-80^{\circ} \mathrm{C}$. 
Table 5.3. Amino acid composition of the test meals.

\begin{tabular}{lcccc}
\hline & Control & Calcium & Protein & Milk \\
\hline Cysteine (g) & 0.17 & 0.17 & 0.30 & 0.32 \\
Methionine (g) & 0.12 & 0.12 & 0.70 & 0.67 \\
Aspartic acid (g) & 0.32 & 0.32 & 1.89 & 1.87 \\
Threonine (g) & 0.24 & 0.24 & 1.18 & 1.09 \\
Serine (g) & 0.35 & 0.35 & 1.52 & 1.45 \\
Glutamic acid (g) & 2.25 & 2.25 & 6.77 & 6.50 \\
Proline (g) & 0.79 & 0.79 & 2.94 & 2.74 \\
Glycine (g) & 0.25 & 0.25 & 0.64 & 0.60 \\
Alanine (g) & 0.22 & 0.22 & 0.88 & 0.87 \\
Valine (g) & 0.30 & 0.30 & 1.66 & 1.55 \\
Isoleucine (g) & 0.25 & 0.25 & 1.34 & 1.30 \\
Leucine (g) & 0.50 & 0.50 & 2.49 & 2.50 \\
Tyrosine (g) & 0.22 & 0.22 & 1.33 & 1.22 \\
Phenylalanine (g) & 0.34 & 0.34 & 1.35 & 1.29 \\
Histidine (g) & 0.15 & 0.15 & 0.72 & 0.65 \\
Lysine (g) & 0.12 & 0.12 & 1.76 & 1.77 \\
Arginine (g) & 0.27 & 0.27 & 1.04 & 1.02 \\
Tryptophan (g) & 0.07 & 0.07 & 0.34 & 0.35 \\
\hline Total AA (g) & 6.93 & 6.93 & 28.85 & 27.76 \\
Essential AA (g) & 1.94 & 1.94 & 10.83 & 10.52 \\
Non-essential AA (g) & 4.99 & 4.99 & 18.02 & 17.24 \\
\hline Essential AA: Methion & (g) & \\
\hline
\end{tabular}

Essential AA: Methionine, Threonine, Valine, Isoleucine, Leucine, Phenylalanine, Lysine, Tryptophan.

Baseline serum samples were analyzed for concentrations of total cholesterol (CHOD-PAP method; Roche, Basel, Switzerland) and HDL-cholesterol (precipitation method; Roche). LDL-cholesterol concentrations were calculated using the Friedewald equation [113]. Concentrations of TAG, with correction for free glycerol, were determined in serum samples from $\mathrm{T}=0,60,120,180,240,300$, and $360 \mathrm{~min}$ (GPO Trinder; Sigma Diagnostics, St. Louis, USA). FFA were analysed by an enzymatic assay (NEFA kit; WAKO, Neuss, Germany) in plasma samples from T=0, 60, 120, 240, and 360 min. Glucose concentrations (Horiba ABX, Monpellier, France) and insulin concentrations (radioimmunoassay, Millipore, Billerica, USA) were measured in plasma samples from $T=0,15,30,45,60,90,120,240$, and 360 min. Plasma amino acid concentrations were determined at $\mathrm{T}=0,60$, and $120 \mathrm{~min}$ as described elsewhere [174]. 


\section{Statistics}

Data are presented as means \pm SD. To evaluate the overall response of total TAG, glucose, and insulin during the 6-h postprandial period, the incremental areas under the postprandial curve (iAUC) or decremental areas under the curve (dAUC) were calculated using the trapezoidal rule. Maximal changes were calculated by subtracting baseline values from the maximal or minimal value. All statistical analyses were performed using SPSS 16.0 for Macintosh OS X package (SPSS, Chicago, USA). Differences in iAUC and maximal changes between the test meals were tested for significance by univariate ANOVA followed by Bonferroni's correction for multiple comparisons. A P-value $<0.05$ was considered as statistically significant.

\section{Results}

\section{Triacylglycerol}

Serum TAG concentrations during the postprandial phase after ingestion of the test meals are presented in Figure 5.1. Compared with baseline values, all test meals increased serum TAG concentrations, which reached peak concentrations after 180 min. After all meals, serum TAG concentrations had not returned to baseline values after $360 \mathrm{~min}$. IAUC and maximal increases are shown in Table 5.4. Addition of protein or milk to the meal significantly increased the iAUC by $38 \%(P=0.001)$ and $25 \%$ $(P=0.024)$, respectively, compared with the control meal. During the early phase (0$180 \mathrm{~min})$, no differences in iAUC between the milk and control meal were present $(P=0.409)$, while in the late phase $(180-360 \mathrm{~min})$ the iAUC was increased after the milk meal $(P=0.016)$. The protein meal increased the iAUC in the early $(P=0.003)$ as well as the late phase $(P=0.007)$. The iAUC after the calcium meal was not different from control $(P=0.275)$. The maximal increases in serum TAG were not different between the four meals $(P=0.498)$. 

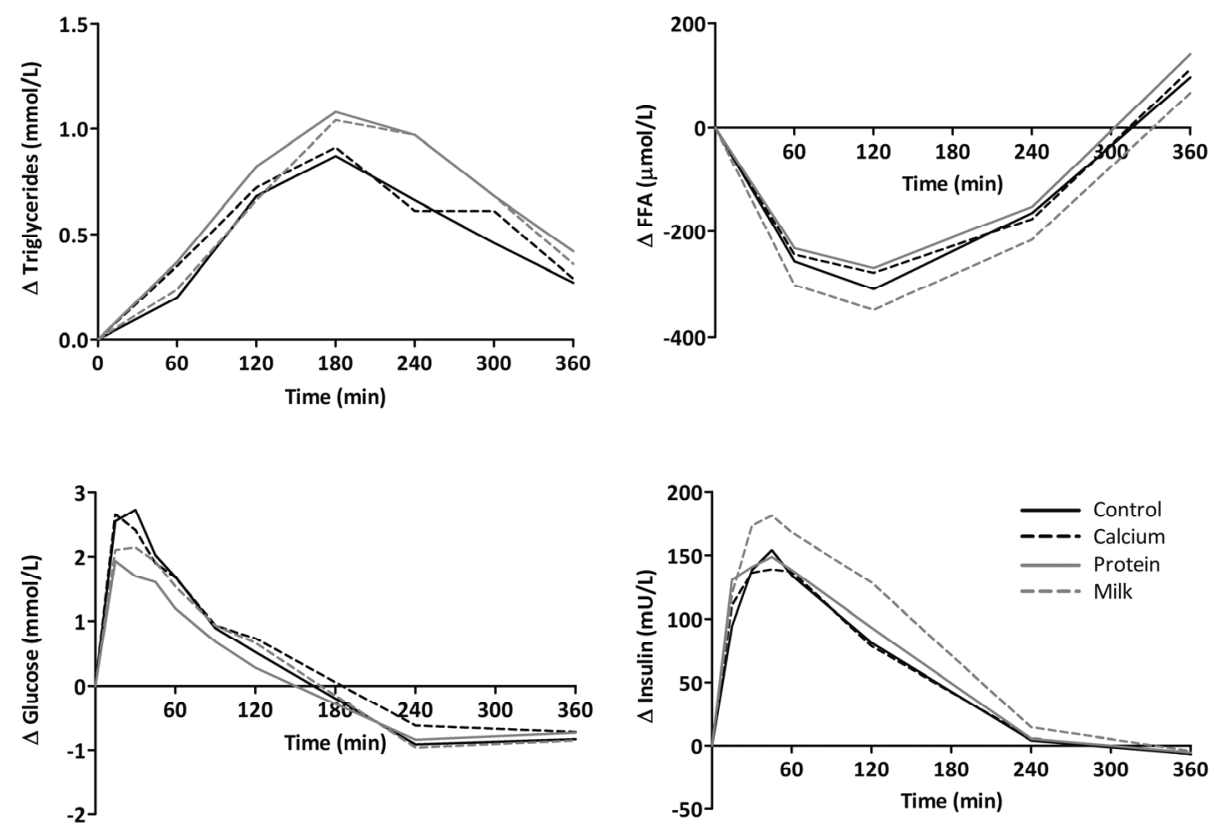

Figure 5.1. Concentrations of triglycerides (TAG), free fatty acids (FFA), glucose and insulin after consumption of a meal providing $40 \mathrm{~g}$ of fat and $500 \mathrm{~mL}$ of a control, calcium, or protein drink, or low-fat milk.

\section{Glucose and insulin}

Plasma concentrations of glucose and insulin are shown in Figure 5.1. Plasma glucose concentrations were maximally increased $15 \mathrm{~min}$ after consumption of the calcium and protein meals and $30 \mathrm{~min}$ after consumption of the control and milk meals. Concentrations decreased below fasting concentrations after $180 \mathrm{~min}$. The maximal increase in plasma glucose from baseline concentrations was significantly lowered after the protein meal by $20 \%(P=0.001)$, and the iAUC by $34 \%$ relative to the control meal, but this latter difference did not reach statistical significance $(P=0.066)$. The milk intervention reduced the maximal increase in glucose by $13 \%$ $(P=0.030)$, but did not affect the iAUC. Calcium did not change postprandial glucose responses (Table 3 ).

Insulin concentrations were maximal $45 \mathrm{~min}$ after consumption of the test meals and had returned to baseline concentrations after $360 \mathrm{~min}$. The iAUC was significantly higher (35\%) after the milk meal than after the control meal $(P=0.001)$. No differences in iAUC were observed after the calcium or the protein meal. The maximal increases were not statistically different between the four test meals $(P=0.227)$. 


\section{Free fatty acids}

Plasma FFA responses after the four meals are shown in Figure 5.1. FFA concentrations decreased after all meals and reached their minimal value after $120 \mathrm{~min}$. Since FFA concentrations dropped below baseline after meal consumption, dAUC instead of iAUC were calculated. The dAUC $(P=0.218)$ and the maximal decrease in FFA $(P=0.114)$ were not different between the interventions.

\section{Amino acids}

Plasma concentrations of total, essential and non-essential amino acids after the 4 meals are given in Table 5.5. After 60 and 120 min, amino acid concentrations were significantly increased on the milk and protein meals compared to the control meal. Concentrations of the individual amino acids are provided in Table 5.6.

Table 5.4. Incremental areas under the curves and maximal changes from baseline.

\begin{tabular}{|c|c|c|c|c|c|}
\hline & Control & Calcium & Protein & Milk & $\begin{array}{l}\text { P for diet } \\
\text { effect }\end{array}$ \\
\hline \multicolumn{6}{|l|}{ Triacylglycerol } \\
\hline iAUC $(\mathrm{mmol} \cdot \mathrm{min} / \mathrm{L})$ & $181 \pm 71$ & $202 \pm 75$ & $249 \pm 97^{*}$ & $226 \pm 127^{*}$ & 0.007 \\
\hline $\begin{array}{l}\text { Maximal change } \\
(\mathrm{mmol} / \mathrm{L})\end{array}$ & $0.97 \pm 0.41$ & $1.12 \pm 0.57$ & $1.16 \pm 0.44$ & $1.07 \pm 0.57$ & 0.498 \\
\hline \multicolumn{6}{|l|}{ Glucose } \\
\hline iAUC (mmol·min/L) & $213 \pm 124$ & $242 \pm 161$ & $155 \pm 136$ & $211 \pm 150$ & 0.051 \\
\hline $\begin{array}{l}\text { Maximal change } \\
(\mathrm{mmol} / \mathrm{L})\end{array}$ & $3.22 \pm 1.10$ & $3.15 \pm 1.14$ & $2.57 \pm 1.46^{*}$ & $2.79 \pm 1.46^{*}$ & 0.004 \\
\hline \multicolumn{6}{|l|}{ Insulin } \\
\hline iAUC (mU·min/L) & $18794 \pm 15189$ & $18706 \pm 11238$ & $17418 \pm 13112$ & $26691 \pm 18608^{*}$ & 0.001 \\
\hline $\begin{array}{l}\text { Maximal change } \\
(\mathrm{mU} / \mathrm{L})\end{array}$ & $179 \pm 122$ & $184 \pm 101$ & $188 \pm 110$ & $206 \pm 116$ & 0.227 \\
\hline \multicolumn{6}{|l|}{ FFA } \\
\hline $\mathrm{dAUC}(\mu \mathrm{mol} \cdot \mathrm{min} / \mathrm{L})$ & $69741 \pm 54093$ & $59594 \pm 35228$ & $54681 \pm 47010$ & $77249 \pm 36292$ & 0.218 \\
\hline $\begin{array}{l}\text { Maximal change } \\
(\mu \mathrm{mol} / \mathrm{L})\end{array}$ & $-319 \pm 180$ & $-290 \pm 128$ & $-274 \pm 188$ & $-356 \pm 131$ & 0.114 \\
\hline
\end{tabular}

Values are means \pm SD. ${ }^{*}$ Significantly different from control $(\mathrm{P}<0.05)$ 
Table 5.5. Plasma amino acid concentrations after the test meals.

\begin{tabular}{|c|c|c|c|c|c|c|}
\hline \multirow{3}{*}{$\begin{array}{l}\text { Total AA } \\
(\mu \mathrm{mol} / \mathrm{L})\end{array}$} & \multicolumn{2}{|r|}{ Control } & Calcium & Protein & Milk & $\begin{array}{l}\text { P for diet } \\
\text { effect }\end{array}$ \\
\hline & TO & $2493 \pm 303$ & $2453 \pm 238$ & $2498 \pm 310$ & $2479 \pm 243$ & 0.890 \\
\hline & T60 & $2367 \pm 320$ & $2342 \pm 270$ & $2776 \pm 419 *$ & $2748 \pm 369^{*}$ & $<0.001$ \\
\hline & T120 & $2245 \pm 340$ & $2202 \pm 300$ & $2610 \pm 306^{*}$ & $2614 \pm 365^{*}$ & $<0.001$ \\
\hline \multirow{3}{*}{$\begin{array}{l}\text { EAA } \\
\qquad(\mu \mathrm{mol} / \mathrm{L})\end{array}$} & TO & $844 \pm 113$ & $816 \pm 100$ & $847 \pm 89$ & $835 \pm 82$ & 0.553 \\
\hline & T60 & $741 \pm 103$ & $721 \pm 88$ & $954 \pm 152^{*}$ & $939 \pm 121 *$ & $<0.001$ \\
\hline & T120 & $653 \pm 97$ & $639 \pm 87$ & $873 \pm 103^{*}$ & $877 \pm 103^{*}$ & $<0.001$ \\
\hline \multirow{3}{*}{$\begin{array}{l}\text { NEAA } \\
\qquad(\mu \mathrm{mol} / \mathrm{L})\end{array}$} & TO & $1649 \pm 220$ & $1636 \pm 169$ & $1651 \pm 251$ & $1644 \pm 183$ & 0.990 \\
\hline & T60 & $1626 \pm 250$ & $1622 \pm 213$ & $1822 \pm 285^{*}$ & $1809 \pm 274^{*}$ & $<0.001$ \\
\hline & T120 & $1592 \pm 267$ & $1562 \pm 229$ & $1737 \pm 234^{*}$ & $1737 \pm 276^{*}$ & $<0.001$ \\
\hline
\end{tabular}

Values are means \pm SD. AA, amino acids; EAA, essential amino acids (Methionine, Threonine, Valine, Isoleucine, Leucine, Phenylalanine, Lysine, Tryptophan); NEAA, non-essential amino acids. * Significantly different from control at corresponding time point $(P<0.05)$.

Table 5.6. Individual amino acid concentrations after the test meals.

\begin{tabular}{|c|c|c|c|c|c|c|}
\hline & & Control & Calcium & Protein & Milk & $\begin{array}{c}\text { P for diet } \\
\text { effect }\end{array}$ \\
\hline \multirow[t]{3}{*}{ Glutamate } & TO & $96.7 \pm 34.1$ & $101.3 \pm 32.4$ & $96.8 \pm 35.8$ & $99.7 \pm 29.6$ & 0.667 \\
\hline & T60 & $91.2 \pm 33.0$ & $88.4 \pm 32.3$ & $93.7 \pm 35.9$ & $89.7 \pm 32.0$ & 0.824 \\
\hline & T120 & $80.2 \pm 30.0$ & $87.7 \pm 26.9$ & $91.6 \pm 27.7$ & $85.4 \pm 27.9$ & 0.345 \\
\hline \multirow{3}{*}{$\begin{array}{l}\text { Aspartic } \\
\text { acid }\end{array}$} & TO & $40.2 \pm 9.9$ & $38.9 \pm 5.2$ & $41.7 \pm 9.5$ & $39.4 \pm 8.9$ & 0.418 \\
\hline & T60 & $35.9 \pm 9.0$ & $36.2 \pm 6.6$ & $46.1 \pm 10.8^{*}$ & $46.2 \pm 12.0^{*}$ & $<0.001$ \\
\hline & T120 & $34.7 \pm 8.5$ & $32.3 \pm 8.1$ & $42.4 \pm 9.9 *$ & $42.0 \pm 12.4^{*}$ & $<0.001$ \\
\hline \multirow[t]{3}{*}{ Serine } & TO & $115.3 \pm 20.5$ & $107.7 \pm 15.9$ & $117.7 \pm 20.8$ & $117.8 \pm 19.5$ & 0.790 \\
\hline & T60 & $106.0 \pm 20.0$ & $102.1 \pm 16.5$ & $123.2 \pm 22.8^{*}$ & $120.5 \pm 22.3^{*}$ & $<0.001$ \\
\hline & T120 & $99.2 \pm 24.4$ & $97.2 \pm 16.8$ & $108.1 \pm 19.2$ & $110.9 \pm 17.8^{*}$ & 0.011 \\
\hline \multirow[t]{3}{*}{ Glutamine } & TO & $493.5 \pm 68.4$ & $489.7 \pm 53.6$ & $509.2 \pm 76.5$ & $493.2 \pm 60.7$ & 0.426 \\
\hline & T60 & $464.0 \pm 75.2$ & $469.2 \pm 78.0$ & $508.3 \pm 92.3^{*}$ & $511.0 \pm 80.0^{*}$ & $<0.001$ \\
\hline & T120 & $469.6 \pm 71.7$ & $459.9 \pm 63.4$ & $494.6 \pm 70.4^{*}$ & $500.6 \pm 84.6^{*}$ & 0.004 \\
\hline \multirow[t]{3}{*}{ Histidine } & TO & $74.0 \pm 14.7$ & $73.4 \pm 11.8$ & $75.1 \pm 12.8$ & $74.6 \pm 10.8$ & 0.921 \\
\hline & T60 & $69.5 \pm 13.4$ & $69.8 \pm 13.3$ & $77.0 \pm 15.0^{*}$ & $80.3 \pm 12.7^{*}$ & $<0.001$ \\
\hline & T120 & $66.4 \pm 15.8$ & $66.4 \pm 12.4$ & $73.5 \pm 13.6^{*}$ & $75.6 \pm 12.4^{*}$ & $<0.001$ \\
\hline \multirow[t]{3}{*}{ Glycine } & TO & $204.2 \pm 44.6$ & $203.7 \pm 34.0$ & $215.3 \pm 47.4$ & $206.6 \pm 39.1$ & 0.350 \\
\hline & $\mathrm{T} 60$ & $185.3 \pm 41.6$ & $190.2 \pm 41.2$ & $199.9 \pm 51.0$ & $196.0 \pm 40.4$ & 0.084 \\
\hline & T120 & $187.2 \pm 42.5$ & $184.9 \pm 41.1$ & $192.3 \pm 42.4$ & $192.3 \pm 40.6$ & 0.501 \\
\hline \multirow[t]{3}{*}{ Threonine } & TO & $128.3 \pm 25.6$ & $118.3 \pm 14.5$ & $132.8 \pm 29.2$ & $119.3 \pm 21.0$ & 0.409 \\
\hline & T60 & $121.9 \pm 37.2$ & $119.2 \pm 19.7$ & $142.0 \pm 31.1^{*}$ & $142.8 \pm 27.0^{*}$ & $<0.001$ \\
\hline & T120 & $109.4 \pm 23.5$ & $110.9 \pm 25.1$ & $127.6 \pm 29.6^{*}$ & $130.6 \pm 27.8^{*}$ & $<0.001$ \\
\hline \multirow[t]{3}{*}{ Citrulline } & TO & $32.8 \pm 6.6$ & $30.3 \pm 5.0$ & $34.3 \pm 7.6$ & $33.1 \pm 6.1$ & 0.022 \\
\hline & T60 & $29.8 \pm 17.4$ & $25.3 \pm 6.1$ & $27.7 \pm 7.6$ & $26.9 \pm \pm 6.9$ & 0.537 \\
\hline & T120 & $24.8 \pm 6.1$ & $25.0 \pm 6.6$ & $28.2 \pm 6.7^{*}$ & $27.4 \pm \pm 7.6^{*}$ & 0.001 \\
\hline
\end{tabular}




\begin{tabular}{|c|c|c|c|c|c|c|}
\hline & & Control & Calcium & Protein & Milk & $\begin{array}{c}\text { P for diet } \\
\text { effect }\end{array}$ \\
\hline \multirow[t]{3}{*}{ Arginine } & T0 & $86.0 \pm 16.1$ & $82.8 \pm 12.3$ & $87.9 \pm 17.8$ & $83.8 \pm \pm 12.7$ & 0.394 \\
\hline & T60 & $76.5 \pm 14.2$ & $77.1 \pm 12.6$ & $91.8 \pm 22.4^{*}$ & $92.0 \pm 17.6^{*}$ & $<0.001$ \\
\hline & T120 & $76.0 \pm 21.0$ & $71.6 \pm 15.6$ & $86.3 \pm 20.9 *$ & $86.4 \pm 18.6^{*}$ & 0.001 \\
\hline \multirow[t]{3}{*}{ Alanine } & TO & $329.5 \pm 84.8$ & $330.8 \pm 102.2$ & $335.5 \pm 89.1$ & $322.3 \pm 99.9$ & 0.921 \\
\hline & T60 & $414.1 \pm 100.2$ & $410.4 \pm 82.9$ & $474.2 \pm 112.2^{*}$ & $462.2 \pm 122.3^{*}$ & 0.001 \\
\hline & T120 & $418.4 \pm 128.1$ & $396.2 \pm 96.9$ & $445.8 \pm 106.5$ & $440.2 \pm 112.7$ & 0.121 \\
\hline \multirow[t]{3}{*}{ Taurine } & TO & $44.9 \pm 6.9$ & $44.4 \pm 7.0$ & $43.5 \pm 6.8$ & $43.7 \pm 8.3$ & 0.754 \\
\hline & $\mathrm{T} 60$ & $35.4 \pm \pm 5.7$ & $33.2 \pm 5.5$ & $35.1 \pm 8.1$ & $36.2 \pm 8.8$ & 0.196 \\
\hline & T120 & $32.7 \pm 9.2$ & $31.7 \pm 5.4$ & $33.4 \pm 7.2$ & $33.9 \pm 8.0$ & 0.328 \\
\hline$\alpha$-Amino & TO & $19.0 \pm 5.6$ & $17.7 \pm 4.1$ & $17.6 \pm 4.9$ & $18.1 \pm 4.2$ & 0.716 \\
\hline \multirow[t]{2}{*}{ butyrate } & T60 & $16.9 \pm 5.5$ & $16.2 \pm 3.3$ & $17.7 \pm 6.2$ & $18.4 \pm 4.9$ & 0.489 \\
\hline & T120 & $15.6 \pm 5.7$ & $15.1 \pm 3.2$ & $16.5 \pm 4.8$ & $17.5 \pm 4.3$ & 0.203 \\
\hline \multirow[t]{3}{*}{ Tyrosine } & TO & $66.8 \pm 13.9$ & $65.1 \pm 14.2$ & $66.2 \pm 15.3$ & $65.5 \pm 14.9$ & 0.820 \\
\hline & $\mathrm{T} 60$ & $59.2 \pm 14.2$ & $58.6 \pm 14.5$ & $78.4 \pm 18.8^{*}$ & $78.8 \pm 15.6^{*}$ & $<0.001$ \\
\hline & T120 & $52.1 \pm 13.7$ & $51.7 \pm 13.2$ & $73.0 \pm 14.8^{*}$ & $72.6 \pm 15.3^{*}$ & $<0.001$ \\
\hline \multirow[t]{3}{*}{ Valine } & TO & $232.3 \pm 39.6$ & $223.1 \pm 28.4$ & $228.0 \pm 27.7$ & $223.8 \pm 26.3$ & 0.503 \\
\hline & $\mathrm{T} 60$ & $207.7 \pm 33.5$ & $197.4 \pm 24.9$ & $256.2 \pm 40.2^{*}$ & $251.4 \pm 24.5^{*}$ & $<0.001$ \\
\hline & T120 & $187.4 \pm 33.9$ & $178.8 \pm 24.4$ & $234.2 \pm 26.3^{*}$ & $230.2 \pm 22.8^{*}$ & $<0.001$ \\
\hline \multirow[t]{3}{*}{ Methionine } & TO & $27.7 \pm 7.8$ & $25.9 \pm 7.7$ & $26.6 \pm 7.9$ & $27.5 \pm 5.5$ & 0.625 \\
\hline & T60 & $23.8 \pm 7.6$ & $23.2 \pm 6.8$ & $32.2 \pm 7.5^{*}$ & $32.1 \pm 6.6^{*}$ & $<0.001$ \\
\hline & $\mathrm{T} 120$ & $18.9 \pm 7.1$ & $19.0 \pm 6.0$ & $27.4 \pm 6.5^{*}$ & $28.2 \pm 7.8^{*}$ & $<0.001$ \\
\hline \multirow[t]{3}{*}{ Isoleucine } & TO & $73.2 \pm 15.0$ & $70.8 \pm 16.7$ & $73.1 \pm 9.9$ & $73.0 \pm 11.1$ & 0.711 \\
\hline & T60 & $62.7 \pm 13.0$ & $58.5 \pm 11.7$ & $89.8 \pm 17.2^{*}$ & $87.3 \pm 9.7^{*}$ & $<0.001$ \\
\hline & T120 & $51.1 \pm 12.3$ & $49.6 \pm 10.9$ & $79.6 \pm 11.5^{*}$ & $77.1 \pm 9.9 *$ & $<0.001$ \\
\hline Phenyl- & TO & $54.2 \pm 10.1$ & $53.1 \pm 7.4$ & $54.1 \pm 7.7$ & $53.9 \pm 8.2$ & 0.936 \\
\hline \multirow[t]{2}{*}{ alanine } & T60 & $51.2 \pm 6.0$ & $48.8 \pm 8.2$ & $61.3 \pm 9.1^{*}$ & $60.4 \pm 8.2^{*}$ & $<0.001$ \\
\hline & T120 & $44.0 \pm 6.5$ & $44.5 \pm 6.0$ & $58.5 \pm 7.9^{*}$ & $57.3 \pm 9.9 *$ & $<0.001$ \\
\hline \multirow[t]{3}{*}{ Tryptophan } & TO & $47.7 \pm 12.7$ & $46.1 \pm 10.1$ & $45.3 \pm 10.3$ & $44.9 \pm 9.6$ & 0.635 \\
\hline & T60 & $42.9 \pm 10.3$ & $41.7 \pm 9.3$ & $48.2 \pm 11.7^{*}$ & $47.3 \pm 10.3^{*}$ & 0.009 \\
\hline & T120 & $37.0 \pm 7.9$ & $36.9 \pm 6.9$ & $45.7 \pm 9.7^{*}$ & $44.1 \pm 11.7^{*}$ & $<0.001$ \\
\hline \multirow[t]{3}{*}{ Leucine } & T0 & $133.5 \pm 26.3$ & $128.4 \pm 23.0$ & $135.6 \pm 19.8$ & $134.5 \pm 17.3$ & 0.238 \\
\hline & T60 & $113.7 \pm 21.3$ & $104.4 \pm 20.4$ & $154.7 \pm 30.3^{*}$ & $160.0 \pm 18.3^{*}$ & $<0.001$ \\
\hline & T120 & $91.5 \pm 20.1$ & $87.8 \pm 17.9$ & $137.2 \pm 19.7^{*}$ & $140.1 \pm 19.2^{*}$ & $<0.001$ \\
\hline \multirow[t]{3}{*}{ Ornithine } & T0 & $53.9 \pm 12.8$ & $53.4 \pm 13.6$ & $58.4 \pm 12.8$ & $55.9 \pm 11.9$ & 0.248 \\
\hline & T60 & $50.4 \pm 12.9$ & $50.2 \pm 12.6$ & $59.9 \pm 15.7^{*}$ & $59.8 \pm 14.5^{*}$ & $<0.001$ \\
\hline & T120 & $48.3 \pm 11.6$ & $47.5 \pm 13.6$ & $56.2 \pm 15.0^{*}$ & $58.9 \pm 15.7^{*}$ & $<0.001$ \\
\hline \multirow[t]{3}{*}{ Lysine } & TO & $154.6 \pm 23.0$ & $155.3 \pm 29.3$ & $161.6 \pm 19.1$ & $160.8 \pm 18.9$ & 0.663 \\
\hline & T60 & $131.1 \pm 19.3$ & $135.6 \pm 20.8$ & $177.3 \pm 38.0^{*}$ & $180.8 \pm 29.2^{*}$ & $<0.001$ \\
\hline & T120 & $121.9 \pm 14.1$ & $120.7 \pm 20.6$ & $167.1 \pm 30.5^{*}$ & $175.7 \pm 27.4^{*}$ & $<0.001$ \\
\hline
\end{tabular}




\section{Discussion}

The aim of this study was to investigate the effects of milk and of protein and calcium, two major milk constituents, on postprandial lipid and glucose metabolism. We found that protein increased the iAUC for TAG, but decreased the maximal increase in glucose. Further, the iAUC for insulin and TAG were increased and the maximal glucose response decreased when milk was added to the meal. The addition of calcium to the fat-containing meal had no effects on these parameters.

Results from other studies on postprandial effects of protein on TAG responses are not conclusive. Our finding that the addition of milk or milk protein increased the iAUC for TAG is in contrast with the observations of Westphal et al., who found in normal-weight men and women no change in this parameter when casein was added to a high-fat, carbohydrate-containing meal [173]. In fact, the iAUC for the chylomicron fraction was even decreased. In a second study, casein and soy also reduced serum TAG concentrations at the early time points, when added to a high-fat meal containing virtually no carbohydrates [175]. However, in that study no iAUC values were given and no difference was made between chylomicron, VLDL, and total serum TAG. The amount of protein given to the subjects was higher than in our study (around $50 \mathrm{~g}$ ), but also the amount of fat (around $70 \mathrm{~g}$ ). The authors suggested that the decreased chylomicron TAG response [173] resulted from a delayed gastric emptying and from the increased insulin concentrations. Insulin activates lipoprotein lipase (LPL), which might degrade chylomicron TAG more rapidly [176]. It has, however, been described that the responsiveness of LPL in adipose tissue to insulin and meals is diminished in obesity [26]. As the subjects in our study were all overweight or obese, in contrast to those in the trials of Westphal et al. [173, 175], it can be speculated that this might at least partly explain the different findings. However, in an other trial in overweight, type 2 diabetic, subjects, Brader et al. did find a decrease in TAG after casein consumption, but only in combination with carbohydrate consumption [177]. Cohen observed no effects of casein addition (23 g) on postprandial lipidemia after a high-fat $(40 \mathrm{~g})$ meal in normal-weight men and women [178]. One study has reported increased TAG concentrations after fat and casein consumption in healthy male subjects [179]. However, since only 4 out of 6 subjects showed increased postprandial lipidemia after protein ingestion and results were not statistically analyzed, the findings of this study are difficult to interpret. The protein we used was a total milk protein, containing the total fraction of cow's milk (mainly casein and whey), and thus somewhat different from the protein used by Westphal et al. [173]. However, they obtained comparable results for casein and soy, suggesting that the type of protein is of less importance [175]. We provided the protein on top of the meals, resulting in a higher energy intake in the protein and milk meals. However, it is not likely that a higher energy intake per se will increase 
postprandial TAG concentrations. For example, when extra energy is added to a fatrich meal in the form of glucose, the TAG response may even be reduced [180, 181].

The serum TAG response was not affected by the addition of calcium to the meal. Lorenzen et al. found that calcium from dairy products (350 or $800 \mathrm{mg}$ ), but not a calcium carbonate supplement $(850 \mathrm{mg})$, reduced the iAUC for chylomicron TAG after a fat load [57]. The authors suggested that this decrease may be due to a reduction in fat absorption, since a number of studies have shown that calcium intake increases faecal fat excretion, probably through the binding of calcium to fatty acids, mainly saturated fatty acids, in the intestine [51, 53, 55, 182]. However, no differences in total plasma TAG were observed, which is in line with our findings. Effects on fat absorption can, however, not be fully excluded as the effect on chylomicron TAG may have been too small to be detected in the total TAG fraction, or counteracted by an increase in VLDL. It should be noted that the calcium supplement used in our trial was derived from a dairy source, as we wanted to investigate whether calcium could be the dairy constituent responsible for the effects of milk, if any.

We further observed a $35 \%$ increase in the insulin response after the milk meal, but no increase after the protein meal. Protein, especially in combination with carbohydrates, has been reported to induce insulin secretion already in 1966 [183]. Van Loon et al. confirmed the insulinotropic potential of various proteins, hydrolysates, and free amino acids in combination with carbohydrates in a series of studies in healthy young subjects [184-186]. One of the most insulinotropic amino acids was leucine, which is highly present in milk protein. In addition, it has been suggested that protein may decrease hepatic insulin extraction from the circulation. Addition of whey protein to a meal resulted in elevated postprandial insulin concentrations, while C-peptide levels were unaffected [187]. However, Westphal et al. did find increased C-peptide concentrations after casein consumption, indicating an increased insulin production [173]. Our observation that the insulin response was elevated by the milk meal, but not by the protein meal, is unexpected, since the protein content, the type of protein, the amino acid composition, and the calcium and lactose content were exactly the same in both drinks. Further, changes in plasma concentrations of amino acids were comparable after the milk and protein meal. So, there should be an additional factor in milk that influences either the secretion or the clearance of insulin.

The iAUC for glucose were not different between the meals, but the peak change was decreased by the milk and protein meal, while it was unaffected by the calcium meal. So, we observed a reduction in the maximal glucose concentration, while the insulin response was not changed after the protein meal. A number of amino acids, including lysine [188], proline [189], glycine [190], and arginine [191], have been found to attenuate plasma glucose levels when ingested in combination with carbohydrates, without elevating insulin concentrations. However, other 
amino acids, such as leucine [192] and phenylalanine [193], have been shown to cause a reduction in plasma glucose and a concurrent increase in insulin secretion. The increased insulin response after the milk could explain the lower peak glucose levels. The increased insulin levels after the milk diet, however, did not affect FFA concentrations. This is in contrast to the reduced FFA concentrations observed by Westphal et al. [173, 175], who contribute this to the increased insulin response. However, Brader et al. did not find significant differences in FFA AUC, in spite of an increase in insulin after casein consumption [177].

In conclusion, our results indicate that adding milk to a fat-containing meal may enhance the TAG and insulin response and may reduce maximal glucose levels. The protein fraction of the milk seems to be mainly accountable for the effects. The calcium content does not change the postprandial responses after a fat meal and does not seem to be the major component responsible for the effects of milk. 


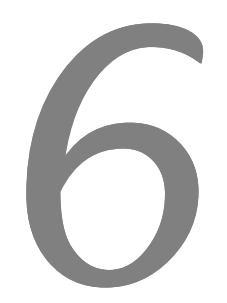

\section{Effects of amino acids on Akt phosphorylation, IL-8 production and NF- $\kappa B$ activity in HepG2 liver cells}




\section{ABSTRACT}

Hepatic insulin resistance and inflammatory cytokine production contribute to the manifestation of the metabolic syndrome. As amino acids have been implicated in modulating insulin signalling and inflammation, we have investigated the effects of glutamine, leucine and proline on markers of inflammation and insulin sensitivity in HepG2 liver cells. Cells were incubated with IL-1 $\beta$ (5 $\mathrm{ng} / \mathrm{mL}$ ) to stimulate IL-8 production. After $24 \mathrm{~h}$, glutamine inhibited IL-8 production significantly $(\mathrm{P}<0.05)$ at 2,5 and $10 \mathrm{mM}$ (to $82 \%, 73 \%$ and $72 \%$ of control), while leucine reduced IL-8 production significantly only at $10 \mathrm{mM}$ (66\%) and proline at 5 and $10 \mathrm{mM}$ (71\% and 52\%). Glutamine, leucine and proline all reduced NF- $\kappa B$ activity after $3 \mathrm{~h}$ of IL-1 $\beta$ stimulation at 2, 5, and $10 \mathrm{mM}$ $(\mathrm{P}<0.001)$. Insulin-induced $(1 \mathrm{nM})$ Akt phosphorylation was reduced in cells treated with tumour necrosis factor- $\alpha(10 \mathrm{ng} / \mathrm{mL})$ for $24 \mathrm{~h}$, but was partly restored by simultaneous incubation with glutamine, leucine and proline (25 $\mathrm{mM}$ ). Phosphorylation of glycogen synthase kinase- $3 \beta$ was unaffected by insulin stimulation and amino acid treatment. Our results indicate that glutamine, leucine and proline attenuate IL-8 production, probably through inhibition of NF- $\kappa B$, and that they increase Akt phosphorylation in HepG2 cells. 


\section{Introduction}

The metabolic syndrome covers numerous factors that enhance the risk for cardiovascular disease and type 2 diabetes mellitus. These risk factors, including dyslipidemia, insulin resistance, hypertension, a prothrombotic state, and chronic inflammation, result from a complex interplay between multiple tissues in the body [13]. Of these tissues, the liver is one of the most important organs involved, because of its central role in lipid and glucose homeostasis. In fact, a strong correlation exists between obesity and non-alcoholic fatty liver disease (NAFLD), which is considered to be a hepatic manifestation of the metabolic syndrome [194]. An increased flux of plasma free fatty acids and elevated levels of inflammatory cytokines, both often the result of an enlarged fat mass, may cause hepatic insulin resistance and subsequent disturbances in hepatic fat and glucose handling. In addition, the inflammatory response of the liver itself is often enhanced in metabolic diseases and results in increased production of pro-inflammatory cytokines and acute phase proteins [34].

Diet is one of the environmental factors that play a part in the development of these metabolic disturbances. Amino acids are one group of nutrients that may be of interest in their prevention and treatment. Amino acids, as provided by proteins, are an important component of the western diet and form 10 to 15 energy percent of the total food intake. They are highly abundant in dairy, meat, and other highprotein foods. Several amino acids have been reported to modulate the inflammatory response. For example, glutamine decreased the release of the proinflammatory cytokines IL-8 and IL-6 in human intestinal cells in vitro [195-197]. Another amino acid, histidine, was also found to inhibit the production of IL-8 in intestinal epithelial cells [198]. In addition, some studies indicated that amino acids might modulate insulin action in isolated adipocytes $[199,200]$. In rat heart tissue, amino acid supplementation was found to upregulate glucose transporter GLUT-4 [201]. Branched chain amino acids (BCAA) were reported to increase glucose uptake in skeletal muscle and hepatocytes in rodents [202, 203]. Moreover, BCAA-enriched supplements have been found to improve insulin resistance in patients with chronic liver disease [204]. These findings may implicate a role for amino acids in the modulation of insulin resistance as well. Furthermore, dairy products, which are a rich source of proteins, have been associated with a lower prevalence or incidence of the metabolic syndrome and its components [36, 37, 39, 43, 44]. It is possible that the amino acids derived from dairy proteins are (partly) responsible for any possible positive effects of dairy products on metabolic abnormalities.

In the present study, we therefore investigated the effects of glutamine, leucine and proline, the most abundant amino acids in dairy products [205], on markers reflecting inflammation and insulin signalling in a liver cell model. 


\section{Materials and methods}

\section{Cell culture}

The liver cell line HepG2 was kindly provided by Dr. S. Braesch-Andersen (Mabtech, Nacka Strand, Sweden). Cells were cultured in Minimum Essential Medium (MEM) containing $10 \%$ foetal bovine serum (FBS), $1 \%$ sodium pyruvate, $1 \%$ L-glutamine, $1 \%$ non-essential amino acids (NEAA), and 1\% penicilline-streptomycine (Invitrogen, Carlsbad, USA). The cells were grown under standard culturing conditions at $37^{\circ} \mathrm{C}$ in a $5 \% \mathrm{CO}_{2}$ humidified atmosphere.

\section{Cytokine production assay}

Cells were seeded in 24-well plates $\left(2 \cdot 10^{5}\right.$ cells/well). After $32 \mathrm{~h}$, the medium was replaced by MEM without FBS, L-glutamine and NEAA, and the cells were maintained on this medium for $16 \mathrm{~h}$ before the start of the experiments. To stimulate cytokine (tumour necrosis factor- $\alpha$ (TNF- $\alpha$ ), IL-6, and IL-8) production, the cells were incubated for $24 \mathrm{~h}$ with IL-1 $\beta$ ( $5 \mathrm{ng} / \mathrm{mL}$ ) (Sigma-Aldrich, Saint Louis, USA). In a pilot experiment, IL-1 $\beta$ was found to be a stronger inducer of IL-8 production than IL-6 and TNF- $\alpha$ in these cells. Simultaneously, the amino acids glutamine, leucine, and proline (Sigma-Aldrich) were added to the media to final concentrations of 2, 5, and $10 \mathrm{mM}$. For all experiments, amino acids were dissolved in MEM. Glucose, also dissolved in MEM, was added at the same concentrations to control for energy effects. After $24 \mathrm{~h}$, supernatants were collected and stored at $-80^{\circ} \mathrm{C}$ for further analysis. During experiments, appearance of the cells was checked microscopically. The protein content of the samples was determined using the BCA-method according the manufacturer's manual (Pierce, Rockford, USA).

The levels of cytokines secreted were measured using ELISA (Hycult biotechnology, Uden, The Netherlands). Briefly, 96-well plates were coated with monoclonal murine anti-human TNF- $\alpha /$ IL-6/IL-8 antibodies. Recombinant human cytokines were used for standard curves. Immobilized cytokines were detected using specific biotinylated rabbit anti-human TNF- $\alpha /$ IL-6/IL-8 polyclonal antibodies, followed by addition of peroxidase-conjugated streptavidin and tetramethylbenzidine (TMB) substrate. Absorption was measured at $450 \mathrm{~nm}$.

\section{NF-KB activity assay}

Cells were seeded in 24 -wells plates $\left(2 \cdot 10^{5}\right.$ cells/well) and grown for $24 \mathrm{~h}$. Transient transfections were performed using FuGENE ${ }^{\circledR}$ HD Transfection Reagent (Roche, Basel, Switzerland) according to manufacturer's instructions. The NF-KB-tk-luciferase 
vector was kindly provided by Dr. David Gius (National Cancer Institute, Bethesda,

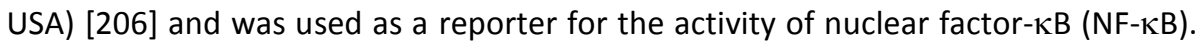
Cells were incubated with the FuGENE ${ }^{\circledR}$-DNA mix for $6 \mathrm{~h}(0.1 \mu \mathrm{g}$ pcDNA + $0.1 \mu \mathrm{g}$ NF$\kappa B$ vector per well).

Cells were placed on media without FBS, L-glutamine and NEAA for $16 \mathrm{~h}$ before start of the experiments. Cells were pre-incubated with glutamine, proline, or leucine $(2,5$ and $10 \mathrm{mM})$ for $24 \mathrm{~h}$. Glucose was added at the same concentrations to control for energy effects. To induce NF- $\kappa B$ activation, IL-1 $\beta(5 \mathrm{ng} / \mathrm{mL})$ was added to the media. After $3 \mathrm{~h}$ incubation, cells were placed on ice, supernatants were removed and cells were lysed with Reporter Lysis Buffer (Promega, Madison, USA). Lysates were stored at $-80^{\circ} \mathrm{C}$. NF- $\mathrm{KB}$ transcriptional activity was measured using a luminometer (Gomex, 96 microplate luminometer, Promega, Madison, USA) and luciferase assay substrate (Promega, Madison, USA) according to the user manual.

\section{Akt and GSK-3 $\beta$ phosphorylation assay}

Cells were seeded in 6 -well plates $\left(5 \cdot 10^{5}\right.$ cells/well). After $32 \mathrm{~h}$, the medium was replaced by MEM without FBS, L-glutamine and NEAA, and the cells were maintained on this medium for $16 \mathrm{~h}$ before the start of the experiments. To evaluate the effect of amino acids on phosphorylation of Akt, a key protein involved in the signalling pathway following insulin stimulation, we first incubated the cells with TNF- $\alpha$ (10 $\mathrm{ng} / \mathrm{mL}$ ) for $24 \mathrm{~h}$. Prolonged exposure to TNF- $\alpha$ downregulates IRS-1 and prevents the occurrence of the insulin signalling cascade, including phosphorylation of Akt, in HepG2 cells, creating a situation reflecting insulin resistance [207]. Cells were incubated simultaneously with or without $25 \mathrm{mM}$ of glutamine, leucine and proline. Glucose was added at the same concentration to control for energy effects. The cells were then exposed to $1 \mathrm{nM}$ of insulin for $5 \mathrm{~min}$ to induce Akt phosphorylation. Cells were placed on ice, supernatants were removed and cells were washed twice with ice cold PBS. Lysates of the cells were obtained by adding $200 \mu \mathrm{L}$ cold lysis buffer [20 mM Tris (pH 7.4), $150 \mathrm{mM} \mathrm{NaCl}$ 1\% Nonidet, 1 mM DTT, 1 mM NaVanadate, $1 \mathrm{mM}$ PMSF, $10 \mu \mathrm{g} / \mathrm{mL}$ Leupeptin, 1\% Aproptenin]. After incubation for $30 \mathrm{~min}$ on ice, cells were scraped and lysates were cleared by centrifugation and mixed with SDS-PAGE sample buffer [125 mM Tris (pH 6.8), 4\% sodium SDS, 20\% glycerol, 200 $\mathrm{mM}$ DTT, $0.02 \%$ Bromphenol Blue], heated for $5 \mathrm{~min}$ at $95^{\circ} \mathrm{C}$ and stored at $-20^{\circ} \mathrm{C}$.

Western blotting was used to visualize the amount of Akt, phosphorylated Akt

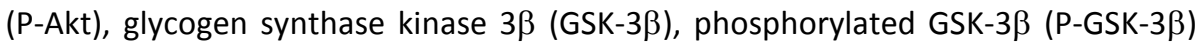
and $\beta$-actin (loading control for equal protein loading) in the lysates. GSK-3 $\beta$, an enzyme that inhibits glycogen synthesis, is inhibited by insulin and is a downstream target of P-Akt. Routinely, $30 \mu \mathrm{g}$ of protein sample was electrophoresed through $10 \%$ SDS-PAGE. Proteins were transferred onto nitrocellulose membranes at 100 $\mathrm{mA}$ overnight at $4^{\circ} \mathrm{C}$ and visualized by Ponceau $\mathrm{S}$ reagent. The blots were blocked 
with $5 \%$ non-fat dry milk/0.05\% TBS-Tween 20 for $1 \mathrm{~h}$ at room temperature. The blots were probed with rabbit anti-Akt, anti-P-Akt, anti-GSK-3 $\beta$, anti-P-GSK-3 $\beta$, and anti- $\beta$-actin antibodies (Cell Signaling Technology Inc., Boston, USA) and visualization was performed using chemiluminiscence reagent (Pierce Biotechnology, Rockford, USA).

\section{Statistics}

All statistical analyses were performed using SPSS 16.0 for Macintosh OS X (SPSS, Chicago, USA). Data were evaluated using univariate analysis of variance (ANOVA), adjusted for multiple comparisons using the Bonferroni's post hoc test.

\section{Results}

\section{Effect of amino acids on IL-1 $\beta$ induced cytokine production}

After stimulation with IL-1 $\beta$, the concentrations of TNF- $\alpha$ and IL- 6 were below the detection limit (60 pg/mL and $40 \mathrm{pg} / \mathrm{mL}$, respectively) and effects of the amino acids on the production of these cytokines could therefore not be evaluated (data not shown). Stimulation with IL-1 $\beta$ increased IL-8 production almost 30-fold after $24 \mathrm{~h}$ of stimulation $(\mathrm{P}<0.001)$. After the experiment, cells appearance had not changed, as checked microscopically. The protein content was not different between the various conditions. IL-8 production is given as percentage of control. As shown in Figure 6.1, incubation with $2 \mathrm{mM}, 5 \mathrm{mM}$ and $10 \mathrm{mM}$ glutamine reduced IL-8 production significantly to $82 \%, 73 \%$ and $72 \%$ of control levels $(P=0.009, P=0.001$ and $\mathrm{P}=0.001$ ), respectively. IL-8 production was unaffected by incubation with 2 and 5 $\mathrm{mM}$ of leucine ( $110 \%, \mathrm{P}=0.125$ and $92 \%, \mathrm{P}=0.232$ respectively), although it was significantly reduced by the addition of $10 \mathrm{mM}$ of leucine $(66 \%, \mathrm{P}=0.001)$. Proline did not affect IL- 8 production at the $2 \mathrm{mM}$ condition ( $99 \%, \mathrm{P}=0.909)$, but inhibited production of IL- 8 to $71 \%$ and $52 \%$ at 5 and $10 \mathrm{mM}(\mathrm{P}=0.001$ and $\mathrm{P}<0.001)$, respectively. The addition of 2, 5, and $10 \mathrm{mM}$ glucose did not alter IL-8 production (106\%, 103\% and $104 \%$, respectively, $\mathrm{P}=1.00$ ).

\section{Effect of amino acids on IL-1 $\beta$ induced NF-KB activity}

Stimulation of the cells with IL-1 $\beta$ increased NF-KB promoter induced luciferase production, as a marker of NF- $\mathrm{KB}$ activity, approximately 7-fold $(\mathrm{P}<0.001)$. Effects of the amino acid incubations on luciferase expression from the NF- $\kappa B$ promoter reporter construct are shown in Figure 6.2. The addition of glutamine reduced IL-1 $\beta$ induced luciferase expression to $75 \%, 76 \%$, and $66 \%$ of control at 2,5 , and $10 \mathrm{mM}$, 
respectively $(\mathrm{P}<0.001)$. Luciferase expression was decreased to $89 \%, 87 \%$, and $78 \%$ by 2,5 , and $10 \mathrm{mM}$ of leucine and to $83 \%, 71 \%$, and $57 \%$ by 2,5 , and $10 \mathrm{mM}$ of proline (all $\mathrm{P}<0.001$ ). Incubation with glucose had no effect on NF- $\kappa B$ promoter driven luciferase expression (96\% ( $P=0.395), 98 \%(P=0.706)$, and $92 \%(P=0.133)$ at 2,5 , and $10 \mathrm{mM}$, respectively).

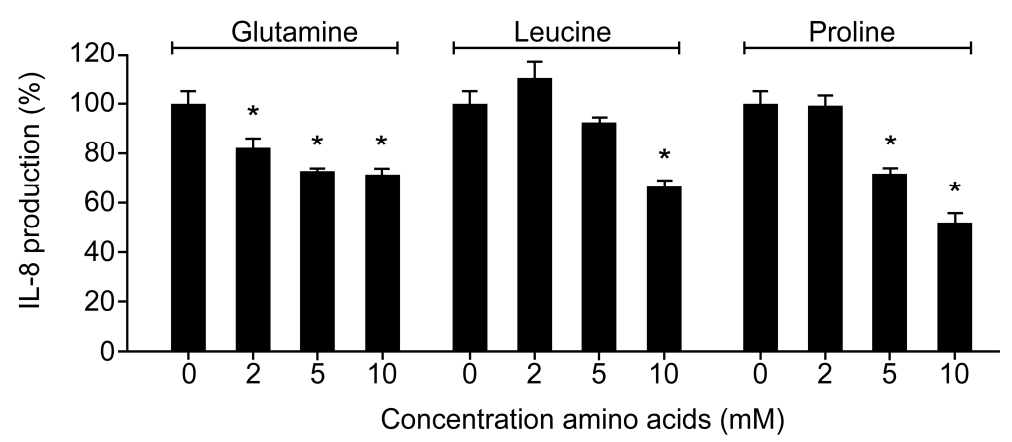

Figure 6.1. Effect of amino acids on IL-8 production in HepG2 cells. Cells were treated with IL-1 (5 $\mathrm{ng} / \mathrm{mL}$ ) and the amino acids glutamine, leucine and proline for $24 \mathrm{~h}$. Values are presented as means \pm SD $(n=6)$.

*Statistically different from control $(\mathrm{P}<0.05)$.

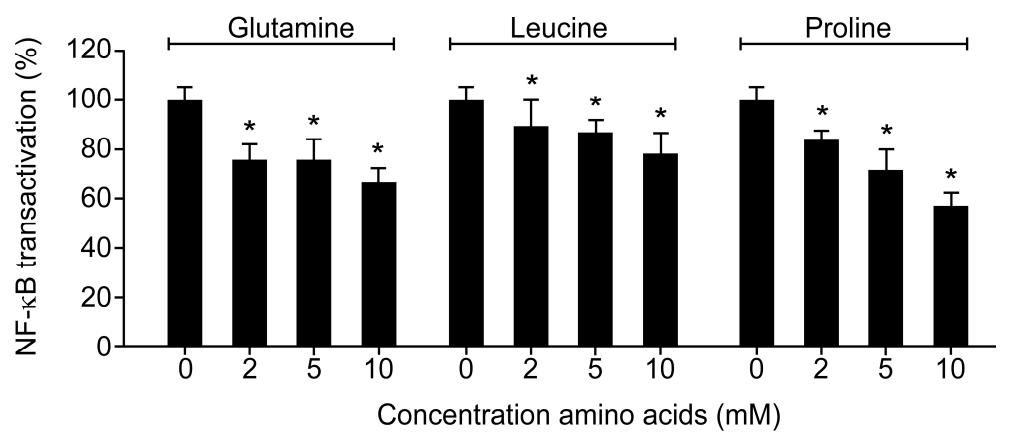

Figure 6.2. Effect of amino acids on NFKB activity, as measured using a NF- $\kappa B$ promoter driven luciferase construct, in HepG2 cells after stimulation with IL-1 $\beta(5 \mathrm{ng} / \mathrm{mL})$ for $3 \mathrm{~h}$. Values are expressed as percentage of control and are presented as means $\pm S D(n=12)$.

*Statistically different from control $(\mathrm{P}<0.05)$.

\section{Effect of amino acids on Akt phosphorylation and GSK-3 $\beta$ phosphorylation}

Glutamine pre-incubation for $24 \mathrm{~h}$ increased basal Akt phosphorylation at $25 \mathrm{mM}$ (Figure 6.3a). In cells treated with both TNF- $\alpha$ and glutamine, Akt phosphorylation was higher than in cells treated with TNF- $\alpha$ alone, but lower than in cells treated 
with only glutamine. Pre-incubation with leucine and proline did not change basal Akt phosphorylation (Figure 6.3b and 6.3c).

As expected, insulin treatment ( $1 \mathrm{nM}$ ) for 5 min increased Akt phosphorylation. Pre-incubation with TNF- $\alpha$ for $24 \mathrm{~h}$ reduced insulin-stimulated phosphorylation of Akt. All three amino acids were able to (partly) restore the TNF- $\alpha$-decreased Akt phosphorylation to the level of Akt phosphorylation in the insulin-stimulated condition without TNF- $\alpha$. The addition of glucose had no effect on Akt phosphorylation in the absence or presence of insulin and TNF- $\alpha$.

Levels of phosphorylated GSK-3 $\beta$ were not changed after insulin stimulation, nor were they affected by amino acid treatment.

\section{Discussion}

In this study, we showed that the amino acids glutamine, leucine and proline may reduce IL-1 $\beta$ stimulated inflammation, probably through inhibition of $N F-\kappa B$, and that they might be able to modulate insulin signalling in the HepG2 liver cell model.

To investigate the effects of these amino acids on inflammation, we studied the production of interleukin 8. IL-8 is a major pro-inflammatory cytokine, which main function is the attraction of leukocytes to the site of infection. IL-8 and other cytokines, such as IL-1, IL- 6 and TNF- $\alpha$, have been found to be elevated in obese subjects [208-210]. In NAFLD patients, circulating levels of IL-8 were increased and correlated with TNF- $\alpha$ and IL-6 concentrations [211]. Moreover, IL- 8 has been associated with the development of atherosclerosis and cardiovascular disease [212]. Adipose tissue is partly responsible for the increased production of these cytokines, but another part of this cytokine production originates from an increased inflammatory response of the liver. We showed that simultaneous incubation of HepG2 cells with amino acids and IL-1 $\beta$ attenuates the production of IL- 8 induced by IL- $1 \beta$. These observations are in agreement with experiments in human intestinal cells, in which several amino acids have also been described to decrease IL-8 production under basal conditions and after stimulation with cytokine mixtures or hydrogen peroxide $[195,198]$. Here we show this inflammation attenuating effect for the first time, to our knowledge, in a liver cell model. 
A

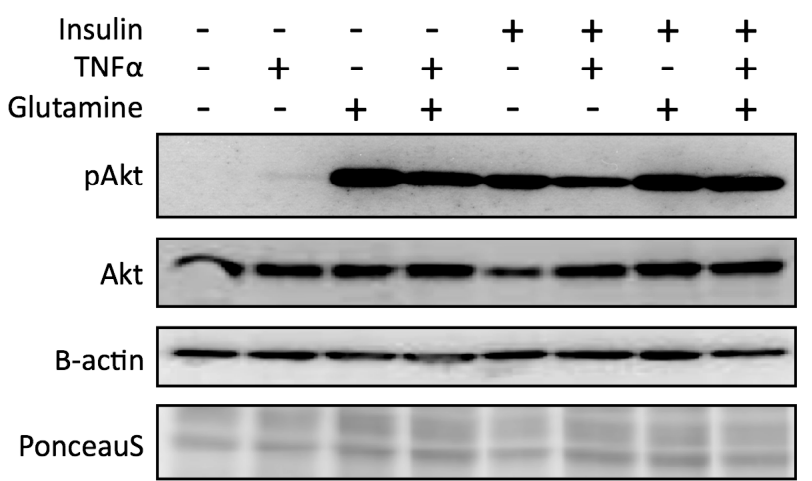

B

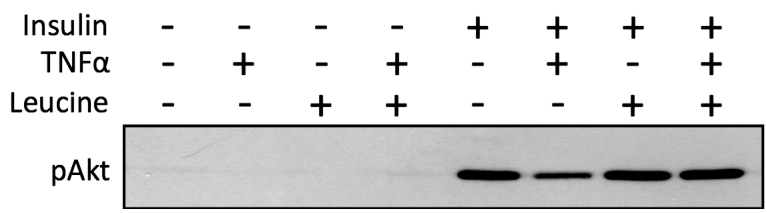

Akt
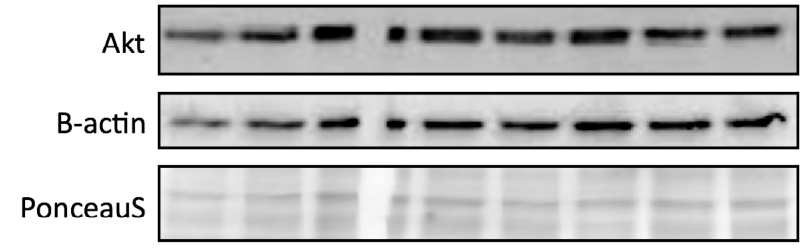

C

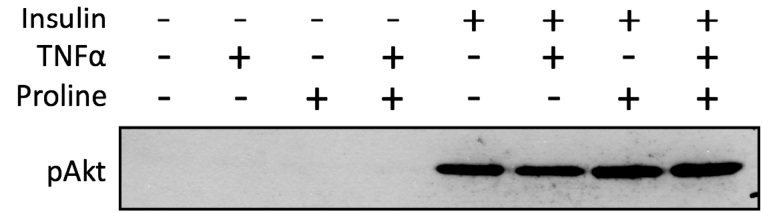

Akt

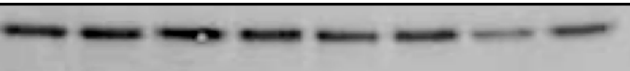

B-actin

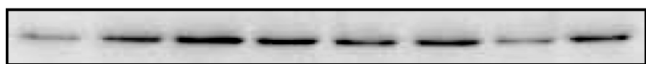

Ponceaus

Figure 6.3. Representative image of the effects of amino acids on Akt phosphorylation in HepG2 cells. Cells were pre-treated with glutamine (A), leucine (B), or proline (C) in absence or presence of TNF- $\alpha$ (10 $\mathrm{ng} / \mathrm{mL}$ ) for $24 \mathrm{~h}$. Cells were then stimulated with insulin $(1 \mathrm{nM})$ for $5 \mathrm{~min}$. 
The production of many pro-inflammatory cytokines, including IL-8, is mainly under control of the transcription factor Nuclear Factor $\kappa B$ (NF- $\kappa B$ ) [213]. Following a proinflammatory stimulus, a signalling cascade is initiated resulting in the translocation of NF- $\mathrm{KB}$ into the nucleus, where it regulates the transcription of its target genes. In our experiments, we found that glutamine, leucine, and proline are all able to significantly reduce the activity of NF- $\kappa B$ induced by IL- $1 \beta$, as measured using a luciferase expression construct driven by the NF- $\kappa B$ promoter. Our results therefore suggest that the inhibition of IL-8 production by these amino acids is mediated through the inhibition of NF-KB transcriptional activity. Hubert-Buron et al. [197], who found a reduction in IL-8 production in human intestinal epithelial cells after glutamine pretreatment, reported a concomitant decrease in ubiquitination of $I \kappa B \alpha$, the cellular inhibitor of $\mathrm{NF}-\mathrm{KB}$. This suggests that amino acids may reduce cytokine production by limiting $I \kappa B$ ubiquitination. However, the exact mechanism behind these effects remains to be unravelled. In summary, our results suggest that it might be of interest to further explore the physiological effects of amino acids and proteins on inflammatory markers.

Furthermore, we studied the effects of amino acids on insulin signalling. Hereto the cells were incubated with TNF- $\alpha$ to induce a state of insulin resistance, as TNF- $\alpha$ has been shown to downregulate IRS-1 and subsequently inhibit the insulin signalling cascade in HepG2 cells [214]. In our experiments, TNF- $\alpha$ indeed reduced insulin stimulated Akt phosphorylation. Addition of glutamine partly abolished this TNF- $\alpha$ induced inhibition. Leucine and proline showed similar effects. These results may imply that these amino acids could (partly) diminish the insulin resistant state induced by TNF- $\alpha$. This could be an important observation for the prevention of metabolic diseases, as these often involve elevated plasma levels of this cytokine. Interestingly, we also observed an increase in Akt phosphorylation after incubation with glutamine alone, without insulin, but not after incubation with leucine or proline only. Amino acids have been shown to downregulate IRS-1, but to upregulate GLUT4 in rat heart tissue [201]. The authors hypothesized that although the expression of IRS-1, the direct downstream substrate of insulin, is reduced, amino acids may stimulate glucose transport and overcome insulin resistance by inducing the expression of GLUT-4 via other routes. However, no data on phosphorylation of IRS-1 or translocation of GLUT-4 were reported and physiological effects are therefore speculative. Our observations also imply that these nutrients may play a role in modulating the insulin signalling pathway and they therefore might be a useful nutrient to consider in the treatment of insulin resistance. Indeed, a high-protein diet may be helpful in controlling blood glucose in type 2 diabetic patients [215]. However, Akt is part of a very complex signalling pathway involving many molecules, and its function may vary from one organ to another. In fact, glucose uptake in the liver, facilitated by GLUT-2, is an insulin- and Akt-independent event [216]. Glycogen syn- 
thesis is a more downstream event in the liver that is dependent on insulin and Akt. Therefore, we also determined the effects of amino acids on levels of phosphorylated GSK-3 $\beta$, the key enzyme in glycogen synthesis. However, we were not able to detect any differences in P-GSK-3 $\beta$ levels after insulin or amino acid treatment. So, although Akt phosphorylation is increased by amino acid treatment, the downstream effects of this phenomenon are not clear. It has also been proposed that a relationship exists between inflammation and insulin resistance. NF- $\kappa B$ is now thought to be involved in the development of obesity- and diet-induced insulin resistance, providing the link between inflammation and insulin resistance $[217,218]$. Our observation that NF- $\mathrm{\kappa B}$ activity is reduced by amino acid treatment could therefore also have implications for insulin sensitivity. In fact, the increased phosphorylation of Akt could also be a result of the NF- $\mathrm{KB}$ suppression exerted by the amino acids. The exact mechanism, as well as the in vivo effects, however, remains to be further investigated.

Taken together, our results indicate that the amino acids glutamine, leucine and proline reduce the production of IL-8 in HepG2 cells, probably by inhibiting NF- $\kappa B$ activity. We also found that these amino acids were able to restore the phosphorylation of Akt after TNF- $\alpha$ treatment, but the physiological consequences of these effects remain to be elucidated. Therefore, further research is necessary to explore the in vivo effects of these amino acids and their possible role in the treatment of metabolic diseases. 



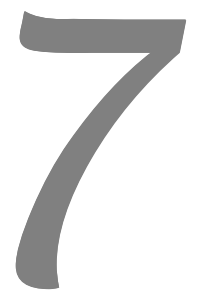

General discussion 


\section{Introduction}

The combination of the metabolic aberrations related to the metabolic syndrome, a growing health problem worldwide, dramatically enhances the risk to develop diabetes and cardiovascular disease, still the leading cause of death in the western world. Dietary changes are important for its prevention and a special role has been suggested for dairy products, since several epidemiological studies have found a negative relation between dairy consumption and the metabolic syndrome and its different components. In the studies described in this thesis, we therefore aimed to increase our understanding into the longer-term and acute effects of dairy consumption on metabolic risk parameters in overweight subjects and the mechanisms behind these effects.

\section{Dairy products: nutrient dense foods}

According to the Dutch Food Consumption Survey, the average daily intake of dairy products in the Netherlands is approximately 400 grams [219]. Milk and milk drinks comprise the largest part of this daily consumption, followed by yogurt, cheese, and desserts. Dairy provides $15 \%$ of total energy and $18 \%$ of total fat intake. Its contribution to saturated fat intake is $29 \%$, which is an important reason to recommend the consumption of reduced-fat dairy products. For total protein consumption, $26 \%$ is comprised by dairy protein, which is, moreover, of high quality. Milk protein has the highest Protein Digestibility Corrected Amino Acid Score (PDCAAS) - a measure of protein quality based on human amino acid needs and protein digestibility - leaving proteins from e.g. egg, beef, soy and wheat behind [220]. Further, milk products supply $68 \%$ of total calcium consumption, as well as substantial amounts of other minerals such as magnesium, copper, zinc and selenium. Its contribution to the intake of B-vitamins is also significant [219]. So, dairy products are an important source for a large variety of essential nutrients. Since they additionally provide relatively little energy, dairy products are considered as nutrient-dense food products.

The Netherlands Nutrition Centre (Voedingscentrum) advises adults to consume $450 \mathrm{~mL}$ milk (products) and $30 \mathrm{~g}$ cheese per day, mainly to meet the daily requirements for calcium (1000-1200 mg for adults). Calcium, in combination with vitamin $D$, and possibly with other nutrients from milk, is needed to obtain and maintain good bone health $[221,222]$. Further, calcium and dairy consumption are associated with a lower risk of colon cancer [223]. In contrast, calcium is thought to increase the risk of prostate cancer at high intakes (>2000 mg/d) [224]. Consumption of milk and milk products is therefore an easy way to meet the body's needs for calcium and other nutrients. Due to their high nutrient density, low-fat dairy products do - 
for most people - fit well within a balanced, healthy diet. Some people, however, suffer from lactose intolerance; a deficiency in the enzyme lactase that leads to maldigestion of lactose and subsequent gastro-intestinal discomfort. While around $75 \%$ of the total world adult population has a decreased ability to digest lactose, only $<5 \%$ of the Northern European population is lactose intolerant. However, for most people with lactose intolerance, consumption of small amounts of dairy does not cause problems [225]. Especially cheese, which contains little lactose, or fermented products such as yogurt, are well tolerated [226]. Cow's milk allergy, in which milk proteins cause an allergic reaction, is another possible problem with dairy consumption. This condition is present in only $<5 \%$ of the European population, mainly in toddlers who outgrow the allergy when they get older.

\section{Long-term effects of dairy intake}

Several cross-sectional and prospective cohort studies have reported a negative correlation between dairy consumption and the development of the metabolic syndrome or its components [36-40,43,44], whereas others have not [41,42]. Though some studies have evaluated individual products [40,43], the majority of studies have considered dairy products as one food group, mostly including milk, yogurt, and cheese [36-39, 44]. The objective of our first trial was to evaluate the longerterm effects of dairy consumption in an intervention study. Overweight subjects were therefore studied for two periods of 8 weeks, in which they either consumed low-fat dairy products or control products. In the dairy intervention, subjects consumed $500 \mathrm{~mL}$ of low-fat milk and $150 \mathrm{~g}$ of low-fat yogurt daily. In the control period, they received fruit juice and fruit biscuits, since subjects who do not or hardly consume dairy products are likely to use carbohydrate-rich products like these instead.

\section{Lipid metabolism}

After 8 weeks of low-fat dairy consumption, there were no differences in total and LDL-cholesterol, but HDL-cholesterol was decreased by $0.04 \mathrm{mmol} / \mathrm{L}$ (chapter 3 ). This decrease was accompanied by a reduction in apoA- 1 concentrations of $0.04 \mathrm{~g} / \mathrm{L}$ and a reduction in HDL particle number of $1.07 \mu \mathrm{mol} / \mathrm{L}$. In a recent trial by Wennersberg et al., middle-aged subjects in Finland, Norway and Sweden with traits of the metabolic syndrome consumed 3-5 portions of dairy products daily [150]. Subjects in the control group maintained their habitual diet. Because dairy products did not replace other food products, energy intake tended to be higher in the milk group, although not statistically significant. After 6 months, a small increase in total cholesterol was found, while changes in LDL and HDL-cholesterol were not statisti- 
cally different between the groups. This increase was mainly seen in the Swedish group, and a statistically significant raise in apoB concentrations was only observed in this group. The Swedish subjects had the largest increase in milk fat intake, because they consumed higher-fat products than the Norwegian and Finnish participants. Their saturated fat intake was raised by $13 \mathrm{~g}$ (5.5 En\%), which was a larger increase than in our intervention ( $4.7 \mathrm{~g}$ or $2.1 \mathrm{En} \%)$.

In our trial, total fat intake was increased by $3.2 \mathrm{En} \%$, saturated fatty acid intake by $2.1 \mathrm{En} \%$, and monounsaturated fatty acid intake by $1.1 \mathrm{En} \%$. It can be estimated that these changes, although small, would have caused an increase of $0.07 \mathrm{mmol} / \mathrm{L}$ in serum total cholesterol, $0.06 \mathrm{mmol} / \mathrm{L}$ in $\mathrm{LDL}$-cholesterol, and $0.03 \mathrm{mmol} / \mathrm{L}$ in $\mathrm{HDL}$ cholesterol [117]. Besides fat and fatty acids, other dairy components may also affect the serum lipid profile. Studies on calcium supplementation have mostly shown reduced concentrations of total and LDL-cholesterol $[49-51,53]$. One study has also reported an increased concentration of HDL-cholesterol [49]. However, we did not find changes in total and LDL-cholesterol, while HDL-cholesterol even decreased. Effects of protein, another major dairy constituent, are not consistent. Krauss et al. have reported increased concentrations of LDL- and HDL-cholesterol [78], whereas Appel et al. have found decreased concentrations of these parameters when a highprotein diet was compared with a high-carbohydrate diet [80]. Both investigators, however, observed a reduced total to HDL-cholesterol ratio when protein intake was increased. Our observation that HDL-cholesterol was reduced by milk consumption may be a result of the exchange of carbohydrate for protein intake, as suggested by the findings from the OmniHeart trial [80].

Further, it has been hypothesized that the matrix of dairy products may influence the response to single constituents, such as fat [227]. A number of intervention studies showed different effects of fat from different dairy products on serum lipid profiles [104-106]. Especially cheese seems to raise LDL-cholesterol less when compared with butter. Differences in calcium content could only partly explain the results. The different packaging of lipid globules in cheese, milk and butter may also be involved, but its influence on fat absorption and metabolism is not yet known. Further, there may be a role for fermentation [228]. Bacteria from fermented products can convert carbohydrates into short chain fatty acids (SCFA) in the colon. An altered intestinal SCFA composition may be reflected in serum SCFA patterns, which might alter cholesterol synthesis $[229,230]$. However, the role of SCFA in cholesterol synthesis and the role of fermented dairy products on serum SCFA concentrations are uncertain. In our study, we used milk and yogurt and the effects of fermentation may thus apply in part of our products. Our results might have been slightly different when other dairy products, e.g. cheese, would have been used, if matrix effects do play a part. Taken these possible effects of the matrix into account, it seems important to study products or meals in addition to single nutrients. While studies on single components contribute to a better mechanistic understanding than studies 
on products, the latter provides more information on the physiological effects in the everyday situation.

\section{Glucose metabolism}

We observed no effects of dairy consumption on fasting glucose or insulin concentrations (chapter 3). The use of fasting concentrations as markers of glucose metabolism and insulin sensitivity is sometimes questioned, since postprandial hyperglycemia is thought to be particularly harmful and may occur before the increase in fasting glucose concentrations is present [231]. Nevertheless, impaired fasting glucose (IFG) and impaired glucose tolerance (IGT) often occur together and fasting hyperglycemia predicts postprandial glucose excursions [162]. To obtain detailed information on glucose profiles throughout the day, we also measured glucose concentrations by a continuous glucose monitoring system (CGMS) in a subgroup of 12 subjects. A glucose sensor, inserted into the subcutaneous adipose tissue of the abdominal region, measured glucose concentrations every 5 min during two days in the last week of each experimental period. From these data, iAUC above several cut off points were calculated during 48 hours. However, the use of these CGMS devices did not reveal any effects of dairy consumption on daylong glucose profiles.

In our in vitro experiments described in chapter $\mathbf{6}$, we showed that the addition of glutamine, leucine, and proline - the amino acids most abundantly present in dairy products - to the culture media of HepG2 liver cells may restore the phosphorylation of Akt after TNF- $\alpha$ treatment. Increased concentrations of inflammatory cytokines have been associated with obesity and the metabolic syndrome, and TNF- $\alpha$ have been shown to induce insulin resistance in these liver cells. In these conditions, amino acids might therefore overcome the TNF- $\alpha$ induced insulin resistance by rescuing P-Akt in the liver. Postprandial effects of several amino acids on glucose and insulin concentrations have been studied in vivo. Lysine [188], proline [189], glycine [190] and arginine [191] reduced glucose concentrations without affecting insulin, whereas leucine [192] and phenylalanine [193] caused a decrease in glucose and a concomitant decrease in insulin concentrations. In the longer term, a high-protein diet was helpful in controlling blood glucose concentrations in type 2 diabetic subjects [215]. However, more information on the longer-term in vivo effects of specific amino acids on glucose and insulin metabolism is needed.

\section{Inflammation}

After 8 weeks of dairy consumption, we observed a significant increase in s-TNFR-2, and a trend towards increased S-TNFR-1 and decreased TNF- $\alpha$ concentrations (chapter 4). Although the role of soluble TNF- $\alpha$ receptors is not fully understood, it has been postulated that they bind TNF- $\alpha$ to inhibit its function. Together with the 
reduction in TNF- $\alpha$ concentrations, the increase in these receptors may imply an overall suppression of the TNF- $\alpha$ pathway. However, the physiological effects require further study. Other markers of inflammation and endothelial dysfunction, such as MCP-1, IL-6, s-ICAM, and s-VCAM, were unaffected by dairy consumption. Wennersberg et al. found no effects on inflammatory (IL-6, TNF- $\alpha$, CRP) and endothelial markers (E-selectin, VCAM-1, vWF) after 6 months of dairy intake [150]. In contrast, Zemel et al. observed reductions in TNF- $\alpha$ and IL- 6 concentrations in mice fed a high-dairy diet [111]. In human subjects, increased concentrations of adiponectin and decreased concentrations of CRP were found after 4 weeks of high dairy consumption by retrospective analysis of archived samples. However, effects of an improved body composition could not be excluded. In a recent trial, the effects of a dairy-rich diet on inflammatory stress were compared with those of a soysupplemented diet in the absence of adiposity changes [156]. The dairysupplemented diet improved the inflammatory profile by suppression of TNF- $\alpha$, IL- 6 and MCP-1, and induction of adiponectin after 4 weeks. The authors suggested that these effects may be due to a suppression of plasma $1,25-(\mathrm{OH})_{2}-\mathrm{D}_{3}$. In our study, plasma concentrations of $1,25-(\mathrm{OH})_{2}-\mathrm{D}_{3}$ were also reduced by dairy consumption, but no effects on inflammatory parameters were found. Another hypothesis is that leucine, highly present in dairy, stimulates sirtuin 1 (Sirt1), which in turn suppresses NF- $\kappa B$ and thereby attenuates inflammatory stress [156]. Taken together, effects of dairy products on inflammatory parameters are controversial and warrant further study.

In our in vitro experiments, we also found that there may be a role for amino acids in modulating inflammatory processes (chapter 6). Glutamine, leucine and proline reduced IL-8 production in liver cells. NF- $\kappa B$ activity was also inhibited by the addition of these amino acids. Unfortunately, since other cytokines in our experiments were below detection limits, no conclusions on other inflammatory proteins, such as IL- 6 and TNF- $\alpha$ can be drawn. Nonetheless, IL- 8 is strongly associated with atherosclerosis and cardiovascular diseases, and reducing the production of this cytokine may be an important target to lower cardiovascular risk. However, more research is needed to explore the in vivo effects of amino acid consumption and their possible role in regulating inflammatory processes.

\section{Blood pressure}

The statistically significant effect of 8-week dairy consumption was a $2.9-\mathrm{mmHg}$ reduction in systolic blood pressure (chapter 3 ). This reduction may have implications for cardiovascular health, since it could substantially reduce the risk of stroke [232, 233]. An association between dairy intake and lower blood pressure has been shown in numerous observational studies [41, 234-236]. In intervention studies, such as the DASH-trial [59], comparing a diet high in fruits, vegetables and dairy 
products with a diet high in fruit and vegetables alone, comparable effects of dairy consumption on blood pressure were observed. Calcium intake has been associated with blood pressure reductions and calcium might therefore be an important dairy component in blood pressure regulation. A recent meta-analysis showed that calcium supplementation (mean dose $1200 \mathrm{mg} / \mathrm{d}$ ) reduced systolic BP by $1.9 \mathrm{mmHg}$ and diastolic BP by $1.0 \mathrm{mmHg}$, with larger reductions found in subjects with low habitual calcium intakes [73]. The reduction in 1,25-(OH) $)_{2}-\mathrm{D}_{3}$ following increased calcium intake might be involved in this process [237]. However, the exchange of carbohydrates for protein may also have contributed to the antihypertensive effects of dairy consumption, since both protein and fat have been reported to lower blood pressure when compared with carbohydrates [80]. In addition, it has been hypothesized that bioactive peptides derived from milk proteins may reduce blood pressure by inhibiting ACE enzyme activity. However, human studies do currently not provide unequivocal evidence that ACE inhibitory proteins from dairy lower blood pressure.

\section{Conclusions on long-term effects of dairy intake}

The results from our 8-week crossover study show that consumption of low-fat dairy products, compared with carbohydrate-rich control products, reduced systolic blood pressure. Further, it reduced HDL-cholesterol and apoA-1 concentrations. It also affected the TNF- $\alpha$ pathway by increasing s-TNFR-2 concentrations, while we observed a trend towards increased s-TNFR-1 and decreased TNF- $\alpha$ concentrations. The physiological consequences of these last observations are not clear. Overall, 8 weeks consumption of $500 \mathrm{~mL}$ low-fat milk and $150 \mathrm{~g}$ low-fat yogurt per day decreased systolic blood pressure, but did not have beneficial effects on other metabolic risk markers in overweight and obese subjects. Whether these effects can be translated to other forms of dairy products, to other quantities, or to other populations remains to be elucidated.

\section{Acute effects of dairy intake}

Besides the longer-terms effects, we were also interested in the short-term postprandial effects of dairy products. Postprandial hyperlipidemia and hyperglycemia have been considered as risk factors for CVD. Managing these factors may be an alternative strategy to reduce CVD risk, as people in Western countries are in the postprandial state for most of the day. Postprandial hyperlipidemia and hyperglycemia are frequently seen in subjects with the metabolic syndrome. In this postprandial study, we investigated the effects of the addition of milk to a high-fat meal. To elucidate which of the components from milk might be involved in its postprandial effects, we also added milk calcium and milk protein to a high-fat meal. The 
meals contained approximately $40 \mathrm{~g}$ fat. After consumption of this amount of fat, a substantial triglyceride response is expected [166], while the meal remains palatable.

\section{Lipid metabolism}

As described in chapter $\mathbf{5}$, the addition of milk and protein increased the postprandial TAG iAUC when compared to control, whereas the addition of calcium did not change the TAG response. Other studies have shown ambiguous effects of protein intake on lipid responses. Casein per se did not modulate the TAG iAUC in healthy subjects $[173,178]$ and type 2 diabetics [177]. However, a reduction and delay in the TAG peak was found when casein was added to a high-fat meal [175], whereas an elevated TAG peak was observed when egg white protein was ingested with a fat-rich meal [179]. When casein was ingested in combination with carbohydrates as well as fat, it was found to reduce the TAG response in the chylomicron-rich fraction in healthy [173] and diabetic subjects [177]. Both investigators suggested that an increased insulin response might account for the reduction in TAG. We did also observe an increased insulin response after the milk meal, but this did not lead to a decreased TAG response. It should be noted, however, that not only the amount of protein used in those trials was substantially higher compared with the meals in our study, but also the amount of fat. Further, while dairy calcium was previously found to reduce postprandial TAG responses [57], we did not observe such an effect. Although the meals contained large amounts of SFA (mainly C14:0, C16:0, and C18:0), which are thought to bind to calcium as described in chapter 2 , calcium did not affect serum TAG.

Despite the increased insulin response, no differences in FFA concentrations were observed. This finding is in line with Brader's observations in diabetic subjects, who also showed an increased insulin response when protein was added to the meal, while there were no differences in FFA AUC [177]. Westphal et al., however, did find a significant decrease in FFA IAUC after casein consumption and the authors postulated that the insulinotropic action of casein is responsible for this effect [173]. In their other postprandial trial, FFA responses were suppressed when casein or soy protein was added to a high-fat meal [175]. However, insulin concentrations were only modestly increased, since the meals did not contain carbohydrates.

\section{Glucose metabolism}

Although the amount and composition of the protein was similar in the milk and the protein meal, the insulin responses were different (chapter 5). The insulin iAUC after the milk meal was $35 \%$ higher when compared to control, whereas the iAUC was not different after the protein meal. The protein content and amino acid composi- 
tion of the milk and protein drinks were similar. Also, plasma amino acid analysis revealed that amino acid concentrations after these drinks were comparable, but different from the control and calcium drinks, which does not suggest that the absorption of amino acids from the milk and protein meal were different. The iAUC for glucose was not affected by protein or milk, but the maximal increases in glucose concentrations were decreased by both drinks compared with the control drink. This observation might be related to the increased concentrations of amino acids, since some amino acids have been found to reduce glucose concentrations even in the absence of an elevated insulin response as described earlier. In our in vitro experiments, we did observe a role for glutamine, leucine, and proline in insulin signalling. The results from these experiments may suggest that amino acids could restore the effects of insulin in a situation of reduced insulin sensitivity. However, the in vivo effects of amino acids, especially in combination with other nutrients, have to be further examined.

\section{Conclusions on acute effects of dairy intake}

The results of our study on postprandial responses after milk and milk constituent intake show that milk and protein increased the postprandial TAG response after a high-fat mixed meal. Further, milk and protein ingestion reduced the maximal increase in glucose concentration, which may be related to increases in plasma amino acid concentrations. Plasma FFA were unchanged, although insulin concentrations were elevated after the milk meal. Calcium did not have effects on postprandial responses. So, addition of $500 \mathrm{~mL}$ low-fat milk to a mixed meal has ambiguous effects on postprandial metabolic risk profiles in overweight subjects, as it decreased glucose concentrations but increased TAG concentrations. For a more complete picture, however, other metabolic risk factors, such as inflammatory markers, should be taken into account.

\section{Methodological considerations}

Although observational studies have reported an inverse association between dairy intake and the metabolic syndrome, they do not provide evidence for a causal relationship. Our intervention studies, however, could not confirm the hypotheses raised by these epidemiological studies. Metabolic health status is the result of a very complex interplay between many factors and the association with nutrition may be subtle. Though in epidemiological research many factors were taken into account, there may always be some unknown confounders.

Overweight subjects often display one or more metabolic disturbances, such as insulin resistance, dyslipidemia, chronic low-grade inflammation, or hypertension. 
They are at increased risk of developing metabolic disorders and eventually the metabolic syndrome. It should be noted that the observed effects may only apply to overweight and obese subjects. It is, however, not likely that dairy consumption would have had a larger impact on metabolic health in lean subjects. It could be speculated that dairy intake above a certain level does not have additional effects. Therefore, a low habitual dairy intake $(<500 \mathrm{~g} / \mathrm{d}$ of milk, yogurt plus cheese products) was one of the inclusion criteria so that only subjects with a low habitual dairy intake were enrolled in the study. Further, the study duration of 8 weeks should have been long enough to establish diet-induced changes in plasma parameters, such as lipoproteins [238]. However, if changes in plasma parameters would be a consequence of changes in body composition, a period of 8 weeks might have been too short to induce such alterations. While fasting concentrations of risk parameters were hardly affected by 8 weeks of dairy consumption, it is possible that postprandial responses would have been altered after a period of low-fat dairy intake. On the other hand, the results in our postprandial trial might have been different if subjects would have consumed milk or milk constituents for a certain period preceding the postprandial tests. To ensure whether longer-term dairy consumption is intertwined with postprandial effects, a study combining a long-term dairy intervention with a postprandial challenge is recommended.

A potential problem with trials in free-living subjects is that study conditions cannot be fully controlled. Subjects were carefully instructed not to change their habitual diet, use of medication or physical activity during the interventions, but we had to rely on the subjects' self-reported acquiescence. Regarding dietary compliance, a strength of our longer-term study is that $1,25-(\mathrm{OH})_{2}-\mathrm{D}_{3}$ was used as a compliance marker, so that we were not fully dependent on dietary records and products returned. Conditions in our postprandial study were easier to control - at least during the test days.

\section{General conclusions}

The results described in this thesis do not fully support the findings from observational research, which indicated a negative relation between dairy intake and the metabolic syndrome. Our first intervention study showed a beneficial reduction in systolic blood pressure, but also a reduction in HDL-cholesterol after daily consumption of $500 \mathrm{~mL}$ low-fat milk and $150 \mathrm{~g}$ low-fat yogurt for 8 weeks. Further, dairy consumption seemed to influence the TNF- $\alpha$ pathway. Our in vitro experiments suggested a beneficial role for amino acids in insulin sensitivity, but this could not be concluded from glucose and insulin concentrations in fasting plasma samples from our 8-week intervention study. Although our subjects were overweight and obese, they were otherwise healthy. It remains therefore to be elucidated to what extent 
these findings can be extended to less insulin-sensitive subjects. Our acute postprandial study did however show that low-fat milk, consumed with a high-fat meal, reduced the postprandial rise in plasma glucose. At the same time, however, it increased the insulin and triglyceride response postprandially. The protein fraction of the milk seemed to be mainly accountable for these effects. Future studies should reveal to what extent these effects can be translated to other forms of dairy products, to other quantities, or to other populations. 

REFERENCES 
1. Kylin E. Studien über das Hypertonie-Hyperglykamie-Hyperurikamiesyndrom. Zentralblatt für Innere Medizin 1923; 44: 105-127.

2. DeFronzo RA and Ferrannini E. Insulin resistance. A multifaceted syndrome responsible for NIDDM, obesity, hypertension, dyslipidemia, and atherosclerotic cardiovascular disease. Diabetes Care 1991; 14(3): 173-94.

3. Reaven GM. Banting lecture 1988. Role of insulin resistance in human disease. Diabetes 1988; 37(12): 1595-607.

4. Kaplan NM. The deadly quartet. Upper-body obesity, glucose intolerance, hypertriglyceridemia, and hypertension. Arch Intern Med 1989; 149(7): 1514-20.

5. Grundy SM, Hansen B, Smith SC, Jr., et al. Clinical management of metabolic syndrome: report of the American Heart Association/National Heart, Lung, and Blood Institute/American Diabetes Association conference on scientific issues related to management. Circulation 2004; 109(4): 551-6.

6. Zimmet P, Alberti KG, and Shaw J. Global and societal implications of the diabetes epidemic. Nature 2001; 414(6865): 782-7.

7. Cameron AJ, Shaw JE, and Zimmet PZ. The metabolic syndrome: prevalence in worldwide populations. Endocrinol Metab Clin North Am 2004; 33(2): 351-75, table of contents.

8. Bos $\mathrm{MB}$, de Vries JH, Wolffenbuttel $\mathrm{BH}$, et al. [The prevalence of the metabolic syndrome in the Netherlands: increased risk of cardiovascular diseases and diabetes mellitus type 2 in one quarter of persons under 60]. Ned Tijdschr Geneeskd 2007; 151(43): 2382-8.

9. van den Donk M, Bobbink IW, Gorter KJ, et al. Identifying people with metabolic syndrome in primary care by screening with a mailed tape measure. A survey in 14,000 people in the Netherlands. Prev Med 2009.

10. Weiss R, Dziura J, Burgert TS, et al. Obesity and the metabolic syndrome in children and adolescents. N Engl J Med 2004; 350(23): 2362-74.

11. Alberti KG and Zimmet PZ. Definition, diagnosis and classification of diabetes mellitus and its complications. Part 1: diagnosis and classification of diabetes mellitus provisional report of a WHO consultation. Diabet Med 1998; 15(7): 539-53.

12. Balkau B and Charles MA. Comment on the provisional report from the WHO consultation. European Group for the Study of Insulin Resistance (EGIR). Diabet Med 1999; 16(5): 442-3.

13. Grundy SM, Brewer HB, Jr., Cleeman JI, et al. Definition of metabolic syndrome: Report of the National Heart, Lung, and Blood Institute/American Heart Association conference on scientific issues related to definition. Circulation 2004; 109(3): 433-8.

14. Zimmet $P$, Magliano D, Matsuzawa $Y$, et al. The metabolic syndrome: a global public health problem and a new definition. J Atheroscler Thromb 2005; 12(6): 295-300.

15. Meigs JB. Definitions and mechanisms of the metabolic syndrome. Curr Opin Endocrinol Diabetes 2006; 13: 103-110.

16. Kershaw EE and Flier JS. Adipose tissue as an endocrine organ. J Clin Endocrinol Metab 2004; 89(6): 2548-56.

17. Boden G. Obesity and free fatty acids. Endocrinol Metab Clin North Am 2008; 37(3): 635-46, viii-ix.

18. Lionetti L, Mollica MP, Lombardi A, et al. From chronic overnutrition to insulin resistance: the role of fat-storing capacity and inflammation. Nutr Metab Cardiovasc Dis 2009; 19(2): 146-52.

19. Abbasi F, Brown BW, Jr., Lamendola C, et al. Relationship between obesity, insulin resistance, and coronary heart disease risk. J Am Coll Cardiol 2002; 40(5): 937-43.

20. de Ferranti $S$ and Mozaffarian D. The perfect storm: obesity, adipocyte dysfunction, and metabolic consequences. Clin Chem 2008; 54(6): 945-55.

21. Funahashi T and Matsuzawa Y. Metabolic syndrome: clinical concept and molecular basis. Ann Med 2007; 39(7): 482-94.

22. Kraegen EW and Cooney GJ. Free fatty acids and skeletal muscle insulin resistance. Curr Opin Lipidol 2008; 19(3): 235-41.

23. Semenkovich CF. Insulin resistance and atherosclerosis. J Clin Invest 2006; 116(7): 1813-22. 
24. Therond P. Catabolism of lipoproteins and metabolic syndrome. Curr Opin Clin Nutr Metab Care 2009; 12(4): 366-71.

25. Huang PL. A comprehensive definition for metabolic syndrome. Dis Model Mech 2009; 2(5-6): 2317.

26. Wang $\mathrm{H}$ and Eckel $\mathrm{RH}$. Lipoprotein lipase: from gene to obesity. Am J Physiol Endocrinol Metab 2009; 297(2): E271-88.

27. Krauss RM. Dense low density lipoproteins and coronary artery disease. Am J Cardiol 1995; 75(6): 53B-57B.

28. Packard CJ. LDL subfractions and atherogenicity: an hypothesis from the University of Glasgow. Curr Med Res Opin 1996; 13(7): 379-90.

29. Sutherland JP, McKinley B, and Eckel RH. The metabolic syndrome and inflammation. Metab Syndr Relat Disord 2004; 2(2): 82-104.

30. Danesh J, Collins R, Appleby P, et al. Association of fibrinogen, C-reactive protein, albumin, or leukocyte count with coronary heart disease: meta-analyses of prospective studies. Jama 1998; 279(18): 1477-82.

31. Zou C and Shao J. Role of adipocytokines in obesity-associated insulin resistance. J Nutr Biochem 2008; 19(5): 277-86.

32. Ross R. Atherosclerosis--an inflammatory disease. N Engl J Med 1999; 340(2): 115-26.

33. Deen D. Metabolic syndrome: time for action. Am Fam Physician 2004; 69(12): 2875-82.

34. Eckel RH, Grundy SM, and Zimmet PZ. The metabolic syndrome. Lancet 2005; 365(9468): 1415-28.

35. Balkau B, Vernay M, Mhamdi L, et al. The incidence and persistence of the NCEP (National Cholesterol Education Program) metabolic syndrome. The French D.E.S.I.R. study. Diabetes Metab 2003; 29(5): 526-32.

36. Mennen LI, Lafay L, Feskens EJM, et al. Possible protective effect of bread and dairy products on the risk of the metabolic syndrome. Nutr Res 2000; 20(3): 335-347.

37. Azadbakht L, Mirmiran P, Esmaillzadeh A, et al. Dairy consumption is inversely associated with the prevalence of the metabolic syndrome in Tehranian adults. Am J Clin Nutr 2005; 82(3): 523-30.

38. Elwood PC, Pickering JE, and Fehily AM. Milk and dairy consumption, diabetes and the metabolic syndrome: the Caerphilly prospective study. J Epidemiol Community Health 2007; 61(8): 695-8.

39. Ruidavets JB, Bongard V, Dallongeville J, et al. High consumptions of grain, fish, dairy products and combinations of these are associated with a low prevalence of metabolic syndrome. J Epidemiol Community Health 2007; 61(9): 810-7.

40. Beydoun MA, Gary TL, Caballero BH, et al. Ethnic differences in dairy and related nutrient consumption among US adults and their association with obesity, central obesity, and the metabolic syndrome. Am J Clin Nutr 2008; 87(6): 1914-25.

41. Snijder MB, van der Heijden AA, van Dam RM, et al. Is higher dairy consumption associated with lower body weight and fewer metabolic disturbances? The Hoorn Study. Am J Clin Nutr 2007; 85(4): 989-95.

42. Snijder $M B$, van Dam RM, Stehouwer $C D$, et al. A prospective study of dairy consumption in relation to changes in metabolic risk factors: the Hoorn Study. Obesity (Silver Spring) 2008; 16(3): 706-9.

43. Pereira MA, Jacobs DR, Jr., Van Horn L, et al. Dairy consumption, obesity, and the insulin resistance syndrome in young adults: the CARDIA Study. JAMA 2002; 287(16): 2081-9.

44. Lutsey PL, Steffen LM, and Stevens J. Dietary intake and the development of the metabolic syndrome: the Atherosclerosis Risk in Communities study. Circulation 2008; 117(6): 754-61.

45. Fleming KH and Heimbach JT. Consumption of calcium in the U.S.: food sources and intake levels. J Nutr 1994; 124(8 Suppl): 1426S-1430S.

46. Hulshof KFAM, Ocké MC, van Rossum CTM, et al. Results of the national food consumption survey 2003. 2004.

47. Drouillet $\mathrm{P}$, Balkau B, Charles MA, et al. Calcium consumption and insulin resistance syndrome parameters. Data from the Epidemiological Study on the Insulin Resistance Syndrome (DESIR). Nutr Metab Cardiovasc Dis 2007; 17(7): 486-92. 
48. Liu S, Song $Y$, Ford ES, et al. Dietary calcium, vitamin $D$, and the prevalence of metabolic syndrome in middle-aged and older U.S. women. Diabetes Care 2005; 28(12): 2926-32.

49. Reid IR, Mason B, Horne A, et al. Effects of calcium supplementation on serum lipid concentrations in normal older women: a randomized controlled trial. Am J Med 2002; 112(5): 343-7.

50. Ditscheid B, Keller $\mathrm{S}$, and Jahreis $\mathrm{G}$. Cholesterol metabolism is affected by calcium phosphate supplementation in humans. J Nutr 2005; 135(7): 1678-82.

51. Shahkhalili Y, Murset C, Meirim I, et al. Calcium supplementation of chocolate: effect on cocoa butter digestibility and blood lipids in humans. Am J Clin Nutr 2001; 73(2): 246-52.

52. Bostick RM, Fosdick L, Grandits GA, et al. Effect of calcium supplementation on serum cholesterol and blood pressure. A randomized, double-blind, placebo-controlled, clinical trial. Arch Fam Med 2000; 9(1): 31-8; discussion 39.

53. Denke MA, Fox MM, and Schulte MC. Short-term dietary calcium fortification increases fecal saturated fat content and reduces serum lipids in men. J Nutr 1993; 123(6): 1047-53.

54. Govers MJ, Termont DS, Lapre JA, et al. Calcium in milk products precipitates intestinal fatty acids and secondary bile acids and thus inhibits colonic cytotoxicity in humans. Cancer Res 1996; 56(14): 3270-5.

55. Jacobsen R, Lorenzen JK, Toubro S, et al. Effect of short-term high dietary calcium intake on 24-h energy expenditure, fat oxidation, and fecal fat excretion. Int J Obes (Lond) 2005; 29(3): 292-301.

56. Boon N, Hul GB, Stegen JH, et al. An intervention study of the effects of calcium intake on faecal fat excretion, energy metabolism and adipose tissue mRNA expression of lipid-metabolism related proteins. Int J Obes (Lond) 2007; 31(11): 1704-12.

57. Lorenzen JK, Nielsen S, Holst JJ, et al. Effect of dairy calcium or supplementary calcium intake on postprandial fat metabolism, appetite, and subsequent energy intake. Am J Clin Nutr 2007; 85(3): 678-87.

58. Zemel MB, Richards J, Milstead A, et al. Effects of calcium and dairy on body composition and weight loss in African-American adults. Obes Res 2005; 13(7): 1218-25.

59. Appel L, Moore TJ, Obarzanek E, et al. A clinical trial of the effects of dietary patterns on blood pressure. DASH Collaborative Research Group. N Engl J Med 1997; 336(16): 1117-24.

60. Zemel MB, Richards J, Mathis S, et al. Dairy augmentation of total and central fat loss in obese subjects. Int J Obes 2005; 29(4): 391-7.

61. Zemel MB, Thompson $\mathrm{W}$, Milstead A, et al. Calcium and dairy acceleration of weight and fat loss during energy restriction in obese adults. Obes Res 2004; 12(4): 582-90.

62. Fernandez ML and West KL. Mechanisms by which dietary fatty acids modulate plasma lipids. J Nutr 2005; 135(9): 2075-8.

63. Kerstetter JE, O'Brien KO, and Insogna KL. Dietary protein affects intestinal calcium absorption. Am J Clin Nutr 1998; 68(4): 859-65.

64. Van der Meer R, Welberg JW, Kuipers F, et al. Effects of supplemental dietary calcium on the intestinal association of calcium, phosphate, and bile acids. Gastroenterology 1990; 99(6): 1653-9.

65. Zemel MB. Mechanisms of dairy modulation of adiposity. J Nutr 2003; 133(1): 252S-256S.

66. Lanou AJ and Barnard ND. Dairy and weight loss hypothesis: an evaluation of the clinical trials. Nutr Rev 2008; 66(5): 272-9.

67. Boon N, Koppes LL, Saris WH, et al. The relation between calcium intake and body composition in a Dutch population: The Amsterdam Growth and Health Longitudinal Study. Am J Epidemiol 2005; 162(1): 27-32.

68. Zemel MB. Role of dietary calcium and dairy products in modulating adiposity. Lipids 2003; 38(2): 139-46.

69. Zemel MB, Shi H, Greer B, et al. Regulation of adiposity by dietary calcium. Faseb J 2000; 14(9): 1132-8.

70. Boon N, Hul GB, Viguerie N, et al. Effects of 3 diets with various calcium contents on 24-h energy expenditure, fat oxidation, and adipose tissue message RNA expression of lipid metabolism-related proteins. Am J Clin Nutr 2005; 82(6): 1244-52. 
71. Boon N, Goossens $\mathrm{GH}$, Blaak EE, et al. The effects of hydralazine on lipolysis in subcutaneous adipose tissue in humans. Metabolism 2007; 56(12): 1742-8.

72. Bucher HC, Cook RJ, Guyatt GH, et al. Effects of dietary calcium supplementation on blood pressure. A meta-analysis of randomized controlled trials. Jama 1996; 275(13): 1016-22.

73. van Mierlo LA, Arends LR, Streppel MT, et al. Blood pressure response to calcium supplementation: a meta-analysis of randomized controlled trials. J Hum Hypertens 2006; 20(8): 571-80.

74. Hatton DC and McCarron DA. Dietary calcium and blood pressure in experimental models of hypertension. A review. Hypertension 1994; 23(4): 513-30.

75. Zemel MB. Calcium modulation of hypertension and obesity: mechanisms and implications. J Am Coll Nutr 2001; 20(5 Suppl): 428S-435S; discussion 440S-442S.

76. Bian K, Ishibashi $\mathrm{K}$, and Bukoski RD. 1,25(OH)2D3 modulates intracellular $\mathrm{Ca} 2+$ and force generation in resistance arteries. Am J Physiol 1996; 270(1 Pt 2): H230-7.

77. Kristal-Boneh E, Froom P, Harari G, et al. Association of calcitriol and blood pressure in normotensive men. Hypertension 1997; 30(5): 1289-94.

78. Krauss RM, Blanche PJ, Rawlings RS, et al. Separate effects of reduced carbohydrate intake and weight loss on atherogenic dyslipidemia. Am J Clin Nutr 2006; 83(5): 1025-31.

79. Katan MB. Alternatives to low-fat diets. Am J Clin Nutr 2006; 83(5): 989-90.

80. Appel L, Sacks FM, Carey VJ, et al. Effects of protein, monounsaturated fat, and carbohydrate intake on blood pressure and serum lipids: results of the OmniHeart randomized trial. Jama 2005; 294(19): 2455-64.

81. Crovetti R, Porrini M, Santangelo A, et al. The influence of thermic effect of food on satiety. Eur J Clin Nutr 1998; 52(7): 482-8.

82. Johnson $\mathrm{J}$ and Vickers Z. Effects of flavor and macronutrient composition of food servings on liking, hunger and subsequent intake. Appetite 1993; 21(1): 25-39.

83. Poppitt SD, McCormack D, and Buffenstein R. Short-term effects of macronutrient preloads on appetite and energy intake in lean women. Physiol Behav 1998; 64(3): 279-85.

84. Stubbs RJ, van Wyk MC, Johnstone AM, et al. Breakfasts high in protein, fat or carbohydrate: effect on within-day appetite and energy balance. Eur J Clin Nutr 1996; 50(7): 409-17.

85. Barkeling B, Rossner S, and Bjorvell H. Effects of a high-protein meal (meat) and a high-carbohydrate meal (vegetarian) on satiety measured by automated computerized monitoring of subsequent food intake, motivation to eat and food preferences. Int J Obes 1990; 14(9): 743-51.

86. Lejeune MP, Westerterp KR, Adam TC, et al. Ghrelin and glucagon-like peptide 1 concentrations, 24$\mathrm{h}$ satiety, and energy and substrate metabolism during a high-protein diet and measured in a respiration chamber. Am J Clin Nutr 2006; 83(1): 89-94.

87. Westerterp-Plantenga MS, Rolland V, Wilson SA, et al. Satiety related to $24 \mathrm{~h}$ diet-induced thermogenesis during high protein/carbohydrate vs high fat diets measured in a respiration chamber. Eur J Clin Nutr 1999; 53(6): 495-502.

88. Hall WL, Millward DJ, Long SJ, et al. Casein and whey exert different effects on plasma amino acid profiles, gastrointestinal hormone secretion and appetite. Br J Nutr 2003; 89(2): 239-48.

89. Layman DK, Boileau RA, Erickson DJ, et al. A reduced ratio of dietary carbohydrate to protein improves body composition and blood lipid profiles during weight loss in adult women. J Nutr 2003; 133(2): 411-7.

90. Westerterp-Plantenga MS, Lejeune MP, Nijs I, et al. High protein intake sustains weight maintenance after body weight loss in humans. Int J Obes Relat Metab Disord 2004; 28(1): 57-64.

91. Aimutis WR. Bioactive properties of milk proteins with particular focus on anticariogenesis. J Nutr 2004; 134(4): 989S-95S.

92. FitzGerald RJ, Murray BA, and Walsh DJ. Hypotensive peptides from milk proteins. J Nutr 2004; 134(4): 980S-8S.

93. Meisel $\mathrm{H}$. Biochemical properties of peptides encrypted in bovine milk proteins. Curr Med Chem 2005; 12(16): 1905-19. 
94. FitzGerald RJ and Meisel H. Lactokinins: whey protein-derived ACE inhibitory peptides. Nahrung 1999; 43(3): 165-7.

95. Aihara $\mathrm{K}$, Kajimoto $\mathrm{O}$, Hirata $\mathrm{H}$, et al. Effect of powdered fermented milk with Lactobacillus helveticus on subjects with high-normal blood pressure or mild hypertension. J Am Coll Nutr 2005; 24(4): 257-65.

96. Mizuno S, Matsuura K, Gotou T, et al. Antihypertensive effect of casein hydrolysate in a placebocontrolled study in subjects with high-normal blood pressure and mild hypertension. Br J Nutr 2005; 94(1): 84-91.

97. Seppo L, Jauhiainen $T$, Poussa $T$, et al. A fermented milk high in bioactive peptides has a blood pressure-lowering effect in hypertensive subjects. Am J Clin Nutr 2003; 77(2): 326-30.

98. Engberink MF, Schouten EG, Kok FJ, et al. Lactotripeptides show no effect on human blood pressure: results from a double-blind randomized controlled trial. Hypertension 2008; 51(2): 399-405.

99. Foltz $\mathrm{M}$, Meynen EE, Bianco $\mathrm{V}$, et al. Angiotensin converting enzyme inhibitory peptides from a lactotripeptide-enriched milk beverage are absorbed intact into the circulation. J Nutr 2007; 137(4): 953-8.

100. Jolles $P$, Levy Toledano S, Fiat AM, et al. Analogy between fibrinogen and casein. Effect of an undecapeptide isolated from kappa-casein on platelet function. Eur J Biochem 1986; 158(2): 379-82.

101. Rutherfurd KJ and Gill HS. Peptides affecting coagulation. Br J Nutr 2000; 84 Suppl 1: S99-102.

102. German JB and Dillard CJ. Composition, structure and absorption of milk lipids: a source of energy, fat-soluble nutrients and bioactive molecules. Crit Rev Food Sci Nutr 2006; 46(1): 57-92.

103. Sacks FM and Katan M. Randomized clinical trials on the effects of dietary fat and carbohydrate on plasma lipoproteins and cardiovascular disease. Am J Med 2002; 113 Suppl 9B: 13s-24s.

104. Tholstrup T, Hoy CE, Andersen LN, et al. Does fat in milk, butter and cheese affect blood lipids and cholesterol differently? J Am Coll Nutr 2004; 23(2): 169-76.

105. Biong AS, Muller H, Seljeflot I, et al. A comparison of the effects of cheese and butter on serum lipids, haemostatic variables and homocysteine. Br J Nutr 2004; 92(5): 791-7.

106. Nestel PJ, Chronopulos A, and Cehun M. Dairy fat in cheese raises LDL cholesterol less than that in butter in mildly hypercholesterolaemic subjects. Eur J Clin Nutr 2005; 59(9): 1059-63.

107. Larsen TM, Toubro S, and Astrup A. Efficacy and safety of dietary supplements containing CLA for the treatment of obesity: evidence from animal and human studies. J Lipid Res 2003; 44(12): 223441.

108. Wang YW and Jones PJ. Conjugated linoleic acid and obesity control: efficacy and mechanisms. Int J Obes Relat Metab Disord 2004; 28(8): 941-55.

109. Terpstra AH. Effect of conjugated linoleic acid on body composition and plasma lipids in humans: an overview of the literature. Am J Clin Nutr 2004; 79(3): 352-61.

110. Whigham LD, Watras AC, and Schoeller DA. Efficacy of conjugated linoleic acid for reducing fat mass: a meta-analysis in humans. Am J Clin Nutr 2007; 85(5): 1203-11.

111. Zemel $M B$ and Sun $X$. Dietary calcium and dairy products modulate oxidative and inflammatory stress in mice and humans. J Nutr 2008; 138(6): 1047-52.

112. Plat J and Mensink RP. Vegetable oil based versus wood based stanol ester mixtures: effects on serum lipids and hemostatic factors in non-hypercholesterolemic subjects. Atherosclerosis 2000; 148(1): 101-12.

113. Friedewald WT, Levy RI, and Fredrickson DS. Estimation of the concentration of low-density lipoprotein cholesterol in plasma, without use of the preparative ultracentrifuge. Clin Chem 1972; 18(6): 499-502.

114. Matthews DR, Hosker JP, Rudenski AS, et al. Homeostasis model assessment: insulin resistance and beta-cell function from fasting plasma glucose and insulin concentrations in man. Diabetologia 1985; 28(7): 412-9.

115. Jeyarajah EJ, Cromwell WC, and Otvos JD. Lipoprotein particle analysis by nuclear magnetic resonance spectroscopy. Clin Lab Med 2006; 26(4): 847-70.

116. Pocock SJ, Clinical Trials. A practical approach. 1983, Hoboken: John Wiley \& Sons. 
117. Mensink RP, Zock PL, Kester AD, et al. Effects of dietary fatty acids and carbohydrates on the ratio of serum total to HDL cholesterol and on serum lipids and apolipoproteins: a meta-analysis of 60 controlled trials. Am J Clin Nutr 2003; 77(5): 1146-55.

118. Riccardi G, Giacco R, and Rivellese AA. Dietary fat, insulin sensitivity and the metabolic syndrome. Clin Nutr 2004; 23(4): 447-56.

119. Krauss RM. Lipids and lipoproteins in patients with type 2 diabetes. Diabetes Care 2004; 27(6): 1496-504.

120. Freedman DS, Otvos JD, Jeyarajah EJ, et al. Relation of lipoprotein subclasses as measured by proton nuclear magnetic resonance spectroscopy to coronary artery disease. Arterioscler Thromb Vasc Biol 1998; 18(7): 1046-53.

121. Van Beresteijn EC, van Schaik M, and Schaafsma G. Milk: does it affect blood pressure? A controlled intervention study. J Intern Med 1990; 228(5): 477-82.

122. Mennen LI, Balkau B, and Vol S. Tissue-type plasminogen activator antigen and consumption of dairy products. The DESIR study. Data from an Epidemiological Study on Insulin Resistance Syndrome. Thromb Res 1999; 94(6): 381-8.

123. Pittas AG, Lau J, Hu FB, et al. The role of vitamin D and calcium in type 2 diabetes. A systematic review and meta-analysis. J Clin Endocrinol Metab 2007; 92(6): 2017-29.

124. Galgani JE, Uauy RD, Aguirre CA, et al. Effect of the dietary fat quality on insulin sensitivity. Br J Nutr 2008; 100(3): 471-9.

125. Vessby B, Uusitupa $M$, Hermansen $K$, et al. Substituting dietary saturated for monounsaturated fat impairs insulin sensitivity in healthy men and women: The KANWU Study. Diabetologia 2001; 44(3): 312-9.

126. Tamakoshi $\mathrm{K}$, Yatsuya $\mathrm{H}$, Kondo $\mathrm{T}$, et al. The metabolic syndrome is associated with elevated circulating C-reactive protein in healthy reference range, a systemic low-grade inflammatory state. Int J Obes Relat Metab Disord 2003; 27(4): 443-9.

127. Pickup JC, Mattock MB, Chusney GD, et al. NIDDM as a disease of the innate immune system: association of acute-phase reactants and interleukin- 6 with metabolic syndrome X. Diabetologia 1997; 40(11): 1286-92.

128. Hotamisligil GS, Arner P, Caro JF, et al. Increased adipose tissue expression of tumor necrosis factoralpha in human obesity and insulin resistance. J Clin Invest 1995; 95(5): 2409-15.

129. Ford ES. The metabolic syndrome and C-reactive protein, fibrinogen, and leukocyte count: findings from the Third National Health and Nutrition Examination Survey. Atherosclerosis 2003; 168(2): 351-8.

130. van Meijl LE and Mensink RP. Low-fat dairy consumption reduces systolic blood pressure, but does not improve other metabolic risk parameters in overweight and obese subjects. Nutr Metab Cardiovasc Dis 2010.

131. Barash J, Dushnitzki D, Barak Y, et al. Tumor necrosis factor (TNF)alpha and its soluble receptor (sTNFR) p75 during acute human parvovirus B19 infection in children. Immunol Lett 2003; 88(2): 109-12.

132. Fernandez-Real JM and Ricart W. Insulin resistance and chronic cardiovascular inflammatory syndrome. Endocr Rev 2003; 24(3): 278-301.

133. Hotamisligil GS, Shargill NS, and Spiegelman BM. Adipose expression of tumor necrosis factor-alpha: direct role in obesity-linked insulin resistance. Science 1993; 259(5091): 87-91.

134. Uysal KT, Wiesbrock SM, Marino MW, et al. Protection from obesity-induced insulin resistance in mice lacking TNF-alpha function. Nature 1997; 389(6651): 610-4.

135. Plomgaard P, Bouzakri K, Krogh-Madsen R, et al. Tumor necrosis factor-alpha induces skeletal muscle insulin resistance in healthy human subjects via inhibition of Akt substrate 160 phosphorylation. Diabetes 2005; 54(10): 2939-45.

136. Gonzalez-Gay MA, De Matias JM, Gonzalez-Juanatey C, et al. Anti-tumor necrosis factor-alpha blockade improves insulin resistance in patients with rheumatoid arthritis. Clin Exp Rheumatol 2006; 24(1): 83-6. 
137. Kiortsis DN, Mavridis AK, Vasakos S, et al. Effects of infliximab treatment on insulin resistance in patients with rheumatoid arthritis and ankylosing spondylitis. Ann Rheum Dis 2005; 64(5): 765-6.

138. Tam LS, Tomlinson B, Chu TT, et al. Impact of TNF inhibition on insulin resistance and lipids levels in patients with rheumatoid arthritis. Clin Rheumatol 2007; 26(9): 1495-8.

139. Bernstein LE, Berry J, Kim S, et al. Effects of etanercept in patients with the metabolic syndrome. Arch Intern Med 2006; 166(8): 902-8.

140. Dominguez $\mathrm{H}$, Storgaard H, Rask-Madsen C, et al. Metabolic and vascular effects of tumor necrosis factor-alpha blockade with etanercept in obese patients with type 2 diabetes. J Vasc Res 2005; 42(6): 517-25.

141. Paquot N, Castillo MJ, Lefebvre PJ, et al. No increased insulin sensitivity after a single intravenous administration of a recombinant human tumor necrosis factor receptor: Fc fusion protein in obese insulin-resistant patients. J Clin Endocrinol Metab 2000; 85(3): 1316-9.

142. Fernandez-Real JM, Broch M, Ricart W, et al. Plasma levels of the soluble fraction of tumor necrosis factor receptor 2 and insulin resistance. Diabetes 1998; 47(11): 1757-62.

143. Moon YS, Kim DH, and Song DK. Serum tumor necrosis factor-alpha levels and components of the metabolic syndrome in obese adolescents. Metabolism 2004; 53(7): 863-7.

144. Zahorska-Markiewicz B, Olszanecka-Glinianowicz M, Janowska J, et al. The effect of weight loss on serum concentrations of FAS and tumour necrosis factor alpha in obese women. Endokrynol Pol 2008; 59(1): 18-22.

145. Warzocha K and Salles G. The tumor necrosis factor signaling complex: choosing a path toward cell death or cell proliferation. Leuk Lymphoma 1998; 29(1-2): 81-92.

146. Aderka D, Englemann H, Hornik V, et al. Increased serum levels of soluble receptors for tumor necrosis factor in cancer patients. Cancer Res 1991; 51(20): 5602-7.

147. Van Zee KJ, Kohno T, Fischer E, et al. Tumor necrosis factor soluble receptors circulate during experimental and clinical inflammation and can protect against excessive tumor necrosis factor alpha in vitro and in vivo. Proc Natl Acad Sci U S A 1992; 89(11): 4845-9.

148. Zhu Y, Mahon BD, Froicu M, et al. Calcium and 1 alpha,25-dihydroxyvitamin D3 target the TNF-alpha pathway to suppress experimental inflammatory bowel disease. Eur J Immunol 2005; 35(1): 217-24.

149. Tomsig JL, Sohma H, and Creutz CE. Calcium-dependent regulation of tumour necrosis factor-alpha receptor signalling by copine. Biochem J 2004; 378(Pt 3): 1089-94.

150. Wennersberg MH, Smedman A, Turpeinen AM, et al. Dairy products and metabolic effects in overweight men and women: results from a 6-mo intervention study. Am J Clin Nutr 2009; 90(4): 960-8.

151. Sun $X$ and Zemel MB. Calcium and 1,25-dihydroxyvitamin D3 regulation of adipokine expression. Obesity (Silver Spring) 2007; 15(2): 340-8.

152. Sun $X$ and Zemel MB. Calcitriol and calcium regulate cytokine production and adipocytemacrophage cross-talk. J Nutr Biochem 2008; 19(6): 392-9.

153. Ardizzone S, Cassinotti A, Trabattoni D, et al. Immunomodulatory effects of 1,25-dihydroxyvitamin D3 on TH1/TH2 cytokines in inflammatory bowel disease: an in vitro study. Int J Immunopathol Pharmacol 2009; 22(1): 63-71.

154. Prabhu Anand S, Selvaraj P, and Narayanan PR. Effect of 1,25 dihydroxyvitamin D3 on intracellular IFN-gamma and TNF-alpha positive T cell subsets in pulmonary tuberculosis. Cytokine 2009; 45(2): 105-10.

155. Tang J, Zhou R, Luger D, et al. Calcitriol suppresses antiretinal autoimmunity through inhibitory effects on the Th17 effector response. J Immunol 2009; 182(8): 4624-32.

156. Zemel MB, Sun X, Sobhani T, et al. Effects of dairy compared with soy on oxidative and inflammatory stress in overweight and obese subjects. Am J Clin Nutr 2010; 91(1): 16-22.

157. Coutinho M, Gerstein HC, Wang Y, et al. The relationship between glucose and incident cardiovascular events. A metaregression analysis of published data from 20 studies of 95,783 individuals followed for 12.4 years. Diabetes Care 1999; 22(2): 233-40.

158. Karpe F. Postprandial lipoprotein metabolism and atherosclerosis. J Intern Med 1999; 246(4): 341 55. 
159. Bansal S, Buring JE, Rifai N, et al. Fasting compared with nonfasting triglycerides and risk of cardiovascular events in women. Jama 2007; 298(3): 309-16.

160. Patel A, Barzi F, Jamrozik K, et al. Serum triglycerides as a risk factor for cardiovascular diseases in the Asia-Pacific region. Circulation 2004; 110(17): 2678-86.

161. Temelkova-Kurktschiev TS, Koehler C, Henkel E, et al. Postchallenge plasma glucose and glycemic spikes are more strongly associated with atherosclerosis than fasting glucose or $\mathrm{HbA1c}$ level. Diabetes Care 2000; 23(12): 1830-4.

162. Carroll MF, Izard A, Riboni K, et al. Fasting hyperglycemia predicts the magnitude of postprandial hyperglycemia: implications for diabetes therapy. Diabetes Care 2002; 25(7): 1247-8.

163. Hwu CM, Lin MW, Liou TL, et al. Fasting triglyceride is a major determinant of postprandial triglyceride response in postmenopausal women. Menopause 2008; 15(1): 150-6.

164. van Wijk JP, Halkes CJ, Erkelens DW, et al. Fasting and daylong triglycerides in obesity with and without type 2 diabetes. Metabolism 2003; 52(8): 1043-9.

165. van Oostrom AJ, Alipour A, Plokker TW, et al. The metabolic syndrome in relation to complement component 3 and postprandial lipemia in patients from an outpatient lipid clinic and healthy volunteers. Atherosclerosis 2007; 190(1): 167-73.

166. Dubois C, Beaumier G, Juhel C, et al. Effects of graded amounts (0-50 g) of dietary fat on postprandial lipemia and lipoproteins in normolipidemic adults. Am J Clin Nutr 1998; 67(1): 31-8.

167. Murphy MC, Isherwood SG, Sethi S, et al. Postprandial lipid and hormone responses to meals of varying fat contents: modulatory role of lipoprotein lipase? Eur J Clin Nutr 1995; 49(8): 578-88.

168. Shimabukuro M, Chinen I, Higa N, et al. Effects of dietary composition on postprandial endothelial function and adiponectin concentrations in healthy humans: a crossover controlled study. Am J Clin Nutr 2007; 86(4): 923-8.

169. Tsai WC, Li YH, Lin CC, et al. Effects of oxidative stress on endothelial function after a high-fat meal. Clin Sci (Lond) 2004; 106(3): 315-9.

170. Vogel RA, Corretti MC, and Plotnick GD. Effect of a single high-fat meal on endothelial function in healthy subjects. Am J Cardiol 1997; 79(3): 350-4.

171. Aljada A, Mohanty $P$, Ghanim $H$, et al. Increase in intranuclear nuclear factor kappaB and decrease in inhibitor kappaB in mononuclear cells after a mixed meal: evidence for a proinflammatory effect. Am J Clin Nutr 2004; 79(4): 682-90.

172. Nappo F, Esposito K, Cioffi M, et al. Postprandial endothelial activation in healthy subjects and in type 2 diabetic patients: role of fat and carbohydrate meals. J Am Coll Cardiol 2002; 39(7): 1145-50.

173. Westphal S, Kastner S, Taneva E, et al. Postprandial lipid and carbohydrate responses after the ingestion of a casein-enriched mixed meal. Am J Clin Nutr 2004; 80(2): 284-90.

174. van Eijk HM, Rooyakkers DR, and Deutz NE. Rapid routine determination of amino acids in plasma by high-performance liquid chromatography with a 2-3 microns Spherisorb ODS II column. J Chromatogr 1993; 620(1): 143-8.

175. Westphal S, Taneva E, Kastner S, et al. Endothelial dysfunction induced by postprandial lipemia is neutralized by addition of proteins to the fatty meal. Atherosclerosis 2006; 185(2): 313-9.

176. Eckel RH. Lipoprotein lipase. A multifunctional enzyme relevant to common metabolic diseases. $\mathrm{N}$ Engl J Med 1989; 320(16): 1060-8.

177. Brader L, Holm L, Mortensen L, et al. Acute effects of casein on postprandial lipemia and incretin responses in type 2 diabetic subjects. Nutr Metab Cardiovasc Dis 2009; 20(2): 101-109.

178. Cohen JC. Protein ingestion does not affect postprandial lipaemia or chylomicron-triglyceride clearance. Eur J Clin Nutr 1989; 43(7): 497-9.

179. Sullivan JF. The effect of protein ingestion on alimentary lipemia. Am J Med Sci 1962; 243: 770-4.

180. Cohen JC and Berger GM. Effects of glucose ingestion on postprandial lipemia and triglyceride clearance in humans. J Lipid Res 1990; 31(4): 597-602.

181. Westphal S, Leodolter A, Kahl S, et al. Addition of glucose to a fatty meal delays chylomicrons and suppresses VLDL in healthy subjects. Eur J Clin Invest 2002; 32(5): 322-7. 
182. Welberg JW, Monkelbaan JF, de Vries EG, et al. Effects of supplemental dietary calcium on quantitative and qualitative fecal fat excretion in man. Ann Nutr Metab 1994; 38(4): 185-91.

183. Rabinowitz D, Merimee TJ, Maffezzoli R, et al. Patterns of hormonal release after glucose, protein, and glucose plus protein. Lancet 1966; 2(7461): 454-6.

184. van Loon $\mathrm{LJ}$, Kruijshoop $\mathrm{M}$, Verhagen $\mathrm{H}$, et al. Ingestion of protein hydrolysate and amino acidcarbohydrate mixtures increases postexercise plasma insulin responses in men. J Nutr 2000; 130(10): 2508-13.

185. van Loon L, Saris WH, Kruijshoop M, et al. Maximizing postexercise muscle glycogen synthesis: carbohydrate supplementation and the application of amino acid or protein hydrolysate mixtures. Am J Clin Nutr 2000; 72(1): 106-11.

186. van Loon $\mathrm{L}$, Saris $\mathrm{WH}$, Verhagen $\mathrm{H}$, et al. Plasma insulin responses after ingestion of different amino acid or protein mixtures with carbohydrate. Am J Clin Nutr 2000; 72(1): 96-105.

187. Lan-Pidhainy $X$ and Wolever TM. The hypoglycemic effect of fat and protein is not attenuated by insulin resistance. Am J Clin Nutr 2010; 91(1): 98-105.

188. Kalogeropoulou D, LaFave L, Schweim K, et al. Lysine ingestion markedly attenuates the glucose response to ingested glucose without a change in insulin response. Am J Clin Nutr 2009; 90(2): 314-20.

189. Nuttall FQ, Gannon MC, and Jordan K. The metabolic response to ingestion of proline with and without glucose. Metabolism 2004; 53(2): 241-6.

190. Gannon MC, Nuttall JA, and Nuttall FQ. The metabolic response to ingested glycine. Am J Clin Nutr 2002; 76(6): 1302-7.

191. Gannon MC, Nuttall JA, and Nuttall FQ. Oral arginine does not stimulate an increase in insulin concentration but delays glucose disposal. Am J Clin Nutr 2002; 76(5): 1016-22.

192. Kalogeropoulou D, Lafave L, Schweim K, et al. Leucine, when ingested with glucose, synergistically stimulates insulin secretion and lowers blood glucose. Metabolism 2008; 57(12): 1747-52.

193. Nuttall FQ, Schweim KJ, and Gannon MC. Effect of orally administered phenylalanine with and without glucose on insulin, glucagon and glucose concentrations. Horm Metab Res 2006; 38(8): 518-23.

194. Neuschwander-Tetri BA. Fatty liver and the metabolic syndrome. Curr Opin Gastroenterol 2007; 23(2): 193-8.

195. Coeffier M, Miralles-Barrachina O, Le Pessot F, et al. Influence of glutamine on cytokine production by human gut in vitro. Cytokine 2001; 13(3): 148-54.

196. Huang Y, Li N, Liboni K, et al. Glutamine decreases lipopolysaccharide-induced IL-8 production in Caco-2 cells through a non-NF-kappaB p50 mechanism. Cytokine 2003; 22(3-4): 77-83.

197. Hubert-Buron A, Leblond J, Jacquot A, et al. Glutamine pretreatment reduces IL-8 production in human intestinal epithelial cells by limiting IkappaBalpha ubiquitination. J Nutr 2006; 136(6): 14615.

198. Son DO, Satsu H, and Shimizu M. Histidine inhibits oxidative stress- and TNF-alpha-induced interleukin-8 secretion in intestinal epithelial cells. FEBS Lett 2005; 579(21): 4671-7.

199. Fox HL, Kimball SR, Jefferson LS, et al. Amino acids stimulate phosphorylation of p70S6k and organization of rat adipocytes into multicellular clusters. Am J Physiol 1998; 274(1 Pt 1): C206-13.

200. Marshall S and Monzon R. Amino acid regulation of insulin action in isolated adipocytes. Selective ability of amino acids to enhance both insulin sensitivity and maximal insulin responsiveness of the protein synthesis system. J Biol Chem 1989; 264(4): 2037-42.

201. Flati V, Pasini E, D'Antona G, et al. Intracellular mechanisms of metabolism regulation: the role of signaling via the mammalian target of rapamycin pathway and other routes. Am J Cardiol 2008; 101(11A): 16E-21E.

202. Broca C, Breil V, Cruciani-Guglielmacci C, et al. Insulinotropic agent ID-1101 (4-hydroxyisoleucine) activates insulin signaling in rat. Am J Physiol Endocrinol Metab 2004; 287(3): E463-71.

203. Nishitani S, Takehana K, Fujitani S, et al. Branched-chain amino acids improve glucose metabolism in rats with liver cirrhosis. Am J Physiol Gastrointest Liver Physiol 2005; 288(6): G1292-300.

204. Kawaguchi T, Nagao Y, Matsuoka $\mathrm{H}$, et al. Branched-chain amino acid-enriched supplementation improves insulin resistance in patients with chronic liver disease. Int J Mol Med 2008; 22(1): 105-12. 
205. [FAO: nutritional studies: amino-acid content of foods and biological data on proteins]. FAO Nutr Stud 1970(24): 1-285.

206. Bradbury CM, Markovina S, Wei SJ, et al. Indomethacin-induced radiosensitization and inhibition of ionizing radiation-induced NF-kappaB activation in HeLa cells occur via a mechanism involving p38 MAP kinase. Cancer Res 2001; 61(20): 7689-96.

207. Gupta D and Khandelwal RL. Modulation of insulin effects on phosphorylation of protein kinase $B$ and glycogen synthesis by tumor necrosis factor-alpha in HepG2 cells. Biochim Biophys Acta 2004; 1671(1-3): 51-8.

208. Bruun JM, Verdich C, Toubro S, et al. Association between measures of insulin sensitivity and circulating levels of interleukin-8, interleukin- 6 and tumor necrosis factor-alpha. Effect of weight loss in obese men. Eur J Endocrinol 2003; 148(5): 535-42.

209. Dandona $P$, Weinstock R, Thusu K, et al. Tumor necrosis factor-alpha in sera of obese patients: fall with weight loss. J Clin Endocrinol Metab 1998; 83(8): 2907-10.

210. Meshkani R and Adeli K. Hepatic insulin resistance, metabolic syndrome and cardiovascular disease. Clin Biochem 2009; 42(13-14): 1331-46.

211. Jarrar MH, Baranova A, Collantes $\mathrm{R}$, et al. Adipokines and cytokines in non-alcoholic fatty liver disease. Aliment Pharmacol Ther 2008; 27(5): 412-21.

212. Romuk E, Skrzep-Poloczek B, Wojciechowska C, et al. Selectin-P and interleukin-8 plasma levels in coronary heart disease patients. Eur J Clin Invest 2002; 32(9): 657-61.

213. Roebuck KA. Regulation of interleukin-8 gene expression. J Interferon Cytokine Res 1999; 19(5): 429-38.

214. Gupta D, Varma S, and Khandelwal RL. Long-term effects of tumor necrosis factor-alpha treatment on insulin signaling pathway in HepG2 cells and HepG2 cells overexpressing constitutively active Akt/PKB. J Cell Biochem 2007; 100(3): 593-607.

215. Gannon MC, Nuttall FQ, Saeed A, et al. An increase in dietary protein improves the blood glucose response in persons with type 2 diabetes. Am J Clin Nutr 2003; 78(4): 734-41.

216. Olson AL and Pessin JE. Structure, function, and regulation of the mammalian facilitative glucose transporter gene family. Annu Rev Nutr 1996; 16: 235-56.

217. Kim JK, Kim YJ, Fillmore JJ, et al. Prevention of fat-induced insulin resistance by salicylate. J Clin Invest 2001; 108(3): 437-46.

218. Yuan M, Konstantopoulos N, Lee J, et al. Reversal of obesity- and diet-induced insulin resistance with salicylates or targeted disruption of Ikkbeta. Science 2001; 293(5535): 1673-7.

219. TNO. Basisrapportage en tabellen voedselconsumptiepeiling 1997-1998 en gegevens op het niveau van voedingsmiddelen en voedingsstoffen over een periode van tien jaar. 1998.

220. Schaafsma G. The protein digestibility-corrected amino acid score. J Nutr 2000; 130(7): 1865S-7S.

221. Heaney RP. Calcium, dairy products and osteoporosis. J Am Coll Nutr 2000; 19(2 Suppl): 83S-99S.

222. Heaney RP. Dairy and bone health. J Am Coll Nutr 2009; 28 Suppl 1: 82S-90S.

223. Cho E, Smith-Warner SA, Spiegelman D, et al. Dairy foods, calcium, and colorectal cancer: a pooled analysis of 10 cohort studies. J Natl Cancer Inst 2004; 96(13): 1015-22.

224. Giovannucci E, Liu Y, Platz EA, et al. Risk factors for prostate cancer incidence and progression in the health professionals follow-up study. Int J Cancer 2007; 121(7): 1571-8.

225. Shaukat A, Levitt MD, Taylor BC, et al. Systematic Review: Effective Management Strategies for Lactose Intolerance. Ann Intern Med.

226. Kolars JC, Levitt MD, Aouji M, et al. Yogurt--an autodigesting source of lactose. N Engl J Med 1984; 310(1): 1-3.

227. Nestel PJ. Effects of dairy fats within different foods on plasma lipids. J Am Coll Nutr 2008; 27(6): 735S-40S.

228. St-Onge MP, Farnworth ER, and Jones PJ. Consumption of fermented and nonfermented dairy products: effects on cholesterol concentrations and metabolism. Am J Clin Nutr 2000; 71(3): 674-81.

229. Wolever TM, Spadafora $\mathrm{P}$, and Eshuis $\mathrm{H}$. Interaction between colonic acetate and propionate in humans. Am J Clin Nutr 1991; 53(3): 681-7. 
230. Wolever TM, Spadafora PJ, Cunnane SC, et al. Propionate inhibits incorporation of colonic [1,213C]acetate into plasma lipids in humans. Am J Clin Nutr 1995; 61(6): 1241-7.

231. Gerich JE. Clinical significance, pathogenesis, and management of postprandial hyperglycemia. Arch Intern Med 2003; 163(11): 1306-16.

232. Hansson L, Zanchetti A, Carruthers SG, et al. Effects of intensive blood-pressure lowering and lowdose aspirin in patients with hypertension: principal results of the Hypertension Optimal Treatment (HOT) randomised trial. HOT Study Group. Lancet 1998; 351(9118): 1755-62.

233. Lawes CM, Rodgers A, Bennett DA, et al. Blood pressure and cardiovascular disease in the Asia Pacific region. J Hypertens 2003; 21(4): 707-16.

234. Alonso A, Beunza JJ, Delgado-Rodriguez $\mathrm{M}$, et al. Low-fat dairy consumption and reduced risk of hypertension: the Seguimiento Universidad de Navarra (SUN) cohort. Am J Clin Nutr 2005; 82(5): 972-9.

235. Steffen LM, Kroenke $\mathrm{CH}, \mathrm{Yu}$ X, et al. Associations of plant food, dairy product, and meat intakes with $15-y$ incidence of elevated blood pressure in young black and white adults: the Coronary Artery Risk Development in Young Adults (CARDIA) Study. Am J Clin Nutr 2005; 82(6): 1169-77; quiz 1363-4.

236. Wang L, Manson JE, Buring JE, et al. Dietary intake of dairy products, calcium, and vitamin $D$ and the risk of hypertension in middle-aged and older women. Hypertension 2008; 51(4): 1073-9.

237. Jespersen B, Randlov A, Abrahamsen J, et al. Acute cardiovascular effect of 1,25dihydroxycholecalciferol in essential hypertension. Am J Hypertens 1998; 11(6 Pt 1): 659-66.

238. Hodson L, Skeaff CM, and McKenzie JE. Maximal response to a plasma cholesterol-lowering diet is achieved within two weeks. Nutr Metab Cardiovasc Dis 2002; 12(5): 291-5. 
SUMMARY 
The metabolic syndrome, a constellation of metabolic disturbances, strongly enhances the risk of cardiovascular diseases and type 2 diabetes mellitus. It is characterized by abnormalities in a wide variety of metabolic risk markers, including abdominal obesity, hypertension, atherogenic dyslipidemia, insulin resistance, and a prothrombotic and proinflammatory state. Although the aetiology of the metabolic syndrome has not been fully established, it is clear that obesity, insulin resistance, and environmental factors, such as diet, are major players in its development. Dietary changes are important for its prevention and a special role has been suggested for dairy products. Numerous observational studies have shown a negative association between dairy intake and the metabolic syndrome or its components, but intervention studies on the metabolic effects of dairy consumption are scarce. In chapter 2, an overview of literature on the physiological effects of three main dairy constituents (calcium, protein, and fat) on components of the metabolic syndrome, as well as the possible mechanisms involved, is given. Calcium supplements improve the serum lipoprotein profile and reduce blood pressure. Effects of calcium may be related to intestinal binding to fatty acids or bile acids, or to changes in intracellular calcium metabolism by suppressing calciotropic hormones. Dietary proteins may play a role in body weight regulation. Further, dairy proteins are precursors of ACEinhibitory peptides, which may lower blood pressure, but such effects have inconsistently been reported in human studies. Finally, CLA, which effectively lowers body weight in animals, has no such effect in humans in the quantities provided by dairy products.

This thesis further describes the results of human intervention studies and in vitro experiments addressing the effects of dairy products or its constituents on several metabolic disturbances associated with the metabolic syndrome. In our first trial, described in chapters 3 and $\mathbf{4}$, we studied the effects of low-fat dairy consumption on metabolic risk parameters in overweight and obese subjects. Thirty-five overweight, but otherwise healthy, subjects consumed $500 \mathrm{~mL}$ of low-fat milk and $150 \mathrm{~g}$ of low-fat yogurt, or $600 \mathrm{~mL}$ of fruit juice and 3 fruit biscuits per day for 8 weeks, in randomized order. Compared with the control period, the decrease in plasma 1,25-dihydroxy vitamin $D_{3}$ concentrations after the low-fat dairy period confirmed dietary compliance. Systolic blood pressure was decreased by $2.9 \mathrm{mmHg}$ after dairy consumption compared with control, while the difference in diastolic blood pressure did not reach statistical significance. Further, low-fat dairy consumption decreased HDL-cholesterol and apoA-1 concentrations. Serum total cholesterol, LDL-cholesterol, apoB, TAG, FFA, glucose, insulin, CRP and PAI-1 were unchanged. We also investigated the effects of dairy consumption on a range of inflammatory markers and adhesion molecules. Dairy consumption affected the TNF- $\alpha$ pathway by increasing s-TNFR-2 concentrations, while we observed a trend towards increased s-TNFR-1 and decreased TNF- $\alpha$ concentrations. The physiological consequences of these last observations are not clear. Overall, we concluded that 8 
weeks of dairy consumption decreased systolic blood pressure, but did not have beneficial effects on other metabolic risk markers in overweight subjects.

Besides the longer-term effects, we were also interested in the short-term postprandial effects of dairy products. Postprandial hyperlipidemia and hyperglycemia have been considered as risk factors for CVD. Managing these factors may be an alternative strategy to reduce CVD risk, as people in Western countries are in the postprandial state for most of the day. Postprandial hyperlipidemia and hyperglycemia are frequently seen in subjects with the metabolic syndrome. In this postprandial study, we investigated the effects of the addition of milk, and the milk constituents protein and calcium, to a high-fat meal, which is described in chapter 5. Sixteen overweight, but otherwise healthy, subjects participated in 4 postprandial tests, in which they consumed a high-fat breakfast and $500 \mathrm{~mL}$ of a control, calcium, protein or milk drink. The results of this study showed that milk and protein increased the postprandial TAG response after a high-fat mixed meal. Further, milk and protein ingestion reduced the maximal increase in glucose concentration. Plasma FFA were unchanged, although insulin concentrations were elevated after the milk meal. Calcium did not have effects on postprandial responses. So, addition of low-fat milk to a mixed meal has ambiguous effects on postprandial metabolic risk profiles in overweight subjects, as it decreased glucose concentrations but increased TAG concentrations.

In our in vitro experiments, described in chapter 6, we investigated the effects of the amino acids glutamine, leucine and proline on inflammation and insulin sensitivity in HepG2 liver cells. Cells were treated with IL-1 $\beta$ to induce an inflammatory response. Incubation with amino acids reduced the production of the proinflammatory cytokine IL-8 and the activity of the transcription factor NF- $\mathrm{KB}$. To study the effects of amino acids on insulin sensitivity, cells were incubated with TNF- $\alpha$ to induce a situation of insulin resistance. The phosphorylation of Akt, which is induced by insulin stimulation, was inhibited by TNF- $\alpha$ treatment. However, addition of glutamine, leucine, or proline to the culture media restored Akt phosphorylation in the situation of decreased insulin sensitivity. Although these results seem promising, further research is needed to explore the role of amino acids on inflammatory processes and insulin signaling in the in vivo situation.

Taken together, the results presented in this thesis do not fully explain the findings from observational research, which indicated a negative relation between dairy intake and the metabolic syndrome. Our first intervention study showed a beneficial reduction in systolic blood pressure, but also a reduction in HDL-cholesterol after daily consumption of $500 \mathrm{~mL}$ low-fat milk and $150 \mathrm{~g}$ low-fat yogurt for 8 weeks. Further, dairy consumption seemed to influence the TNF- $\alpha$ pathway. Our in vitro experiments suggested a beneficial role for amino acids in insulin sensitivity, but this could not be concluded from glucose and insulin concentrations in fasting plasma samples from our 8-week intervention study. Our acute postprandial study did 
however show that low-fat milk, consumed with a high-fat meal, reduced the postprandial rise in plasma glucose. At the same time, however, it increased the insulin and triglyceride response postprandially. The protein fraction of the milk seemed to be mainly accountable for these effects. Future studies should reveal to what extent the observed effects can be translated to other forms of dairy products, to other quantities, or to other populations. 
SAMENVATTING 
Het metabool syndroom, een combinatie van verschillende metabole stoornissen, verhoogt het risico op hart- en vaatziekten en type 2 diabetes. Het wordt gekenmerkt door diverse metabole risicofactoren, zoals abdominale obesitas, hypertensie, atherogene dyslipidemie, insulineresistentie, chronische inflammatie, en een verhoogde stollingsneiging. Hoewel de exacte oorzaak van het metabool syndroom onbekend is, is het wel duidelijk dat overgewicht, insulineresistentie en omgevingsfactoren zoals voeding, een belangrijke rol spelen bij het onstaan ervan. Gezonde eetgewoonten zijn belangrijk bij het voorkomen van het metabool syndroom en een speciale rol lijkt te zijn weggelegd voor zuivelproducten. Verschillende observationele studies hebben aangetoond dat er een negatieve relatie bestaat tussen zuivelconsumptie en (kenmerken van) het metabool syndroom. Interventiestudies op dit gebied zijn er echter nauwelijks.

In hoofdstuk 2 wordt een overzicht gegeven van studies naar de fysiologische effecten van drie belangrijke zuivelbestanddelen (calcium, eiwit en vet) op kenmerken van het metabool syndroom en de mogelijke achterliggende mechanismen. Calciumsupplementen verbeteren het serum lipoproteïnenprofiel en verlagen de bloeddruk. De effecten van calcium zouden te maken kunnen hebben met de binding van vetzuren of galzouten in de darm, of met het onderdrukken van de werking van calciotrope hormonen. Eiwitten in de voeding lijken een rol te spelen in de regulatie van lichaamsgewicht. Verder hebben peptiden gevormd uit melkeiwitten een remmende werking op ACE, maar effecten op de bloeddruk zijn nog niet eenduidig aangetoond in mensen. Geconjugeerd linolzuur (CLA), tenslotte, verlaagt het lichaamsgewicht in proefdieren, maar in de hoeveelheden aanwezig in zuivelproducten lijkt het geen effect te hebben bij mensen.

Dit proefschrift beschrijft verder de resultaten van humaan interventieonderzoek en in vitro experimenten naar de effecten van zuivelproducten en -bestanddelen op verschillende metabole risicofactoren die geassocieerd zijn met het metabool syndroom. In onze eerste interventiestudie, beschreven in hoofdstuk 3 en 4, hebben we de effecten van zuivelconsumptie op metabole risicoparameters bestudeerd bij mensen met overgewicht. Vijfendertig gezonde proefpersonen met overgewicht consumeerden in willekeurige volgorde 8 weken lang dagelijks $500 \mathrm{ml}$ halfvolle melk en $150 \mathrm{~g}$ halfvolle yoghurt, of $600 \mathrm{ml}$ vruchtensap en 3 vruchtenbiscuits. De plasma concentratie van 1,25-dihydroxy vitamine $D_{3}$ was lager na de zuivelperiode dan na de controleperiode, hetgeen laat zien dat de deelnemers de experimentele producten hebben gebruikt. De systolische bloeddruk daalde met $2.9 \mathrm{mmHg}$ na zuivelconsumptie, terwijl de diastolische bloeddruk niet significant veranderde. Verder verlaagde zuivelconsumptie de concentratie van HDL-cholesterol en apoA-1. Er waren geen verschillen in totaal cholesterol, LDL-cholesterol, apoB, triglyceriden, vrije vetzuren, glucose, insuline, CRP en PAI-1. We hebben ook de effecten van zuivel op een aantal inflammatoire eiwitten en adhesiemoleculen bestudeerd. Zuivelconsumptie beïnvloedde de TNF- $\alpha$ pathway door verhoging van de S-TNFR- 2 con- 
centratie. Ook was er een trend tot verhoogde s-TNFR-1 en verlaagde TNF- $\alpha$ concentraties. De fysiologische gevolgen van deze veranderingen zijn niet helemaal duidelijk. Uit deze resultaten kunnen we echter concluderen dat de consumptie van zuivelproducten de systolische bloeddruk verlaagt, maar dat het verder geen gunstige effecten heeft op andere metabole risicofactoren bij mensen met overgewicht.

Naast de langetermijneffecten, waren we ook geïnteresseerd in de postprandiale effecten van zuivelproducten. Postprandiale hyperlipidemie en hyperglycemie zijn namelijk ook risicofactoren voor hart- en vaatziekten en tegenwoordig bevinden mensen in de Westerse wereld zich gedurende het grootste gedeelte van de dag in de postprandiale fase. Postprandiale hyperlipidemie en hyperglycemie komen vaak voor bij mensen met het metabool syndroom. In onze postprandiaalstudie hebben we gekeken naar de effecten van het toevoegen van melk en de melkbestanddelen calcium en eiwit aan een vetrijke maaltijd (hoofdstuk 5). Zestien gezonde proefpersonen met overgewicht ondergingen 4 postprandiaaltesten, waarin ze een vetrijk ontbijt consumeerden en 500 ml van een controle-, calcium-, eiwit-, of melkdrank. Uit de resultaten blijkt dat melk en eiwit de triglyceridenrespons na de vetrijke maaltijd verhoogden. Verder verlaagden melk en eiwit de maximale stijging in glucoseconcentratie. De respons in vrije vetzuren was niet verschillende tussen de interventies, terijl de insulinerespons verhoogd was na de melk-maaltijd. Calcium had geen effect op de postprandiale responsen. We concluderen hieruit dat het toevoegen van melk aan een vetrijke maaltijd tegengestelde effecten heeft op het postprandiale risicoprofiel, omdat het triglycerideconcentraties verhoogt en glucoseconcentraties verlaagt.

In hoofdstuk 6 zijn de in vitro experimenten beschreven, waarin we hebben gekeken naar de effecten van de aminozuren glutamine, leucine en proline op inflammatie en insulinegevoeligheid in HepG2 levercellen. De cellen werden behandeld met IL-1 $\beta$ om een inflammatoire respons op gang te brengen. Het incuberen van de cellen met aminozuren verminderde de productie van het proinflammatoire cytokine IL-8 en de activiteit van de transcriptiefactor NF-KB. Om de invloed van aminozuren op insulinegevoeligheid te bestuderen, werden de cellen eerst geïncubeerd met TNF- $\alpha$. Hierdoor werden de cellen insulineresistent en werd de fosforylering van Akt, door insuline, geremd. Wanneer we echter aminozuren aan het medium toevoegden, werd de fosforylering van Akt hersteld. Deze resultaten lijken veelbelovend, maar er is verder onderzoek nodig om te bepalen wat de invloed van aminozuren op inflammatie en insulinegevoeligheid is in de in vivo situatie.

De resulten van de studies beschreven in dit proefschrift kunnen de bevindingen van observationeel onderzoek, die een negatieve relatie tussen zuivelconsumptie en het metabool synroom lieten zien, niet geheel bevestigen. Onze eerste interventiestudie liet zien dat het 8 weken lang consumeren van $500 \mathrm{ml}$ melk en $150 \mathrm{~g}$ yogurt per dag de systolische bloeddruk verlaagde, maar dat het tevens het HDLcholesterol reduceerde. Verder lijkt zuivelconsumptie een effect te hebben op de 
TNF- $\alpha$ pathway. Onze celexperimenten gaven indicaties voor gunstige effecten van aminozuren op insulinegevoeligheid, maar dit bleek niet uit de nuchtere glucose- en insulineconcentraties in onze interventiestudie. Uit de resultaten van onze postprandiaalstudie bleek wel dat het toevoegen van melk aan een vetrijke maaltijd de stijging in plasma glucosewaarden vermindert. Tegelijkertijd verhoogde melk de triglyceriden- en insulineresponse. Het eiwit uit de melk lijkt hier grotendeels verantwoordelijk voor te zijn. Verder onderzoek moet aantonen of deze resultaten ook gelden voor andere zuivelproducten, andere hoeveelheden, of andere populaties. 


\title{
APPENDIX
}

\author{
Dankwoord
}

Curriculum vitae

List of publications 



\section{DANKWOORD}

Dit is het dan: Het Boekje. Hoewel het mijn naam is die op de omslag vermeld staat, hebben vele mensen, op welke wijze dan ook, hun bijdrage hieraan geleverd. Deze laatste pagina's wil ik daarom graag gebruiken om een woord van dank tot hen te richten.

Op de eerste plaats gaat mijn dank natuurlijk uit naar mijn promotor, prof. dr. ir. Ronald Mensink. Beste Ronald, hoewel je me behoorlijk vrij liet om dit project naar eigen inzicht tot een goed einde te brengen, was je altijd zeer betrokken en kon ik, wanneer nodig, altijd op je rekenen (zelfs al betekende dat een heel weekend heen en weer mailen...). Bedankt voor de kans die je mij hebt gegeven, voor je immer kritische blik en voor de fijne samenwerking. Ik heb veel van je geleerd.

De beoordelingscommissie, bestaande uit prof. dr. K.R. Westerterp, dr. J.M. Geleijnse, prof. dr. E. Mariman, prof. dr. ir. A.M.W.J. Schols en dr. P.L. Zock, wil ik graag bedanken voor het lezen en beoordelen van dit proefschrift.

De studies beschreven in dit proefschrift waren nooit tot stand gekomen zonder de inzet van alle proefpersonen. Dank jullie wel voor de enthousiaste medewerking en voor het gezamenlijk wegwerken van onder andere zo'n 1000 liter melk en 300 kg yoghurt!

Mijn jaren bij Humane Biologie heb ik mede dankzij de vele fijne collega's als zeer prettig ervaren. Bedankt voor de gezelligheid op en buiten de werkvloer en voor alle hulp en ondersteuning! Alle analisten, diëtisten, secretaresses, computerdokters, prikdeskundigen en andere collega's die me, op welke wijze dan ook, de afgelopen jaren geholpen hebben, wil ik hiervoor ontzettend bedanken. Jos, als initiatiefnemer van menig activiteit verdien jij natuurlijk een speciale vermelding. Elke en Marjolijn, jullie waren fantastische kamergenootjes! Of het nou ging over onderzoeksperikelen, zwangerschapsdementie of kleurenanalyses; ik heb enorm genoten van alle zin en onzin die we samen deelden. Chris, ook op jou kon in altijd terugvallen en ook wij hadden het erg gezellig! Ruth, wij zaten in hetzelfde schuitje en we konden dan ook altijd bij elkaar terecht voor hulp of relativerende woorden. Carla, jij maakte de werkdagen vrolijk en het was dan ook erg stil toen je ons verliet! Sanne, jij bracht nog wat extra Brabantsche gezelligheid in de groep! Herman, zonder jouw enthousiasme en hulp was hoofdstuk 6 misschien nooit af gekomen... Ook alle an- 
dere (ex-)leden van de middenlob: Ariënne, Chantal, Els, Florence, Gemma, Jogchum, Julian, Kirsten, Martine, Maurice, Pascal, Pia, Stan, Stefan, Tineke, Yvonne; dank jullie wel voor alle praktische danwel morele ondersteuning. De vele koffierondes, lunches, etentjes en andere gezellige momenten hebben ervoor gezorgd dat de afgelopen jaren voorbij zijn gevlogen!

Natuurlijk wil ik ook alle familie, vrienden en bekenden bedanken, die altijd geïnteresseerd informeerden naar de resultaten van mijn onderzoek en de voortgang van mijn proefschrift, en die steeds bleven vragen wanneer ik nou eens zou 'afstuderen'. Eindelijk kan ik jullie laten zien waar ik al die tijd aan gewerkt heb.

Tsja, Bram, ons eerste boek is eindelijk af... Jouw bijdrage aan dit proefschrift is groter dan je misschien denkt. Dankjewel voor je steun, je enthousiasme, je luisterend oor, je adviezen, je liefde en zoveel meer.

Lieve Ellen, onze wegen kruisten elkaar in de brugklas en sinds die tijd is er veel gebeurd. Hoewel we elkaar niet altijd even frequent zien, zelfs niet toen jij ook in Maastricht woonde, weten we elkaar toch altijd weer te vinden voor de leuke en de minder leuke dingen die voorbij komen. Ik geniet zowel van onze serieuze gesprekken als van de ontspannende (en vaak cultureel verantwoorde) uitstapjes en ben nog steeds heel blij met jou als vriendinnetje!

Lieve Janneke, negen jaar geleden, tijdens de facultaire introductie Gezondheidswetenschappen, bepaalde het toeval dat wij bij elkaar in de onderwijsgroep terecht kwamen. Vanaf dat moment waren we onafscheidelijk! Zowel in onze studententijd als in onze AIO-tijd hebben we heel wat lief en leed gedeeld en we hebben samen dan ook heel wat meegemaakt! Dat we nu ook deze dag samen kunnen beleven, vind ik heel bijzonder.

Julia, het begon als collega's, maar inmiddels heeft zich een mooie vriendschap ontwikkeld. Ik kan altijd bij je terecht en onze dates (hoeveel La Chouffejes zouden we samen hebben weggewerkt...?) zijn altijd erg gezellig! Ik vond het een eer om bij jouw promotie aan jouw zijde te staan, en ben erg blij dat jij nu aan de mijne staat. Sabine, al snel nadat jij je intrek nam in kamer 2.220 bleek dat we behoorlijk wat interesses deelden, waarmee we anderen af en toe tot waanzin dreven (sorry Chris...)! Je was een fantastisch kamergenootje en je bent een van de meest lieve, oprechte en behulpzame personen die ik de afgelopen tijd ben tegengekomen. Noud, ookal zit je nu aan de andere kant van de wereld, ik reken je nog steeds een beetje tot mijn paranimfen... Al vrij snel na jouw eerste dag op de middenlob konden we het erg goed met elkaar vinden. Je was mijn steun en toeverlaat en stond op moeilijke momenten altijd voor me klaar met een luisterend oor en relativerende 
woorden. Ook voor de leuke dingen probeerde je altijd tijd te maken en we hebben dan ook heel wat gezellige uurtjes samen doorgebracht! Ik denk dat je wel weet wat je voor mij betekent. Lieve lieve nimfjes, ik ben heel erg blij met jullie steun.

Liefste pap en mam, jullie hebben mij altijd onvoorwaardelijk gesteund in alles wat ik deed en daar ben ik jullie ontzettend dankbaar voor. Het is fijn om te weten dat jullie altijd achter me staan. Mede dankzij jullie liefde, vertrouwen en hulp (op welk vlak dan ook), heb ik nu deze Meijlpaal bereikt!

ledereen, heel erg bedankt!

Leonie 



\section{CURRICULUM VITAE}

Leonie Elisabeth Catharina van Meijl was born on 30 December 1982 in Eindhoven. She completed secondary school at the Bisschoppelijk College in Weert in 2001. In the same year, she started her study Health Sciences, with a specialization in Biological Health Sciences, at Maastricht University. After graduation in 2005, she was appointed as a PhD-student at the department of Human Biology of Maastricht University under supervision of prof. dr. ir. R.P. Mensink. Her research, described in this thesis, was supported by the Dutch Dairy Association. She conducted human intervention studies to investigate the effects of dairy product consumption on metabolic risk parameters associated with the metabolic syndrome. She also performed in vitro experiments to unravel the molecular mechanisms underlying these effects. 



\section{LIST OF PUBLICATIONS}

Vrolix R, Van Meijl LEC, Mensink RP. The metabolic syndrome in relation with the glycemic index and the glycemic load. Physiol Behav 2008; 94(2): 293-9.

Van Meijl LEC, Vrolix R, Mensink RP. Dairy product consumption and the metabolic syndrome. Nutr Res Rev 2008; 21(2): 148-57.

Van Meijl LEC, Mensink RP. Low-fat dairy consumption reduces systolic blood pressure, but does not improve other metabolic risk parameters in overweight and obese subjects. Nutr Metab Cardiovasc Dis 2010. In press.

Van Meijl LEC, Mensink RP. Effects of low-fat dairy consumption on markers of lowgrade systemic inflammation and endothelial function in overweight and obese subjects: an intervention study. Br J Nutr 2010. In press.

Van Meijl LEC, Popeijus HE, Mensink RP. Amino acids stimulate Akt phosphorylation, and reduce IL-8 production and NF-kB activity in HepG2 liver cells. Mol Nutr Food Res 2010. In press.

Van Meijl LEC, Mensink RP. Effects of milk and milk constituents on postprandial lipid and glucose metabolism in overweight and obese subjects. Submitted. 